UNIVERSIDADE DE SÃO PAULO

ESCOLA DE ENGENHARIA DE SÃO CARLOS

PROGRAMA DE PÓS-GRADUAÇÃ̃ EM ENGENHARIA DE PRODUÇÃO

RODRIGO MESSIAS DE ANDRADE

Orientação estratégica e desempenho organizacional na pequena empresa:

uma análise do setor metal-mecânico 



\section{Orientação estratégica e desempenho organizacional na pequena empresa: uma análise do setor metal-mecânico}

Dissertação apresentada à Escola de Engenharia de São Carlos da Universidade de São Paulo, como parte dos requisitos para obtenção do título de Mestre em Engenharia de Produção.

Área de Concentração: Economia, Organizações e Gestão do Conhecimento

Orientador: Prof. Dr. Edmundo Escrivão Filho 
AUTORIZO A REPRODUÇÃO TOTAL OU PARCIAL DESTE TRABALHO, POR QUALQUER MEIO CONVENCIONAL OU ELETRO̊NICO, PARA FINS DE ESTUDO E PESQUISA, DESDE QUE CITADA A FONTE.

A553 Andrade, Rodrigo Messias de
/ Rodrigo Messias de Andrade; orientador Edmundo
Escrivão Filho. São Carlos, 2015.
Dissertação (Mestrado) - Programa de Pós-Graduação
em Engenharia de Produção e Area de Concentração em
Economia, Organizaçōes e Gestão Conhecimento -- Escola
de Engenharia de Săo Carlos da Universidade de São
Paulo, 2015. Pequena empresa. 2. Orientaçăo estratégica. 3.
1. Pitulo.
Desempenho da pequena empresa. I. Tín.




\section{FOLHA DE JULGAMENTO}

Candidato: Bacharel RODRIGO MESSIAS DE ANDRADE.

Título da dissertação: "Orientação estratégica e desempenho organizacional na pequena empresa: uma análise do setor metalmecânico".

Data da defesa: 04/08/2015

\section{Comissão Julgadora:}

Resultado:

Prof. Associado Edmundo Escrivão Filho (Orientador)

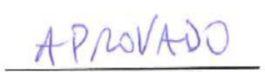

(Escola de Engenharia de São Carlos/EESC)

Prof. Dr. Luiz Ricardo Kabbach de Castro

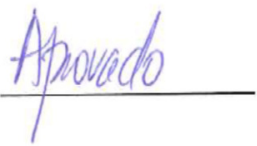

(Escola de Engenharia de São Carlos/EESC)

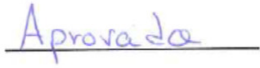

Prof. Dr. Edemilson Nogueira

(Universidade Federal de São Carlos/UFSCar)

Coordenadora do Programa de Pós-Graduação em Engenharia de Produção:

Profa. Associada Daisy Aparecida do Nascimento Rebelatto

Presidente da Comissão de Pós-Graduação:

Prof. Associado Paulo César Lima Segantine 



\section{DEDICATÓRIA}

Aos meus pais, que me apoiaram e me possibilitaram chegar até aqui. Este trabalho não existiria sem vocês. 



\section{AGRADECIMENTOS}

Ao amigo professor Dr. Edmundo Escrivão Filho por todo o ensinamento, atenção e paciência nesses últimos anos. Muito obrigado pela ajuda em todos os momentos.

Aos professores Dr. Luiz Ricardo Kabbach de Castro e Dr. Edemilson Nogueira por todas as contribuições dadas no exame de qualificação, as quais foram de grande importância para a conclusão do trabalho.

À Nathalie por todo o apoio e incentivo que meu deu durante meu mestrado.

À Amanda por toda a compreensão nos momentos que não pude estar presente, por sua torcida pelo meu sucesso e pela sua paciência nestes últimos tempos.

Aos colegas de grupo de pesquisa GEOPE (Alexandre, Daniela, Lie, Carol, Luis, Heloisa, Thiago e Fabiana) pelos bons momentos de convivência e aprendizagem.

Aos funcionários do Departamento de Engenharia de Produção da EESC por todo apoio recebido e presteza nas minhas solicitações. Meu muito obrigado a vocês.

À equipe de limpeza do Departamento de Engenharia de Produção os quais mantém, diariamente, através de seus esforços, um ambiente adequado para a condução dos nossos trabalhos. Muito obrigado. 



\section{EPÍGRAFE}

"Precisamos dar um sentido humano às nossas construções. E, quando o amor ao dinheiro, ao sucesso nos estiver deixando cegos, saibamos fazer pausas para olhar os lírios do campo e as aves do céu."

(Erico Verissímo) 



\section{RESUMO}

\section{ANDRADE, R. M. Orientação estratégica e desempenho organizacional na pequena}

empresa: uma análise do setor metal-mecânico. 2015. 141f. Dissertação (Mestrado) Escola de Engenharia de São Carlos, Universidade de São Paulo, São Carlos, 2015.

O presente trabalho tem como objetivo verificar a relação entre as orientações estratégicas de Miles e Snow (1978) com o desempenho organizacional nas pequenas empresas à luz de suas especificidades. $\mathrm{O}$ atual contexto econômico é marcado essencialmente pelo acirramento da competição entre as empresas. Neste ambiente dinâmico é fundamental que as empresas consigam formular e implementar estratégias que lhes confiram uma vantagem competitiva sobre seus concorrentes e, assim, maximizar seu desempenho. Apesar dessa importância, poucos estudos têm se dedicado a discutir os antecedentes da estratégica, especialmente a orientação estratégica seguida por uma firma e sua ligação com o desempenho da firma, sobretudo quando considerado o universo específico das pequenas empresas, o qual se mostra distinto do das grandes organizações. Através de um questionário aplicado em 35 empresas do setor metal mecânico dados foram coletados e analisados empiricamente utilizando técnicas estatísticas de análise de variância e teste de Fischer. A principal contribuição do trabalho é mostrar que em pequenas empresas a orientação estratégica seguida por uma firma, isoladamente, não tem relação direta com o desempenho organizacional, evidenciando que nestas empresas outros fatores além da orientação estratégica devem ser considerados ao analisar o desempenho organizacional.

Palavras-chave: Pequena empresa; Orientação estratégica; Desempenho da pequena empresa. 



\begin{abstract}
ANDRADE, R. M. Strategic Orientation and Organizational Performance: An analysis of metal-mechanic industry. 2015. 141f. Dissertação (Mestrado) - Escola de Engenharia de São Carlos, Universidade de São Paulo, São Carlos, 2015.

The current economic context is marked primarily by stronger competition among enterprises. In this dynamic environment is vital for the companies be able to formulate and implement strategies that give them a competitive advantage over their competitors and, therefore, maximize their performance. Despite this importance, few studies have been devoted to discuss the background of the strategy and its connection with the firm's performance, particularly the strategic orientation followed by a firm and its connection with firm's performance, especially when considering the specific universe of small businesses. Thus, this study aims to analyze how the relationship between the strategic orientation and organizational performance occurs in small businesses. Throughout a questionnaire applied in 35 companies in the metal mechanic sector, data were collected and later analyzed empirically utilizing ANOVA and Fischer test. The main contribution of this work is to show that for small businesses the strategic orientation followed by a firm is not directly related to organizational performance, showing that for those kinds of companies other factors besides the strategic orientation should be considered when analyzing organizational performance.
\end{abstract}

Key words: Small business; Strategic orientation; Small business performance. 



\section{LISTA DE FIGURAS}

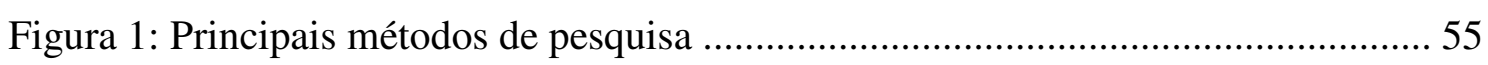

Figura 2: Influência das especificidades.............................................................. 59

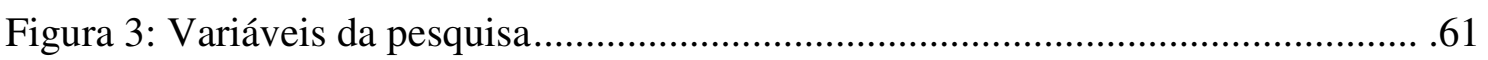

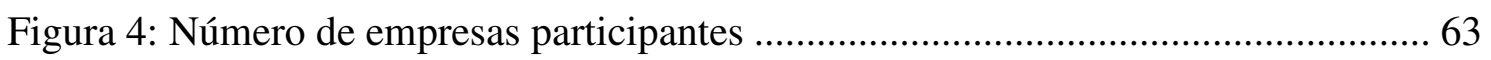

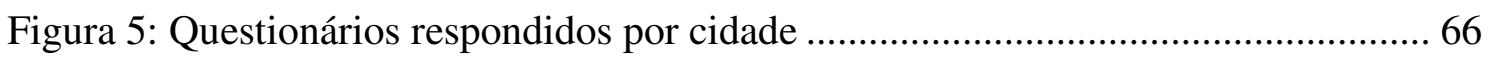

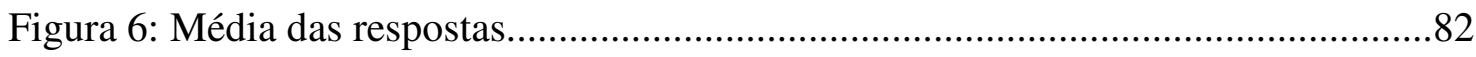

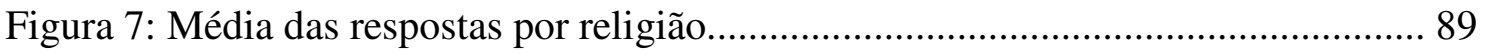

Figura 8: Média das respostas por raça.............................................................. 90

Figura 9: Média das respostas por escolaridade......................................................90

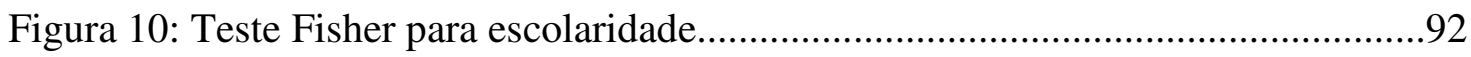

Figura 11: Média por tempo de experiência..................................................................94

Figura 12: Teste de Fisher da questão 07 relacionada ao tempo de experiência.............96

Figura 13: Teste de Fisher da questão 06 relacionada ao tempo de experiência.............96

Figura 14: Teste de Fisher da questão 11 relacionada ao tempo de experiência.............97

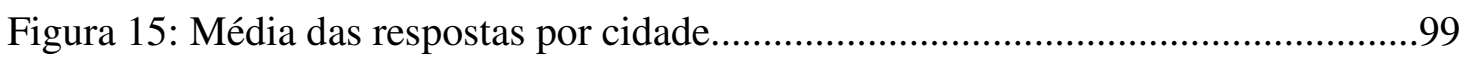

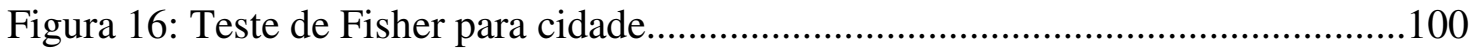

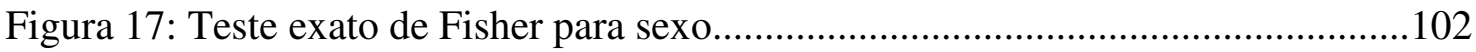

Figura 18: Teste exato de Fisher para escolaridade......................................................102

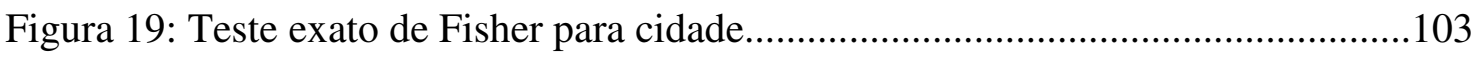

Figura 20: Figura 19 - Teste exato de Fisher para cidade..........................................104

Figura 21: Boxplot para faturamento entre 2012-2013 .............................................106

Figura 22: Boxplot para faturamento entre 2013-2014 ...........................................107

Figura 23: Boxplot para rotatividade entre 2011-2012 _..........................................108 
Figura 24: Boxplot para rotatividade entre 2012-2013 _............................................109

Figura 25: Boxplot para rotatvidade entre 2013-2014_...........................................109 


\section{LISTA DE QUADROS}

Quadro 1: Escolas do pensamento estratégico

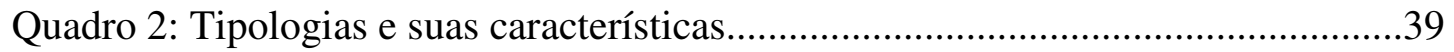

Quadro 3: Relações das orientações estratégicas.....................................................41

Quadro 4: Características das pequenas empresas.................................................50 



\section{LISTA DE TABELAS}

Tabela 1: Quantidade de resposta por pontuação.........................................................82

Tabela 2: Percentual de resposta por pontuação..............................................................83

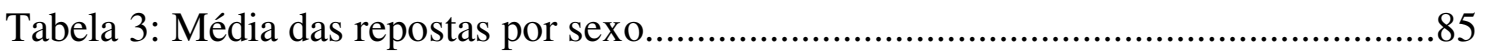

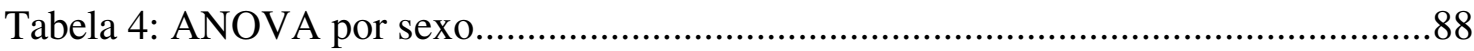

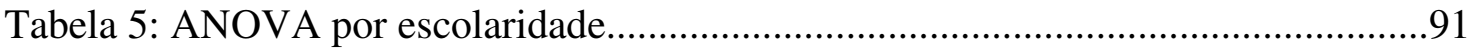

Tabela 6: Valor das médias das repostas por tempo de escolaridade...........................93

Tabela 7: Valor das Médias das respostas por tempo de experiência.............................94

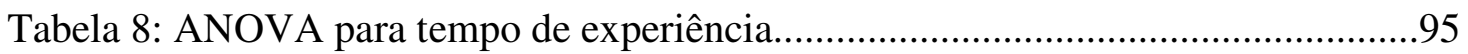

Tabela 9: Valor das médias das repostas por cidade ..............................................98

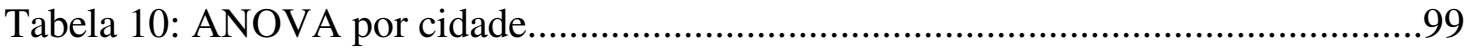

Tabela 11: Classificação por orientação estratégica.....................................................101

Tabela 12: Média de desempenho de faturamento........................................................105

Tabela 13: Média de desempenho de rotatividade.....................................................108

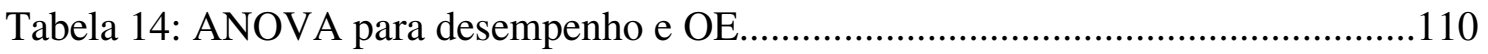





\section{LISTA DE ABREVIATURAS E SIGLAS}

ANOVA - Análise de Variância

DO - Desempenho Organizacional

DRF - Desempenho em termos de faturamento

DRT - Desempenho em termos de rotatividade

EESC - Escola de Engenharia de São Carlos

OE - Orientação Estratégica

GEOPE - Grupo de Estudos Organizacional da Pequena Empresa

SEBRAE - Serviço Brasileiro de Apoio às Micro e Pequenas Empresas

USP - Universidade de São Paulo 



\section{SUMÁRIO}

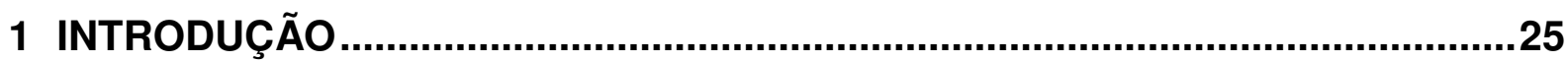

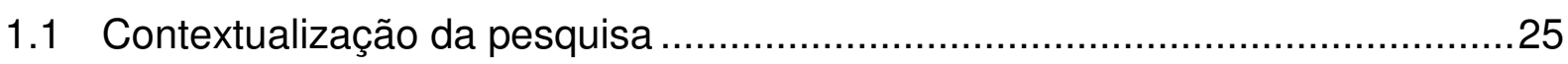

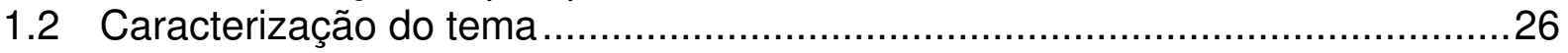

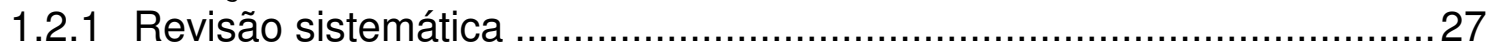

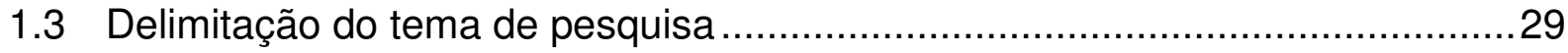

1.4 Formulação do problema da pesquisa ....................................................... 31

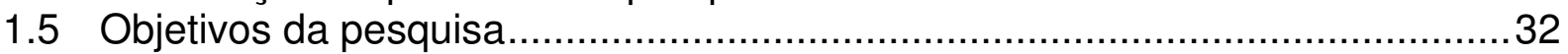

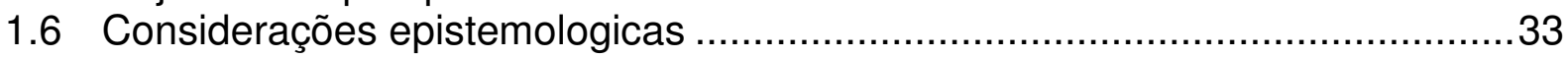

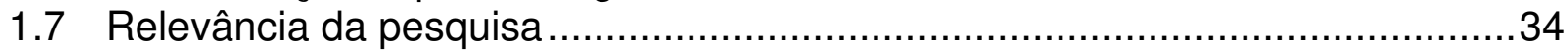

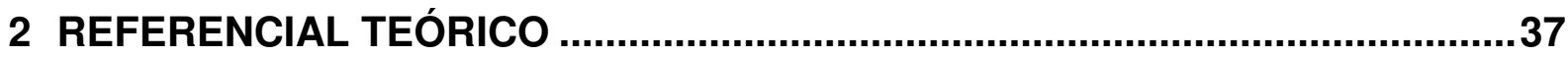

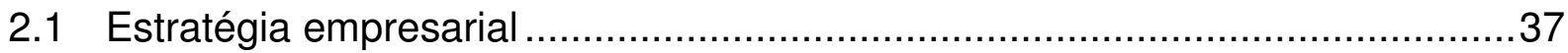

2.2 Caracterização da orientação estratégica ...................................................... 41

2.3 Linhas de estudo da orientação estratégica ................................................43

2.4 Categorias de estudo sobre orientação estratégica ......................................47

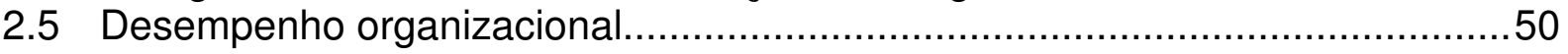

2.6 Orientação estratégica e desempenho organizacional...............................52

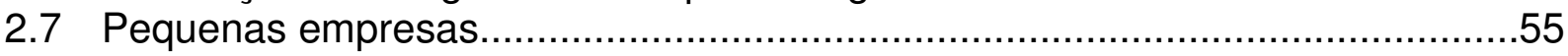

2.7.1 Classificação e definição de pequenas empresas...............................55

2.7.2 Especificidades organizacionais das pequenas empresas......................57

2.7.3 Pequenas empresas e orientação estratégica.....................................60

3 MÉTODOS DA PESQUISA ..........................................................................65

3.1 Métodos de pesquisa na literatura de orientação estratégica.........................65

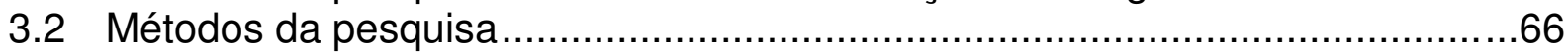

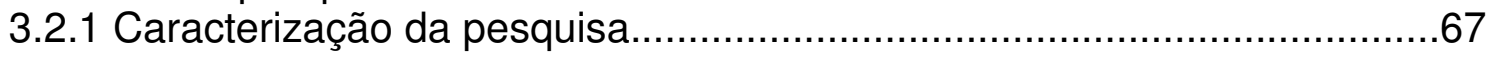

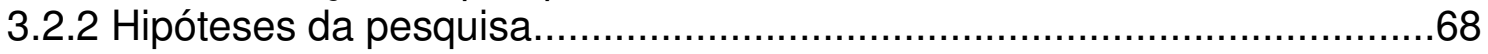

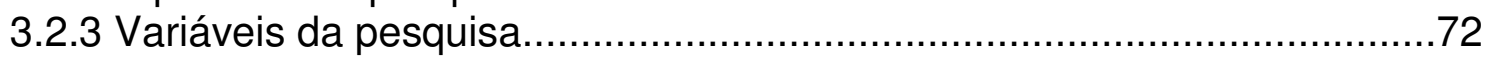

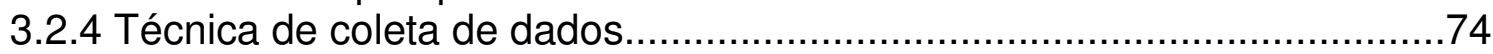

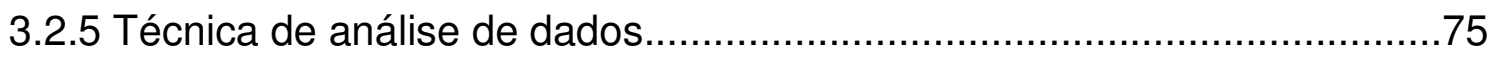

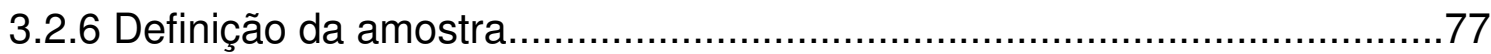

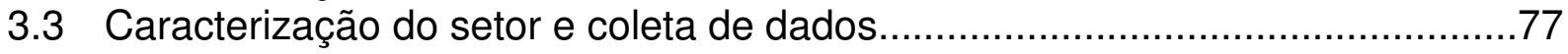

3.3.1 Setor metal mecânico....................................................................... 78

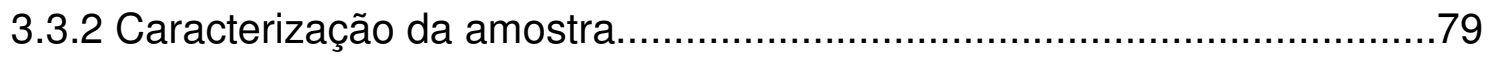

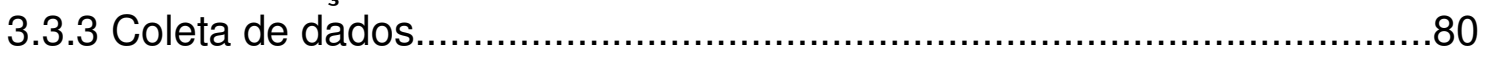


4 APRESENTAÇÃO E ANÁLISE DOS RESULTADOS....................................83

4.1 Especificidades da pequena empresa....................................... 83

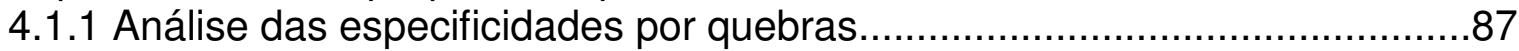

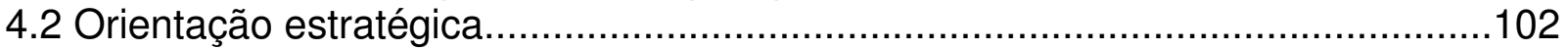

4.2.1 Análise das orientações estratégicas por quebras..................................103

4.2.2 Orientação estratégica e desempenho organizacional.............................106

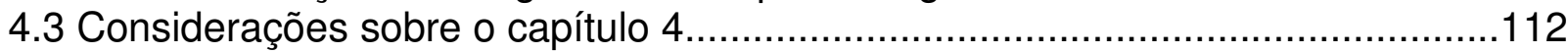

5 CONCLUSÃO.................................................................................................115

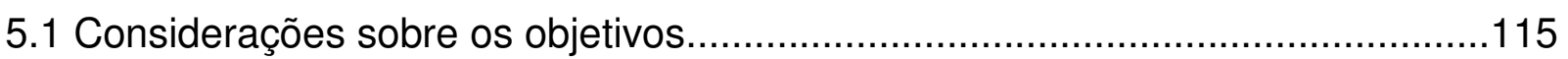

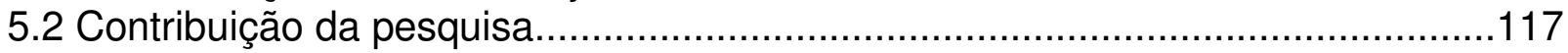

5.3 Limites da pesquisa.............................................................................118

5.4 O treinamento a nível de pós graduação e a aprendizagem em pesquisa...........119

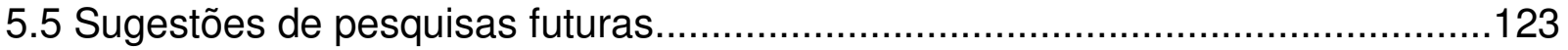

REFERÊNCIAS...............................................................................................123

APÊNDICE A - REVISÃO SISTEMÁTICA DO ESTADO DA ARTE........................129

APÊNDICE B - PROTOCOLO DE PESQUISA....................................................131

APÊNDICE C - QUESTIONÁRIO DE ESPECIFICIDADES.................................135

APÊNDICE D - TERMO DE COMPROMISSO...................................................137

ANEXO A - QUESTIONÁRIO DE ORIENTAÇÃO ESTRATÉGICA........................139 


\section{INTRODUÇÃO}

Esse capítulo tem por finalidade apresentar e discutir a natureza e o propósito da pesquisa. Inicialmente será feita uma contextualização do ambiente que gerou o tema de pesquisa. Em um segundo momento haverá uma caracterização do tema através da exposição do estado da arte do tema de pesquisa. A partir da exposição do estado da arte será feito uma delimitação do tema a ser pesquisado, com a posterior formulação do problema de pesquisa e a declaração dos objetivos. Por fim será feita uma breve consideração epistemológica e será demonstrada a relevância da pesquisa.

\subsection{CONTEXTUALIZAÇÃO DO TEMA}

O atual contexto econômico, oriundo das transformações ocorridas pela globalização, pode ser caracterizado pela rapidez das informações, pelas transformações dos padrões de consumo e, sobretudo, para fazer frente a velocidades desses acontecimentos, pelo acirramento da competitividade entre as empresas (WIERSMA; BOWEN, 2008).

A competitividade para Coutinho e Ferraz (2002) pode se entendida como a aptidão de uma empresa em obter sucesso, seja em forma de lucros e/ou aumento da participação no mercado, dado um certo contexto econômico. Há dois tipos principais de fatores que irão influenciar no desempenho competitivo de uma empresa: externos e internos. Para os autores, fatores externos se referem aos elementos que estão fora do controle da empresa, tais quais: volume de crédito disponível no mercado, taxa de juros, características próprias do setor em que a empresa opera, dentre outros. Os fatores internos são elementos controlados pela empresa, tais quais: capacidades ou competências e recursos financeiros. 
Sendo assim, torna-se imprescindível que essa esfera sobre controle da empresa seja bem gerenciada, bem como o monitoramento do ambiente externo, a fim de que a empresa possa alcançar um bom desempenho competitivo. Nesse sentido, Haguenauer, Ferraz e Kupfer (1996) destacam que fundamental para a competitividade é a capacidade da empresa em formular e implementar estratégias, uma vez que essas consideram tanto fatores internos quanto externos.

\subsection{CARACTERIZAÇÃO DO TEMA}

Para fazer frente ao novo contexto econômico, as empresas devem devotar uma grande parte dos seus esforços para a estratégia empresarial, visto que ela será responsável por direcionar as ações das empresas dentro deste ambiente dinâmico. Parte importante deste processo é, portanto, compreender a gestão estratégica.

Para Hitt, Ireland e Hoskisson (2008) a gestão da estratégia ou gestão estratégica de uma empresa pode ser entendida como um processo contínuo de decisões pautadas nos recursos disponíveis, nas capacidades da empresa e no ambiente de negócios. Sendo assim a gestão estratégica compreenderá os objetivos da empresa, os fatores internos e também fatores externos à empresa.

Todas essas decisões estratégicas feitas pela empresa estão fundamentadas sobre valores e crenças da organização, os quais guiam as ações gerenciais, ou ainda, valores e crenças que orientam as ações dos dirigentes, estando inseridos, portanto, dentro dos estudos de orientação estratégica (NOBLE, SINHA, KUMAR, 2002). Sendo assim, parte fundamental da análise da competitividade é o entendimento do comportamento e da orientação estratégica das empresas.

Para alcançar maior compreensão sobre a temática da orientação estratégica e para descobir artigos relevantes sobre o tema, foi realizada uma revisão sistemática da 
literatura.

\subsubsection{Revisão sistemática}

O método de revisão sistemática da literatura tem por objetivo buscar todo material disponível e relevante para determinado tema de pesquisa ou fenômeno de interesse (COOPER, 1998). Esse método de pesquisa faz parte do procedimento de estudo bibliométrico, o qual segundo Araujo (2006) pode contribuir para o direcionamento de estudos e para o embasamento de pesquisas com base nos principais autores do tema abordado.

Portanto, a revisão sistemática realizada nesse capítulo teve como objetivo analisar o que já foi pesquisado sobre orientação estratégica e verificar, dessa forma, as tendências relativas ao tema, assim como as lacunas de pesquisa não respondidas.

Foram considerados artigos pertencentes ao estado da arte aqueles publicados após o ano de 2005. Com a revisão sistemática, descrita no apêndice A, foram identificados 69 artigos, os quais foram posteriormente agrupados em seis principais perspectivas que estudam o tema "orientação estratégica". São elas:

- $\quad$ Perspectiva associada ao desempenho organizacional: 19 artigos;

- $\quad$ Perspectiva associada à inovação: 16 artigos;

- $\quad$ Perspectiva associada à gestão do conhecimento: 14 ;

- $\quad$ Perspectiva associada às características dos dirigentes: 7 artigos;

- $\quad$ Perspectiva associada ao ambiente externo da firma: 7;

- $\quad$ Perspectiva associada à internacionalização das firmas: 6;

A primeira perspectiva irá relacionar o tema orientação estratégica com o desempenho organizacional das empresas, ou seja, ela irá inter-relacionar essas duas 
variáveis a fim de estabelecer relações de causa e efeito. Dentre os estudos que abordam essa perspectiva podem ser identificados temas como a influência da orientação estratégica adotada pela organização e seu impacto no desempenho em termos de aumento da receita ou retorno sobre o ativo. E também temas que estabelecem uma relação inversa, procurando compreender como a orientação estratégica é influenciada pelo resultado financeira da organização.

A segunda perspectiva irá inter-relacionar a inovação com o a orientação estratégica, ou seja, como a orientação estratégica pode influenciar a inovação dentro das empresas. Os trabalhos inseridos dentro dessa categoria abordam a inovação como um fim, ao contrário do grupo anterior no qual ela é tratada como um meio, ou seja, enquanto a primeira perspectiva irá abordar o caráter inovador de uma organização analisando o impacto de algumas orientações estratégicas voltadas para a inovação no resultado financeiro da empresa, essa última perspectiva irá tentar compreender como uma orientação estratégica pode influenciar no nível de inovação alcançado pela organização.

A terceira perspectiva relaciona a orientação estratégica com a gestão do conhecimento, ou seja, como a gestão eficaz do conhecimento afeta ou é afetada pela orientação estratégica da empresa. Novamente, assim como no desempenho organizacional, a orientação estratégica se comporta ora como variável dependente e ora como independente.

A quarta perspectiva refere-se à relação entre orientação estratégica e características dos dirigentes, ou seja, como os aspectos pessoais dos gestores das empresas influenciam a orientação estratégica adotada pela organização. Entre os aspectos pessoais, os que poderiam ser a causa dessa influência seriam a idade dos gestores, o grau de qualificação, experiência profissional, nacionalidade, gênero, 
religião, dentre outros aspectos tantos pessoais, como profissionais e culturais.

A quinta perspectiva refere-se à relação entre a orientação estratégica e $\mathrm{o}$ ambiente externo, ou seja, como os diversos aspectos do ambiente externo a empresa, sejam eles as características do setor que empresa está inserida, a incerteza ou os riscos são determinantes na escolha da orientação estratégica adotada pela firma. Em um ambiente de alta competitividade, fatores externos e sua análise tornam-se necessários para a sobrevivência das empresas.

A sexta e última perspectiva aborda a relação entre orientação estratégica e internacionalização das firmas. Nessa abordagem é investigado o impacto dos diversos tipos de orientações estratégicas nas firmas que expandem suas operações para mercados externos ao de sua origem. Essa tendência é compatível com o contexto estratégico, o qual está inserido em um ambiente de alta competitividade.

A análise aqui realizada se deu através de um entendimento dos estudos encontrados no estado da arte. A classificação foi feita com base nas tendências encontradas e não é única e definitiva, pois pode ser alterada por outros pesquisadores conforme o conhecimento e a experiência pessoal.

\subsection{DELIMITAÇÃO DO TEMA DE PESQUISA}

Na seção anterior foram identificas, a partir da revisão sistemática do estado da arte, tendências de abordagem do tema orientação estratégica.

Para esta pesquisa a abordagem escolhida será a que relaciona o desempenho organizacional com a orientação estratégica. Dentro da perspectiva de orientação estratégica e desempenho organizacional, há duas vertentes, uma que procura compreender como a orientação estratégica é influenciada pelo resultado financeiro da organização e outra que irá estudar o impacto da orientação estratégica no desempenho 
organizacional (SLATER et al., 2006; ACQUAHH, 2007; ARAGON; ANCHEZ, 2005; ZHOU; LI, 2007; ZHOU et al., 2005), sendo esta última a delimitação do tema de pesquisa.

Dentro desta linha escolhida, Slater et al. (2006) mostraram que há evidencias que suportam a existência de relações entre orientação estratégica e desempenho organizacional nas firmas, porém destacam a necessidade de estudos mais aprofundados sobre o tema.

Acquaah (2007) argumenta na conclusão do seu estudo que o impacto da orientação estratégica no desempenho organizacional depende de fatores contingenciais, da mesma forma Aragon e Sanchez (2005) concluem que há diferentes influências que cada uma das orientações estratégicas exerce no desempenho organizacional das firmas, de tal forma que não há um modelo ótimo de orientação estratégica, mas sim orientações estratégicas mais adequadas para firmas considerando o seu tamanho, setor em que atua, ambiente macroeconômico, dentre outros.

Zhou e Li (2007), através de uma revisão da literatura em orientação estratégica, indicam lacunas de pesquisas dentro do tema, dentre as quais se destacam também a necessidade de mais estudos que abordem a relação orientação estratégica e desempenho organizacional.

Sendo assim, o presente trabalho assim como os demais mencionados nessa seção, pretende aprofundar os estudos já existentes e que trabalham a relação entre a orientação estratégica e o desempenho organizacional, utilizando como base as tipologias desenvolvidas pela literatura da administração estratégica, as quais têm como referência o trabalho seminal de Miles e Snow (1978) e compreende as seguintes orientações estratégias: prospectora, analista, defensora e reativa. 


\subsection{FORMULAÇÃO DO PROBLEMA DE PESQUISA}

Estudos anteriores que utilizaram as tipologias de orientação estratégica de Miles e Snow (1978) relacionando-as com o desempenho organizacional foram testadas e validadas empiricamente (HAMBRICK, 1983; GIMENEZ 1999; ACQUAHH, 2007; SLATER et al, 2006; WRIGHT et al, 1995; DURAND; COEURDEROY, 2001; NOBLE; RAJIV; KUMAR, 2002; ARAGON; SANCHEZ, 2005; MILLER, 1983). Porém, nas pequenas empresas poucos estudos, de acordo com Aragon e Sanchez (2005), têm procurado compreender essa relação.

Em qualquer estudo que procure investigar a gestão de pequenas empresas, há que levar em consideração a existência de especificidades que as distinguem das grandes organizações (TORRES; JULIEN, 2005)

Uma das especificidades, que pode ser relacionada diretamente ao tema de desempenho organizacional, é a questão do crescimento financeiro, que para Zahra (1993), é possível que pequenas empresas escolham deliberadamente um aumento dos lucros a curto prazo em contraste com o crescimento a longo prazo.

Um ponto importante e a ser destacado nos estudos que busquem compreender o fenômeno do desempenho organizacional na pequena empresa, é que muitas delas não estão orientadas para o crescimento (LANG, 1996).

As pequenas empresas na maioria das vezes não crescem, pois seus dirigentes optam por pararem o processo de crescimento, sendo assim tão logo atinjam um nível satisfatório irão mantém o nível de retorno suficiente para sobreviverem (STOREY, 1994).

Pequenas empresas possuem, portanto, características próprias que podem alterar as relações entre orientação estratégica e desempenho organizacional observada nas grandes empresas. 
Sendo assim, tomando como base as especificidades das pequenas empresas, sobretudo aquelas relacionadas com o desempenho organizacional, e tendo em vista que os problemas de origem estratégica enfrentados pelas mesmas é por volta de $80 \%$ das suas dificuldades (BORTOLI NETO, 1997) somados ao fato da necessidade apontada por trabalhos como Slater et al. (2006) e Zhou e Li (2007) de estudos mais conclusivos sobre o tema, é formulado o seguinte problemas de pesquisa:

Qual a relação entre as orientações estratégicas de Miles e Snow com o desempenho organizacional nas pequenas empresas?

\subsection{OBJETIVOS DA PESQUISA}

A partir do problema de pesquisa formulado, o objetivo principal deste trabalho é: verificar a relação entre as orientações estratégicas de Miles e Snow (1978) com o desempenho organizacional nas pequenas empresas à luz de suas especificidades.

Essa pesquisa ainda possui os seguintes objetivos específicos:

- Identificar a orientação estratégica seguida por firmas que apresentam os melhores índices de desempenho organizacional, quando este é entendido em termos de aumento do faturamento;

- Identificar a orientação estratégica seguida por firmas que apresentam os melhores índices de desempenho organizacional, quando este é entendido em termos de rotatividade;

- Verificar se as orientações estratégicas identificadas nas empresas que apresentam os melhores índices de faturamento e de rotatividade são idênticas ou distintas;

- Verificar as especificidades da pequena empresa mais evidentes nas firmas participantes da amostra; 
- Verificar as especificidades da pequena empresa menos evidentes nas firmas participantes da amostra;

\subsection{CONSIDERAÇÕES EPISTEMOLÓGICAS}

No campo de estudos das ciências sociais é importante que haja um entendimento das abordagens que estão por trás da construção da ciência e sua natureza filosófica (BURRELL; MORGAN, 1979). Portanto, torna-se indispensável uma análise de como estará pautada a construção do conhecimento nesse trabalho.

Para Burrel e Morgan (1979) há quatro paradigmas epistemológicos da pesquisa científica, sendo dois ligados ao polo subjetivo e dois ligados ao polo objetivo. Os paradigmas do polo subjetivo compreendem: humanismo radical e interpretativismo. Os paradigmas do polo objetivo compreendem: o estruturalismo radical e o funcionalismo.

De acordo com Paula et al. (2010) o interpretativismo é marcado por ter foco na interpretação de símbolos e significados da vida organizacional e o humanismo radical pelo forte emprego da dialética e do existencialismo. Já o paradigma do estruturalismo radical, caracterizado por uma visão objetiva, irá se apresentar como um representante da emancipação e da busca por uma visão realística frente ao mundo (PAES et al., 2010). Por fim o paradigma funcionalista irá ser marcado por buscar uma explicação prática para os diversos problemas encontrados dentro do contexto organizacional (PAES et al., 2010).

O presente trabalho estará fundamentado dentro do paradigma funcionalista. Desta maneira ele irá assumir uma abordagem tipicamente objetiva considerando que a realidade apenas pode ser compreendida se estiver fundamentada em uma análise de dados colhidos através de instrumentos padronizados e neutros (FONSECA, 2002), 
instrumento este que nessa pesquisa assumirá a forma de uma survey.

Ainda em adequação ao funcionalismo, o qual para Burrel e Morgan (1979) se pauta em uma postura realista e positivista, o objetivo deste trabalho é a produção da descrição quantitativa dos dados, estando, dessa forma, a pesquisa fundamentada dentro dos preceitos positivistas.

\subsection{RELEVÂNCIA DA PESQUISA}

Em recente estudo promovido pelo SEBRAE (2010) foi analisado o comportamento das micro e pequenas empresas no período de 2000 a 2010. De acordo com os dados, durante essa última década pôde ser verificado o aumento na participação dessas empresas na economia. No inicio do período haviam 4,2 milhões de estabelecimentos considerados como micro e pequeno porte. No final do período esse número subiu para 6,1 milhões, apresentando um aumento de 1,9 milhões de novas micro e pequenas empresas seguindo uma taxa de aumento de novos estabelecimentos na média de $3,7 \%$ ao ano.

Somam-se aos dados apresentados acima outros levantamentos, tais quais: Em 2010, as micro e pequenas empresas foram responsáveis por $99 \%$ dos estabelecimentos, 51,6\% dos empregos privados não agrícolas formais no país e quase $40 \%$ da massa de salários. Em média, durante a década de 2000, de cada $\mathrm{R} \$ 100$ pagos aos trabalhadores no setor privado não agrícola, aproximadamente $\mathrm{R} \$ 41$ foram

gerados pelas micro e pequenas empresas. É importante ressaltar também que de acordo com a pesquisa, os trabalhadores tiveram um aumento real três vezes maior que o de trabalhadores de grandes empresas (SEBRAE, 2010)

Em relação ao âmbito paulista, as micro e pequenas empresas do estado de São Paulo, em relação ao setor de atividade dentro da economia brasileira, representam 
$40 \%$ do setor de comércio, $39 \%$ do setor de serviço, $12 \%$ do setor industrial e $9 \%$ do setor agropecuário. Ainda, as micro e pequenas empresas representam ainda $99 \%$ dos estabelecimentos, $47 \%$ dos empregos e $36 \%$ da folha de salário (SEBRAE, 2014).

A partir desses dados pode ser observada a relevância dessas empresas para a economia brasileira. Sua importância econômica e social é notadamente reconhecida, sobretudo em países em desenvolvimento, como o Brasil, onde elas são uma resposta à falta de grandes investimentos (JULIEN, 1997). Elas funcionam, portanto, como incubadoras de desenvolvimento regional e na alocação de mão-deobra, proporcionando o aumento do nível de emprego onde estão inseridas.

De acordo com Leone (1999), apesar da grande dificuldade em estudar o universo das pequenas empresas em decorrência de sua grande heterogeneidade, essas empresas por serem organizações geradoras de emprego despertam grande interesse dos que acreditam que o aprofundamento do conhecimento sobre elas seja importante para dar uma resposta adequada às dificuldades enfrentadas pelo setor.

Portanto, estando muito longe de ocupar um papel secundário, o campo de estudo sobre pequenas empresas é importante para o empresariado local na tentativa de melhor orientar suas decisões, para o setor público na formulação de políticas de fomento ao empresariado, para consultores fortalecerem suas orientações e para o meio acadêmico ampliando o horizonte de novas pesquisas.

Desta maneira, o presente trabalho tem como principal motivação a carência de estudos relacionados com o comportamento da orientação estratégica sobre o desempenho organizacional considerando o ambiente específico das pequenas empresas, sobretudo quando levado em consideração a magnitude dos problemas de origem estratégica enfrentados por essas empresas.

Sendo assim a principal contribuição científica será a identificação de 
orientações estratégicas, que impactam positivamente no desempenho organizacional, explicadas com base nas especificidades das pequenas empresas, uma vez que trabalhos dessa forma não foram identificados na literatura apesar de sua importância. A pesquisa contribuirá com o pesquisador pelo aprimoramento do conhecimento no campo das ciências sociais aplicadas; ao conjunto das pequenas empresas através da disponibilização dos resultados obtidos na pesquisa, com a esperança que estes possam ser úteis ao processo gerencial; ao meio acadêmico através do incremento da literatura sobre o tema orientação estratégica na pequena empresa que é relativamente escasso; ao Grupo de Estudos Organizacionais da Pequena Empresa - GEOPE da EESC-USP no aprofundamento da compreensão da pequena empresa por meio da exposição dos conceitos sobre orientação estratégica. 


\section{REFERENCIAL TEÓRICO}

Este capítulo tem por objetivo apresentar a fundamentação teórica do trabalho relativa ao tema orientação estratégica e pequenas empresas. A construção deste capítulo é fundamental para embasar a elaboração das hipóteses de pesquisa e, posteriormente, da elaboração do questionário. Inicialmente nesse capítulo, na tentativa de localizar a orientação estratégica, será apresentada a definição de estratégia empresarial. Continuando o capítulo haverá uma caracterização, apresentação das linhas e categorização do tema de pesquisa. Seguindo a construção do polo teórico, e em concordância com a tendência de pesquisa sobre o tema adotada no capítulo 1, será feita uma fundamentação teórica sobre desempenho organizacional e finalmente sua inter-relação com o tema. Finalmente serão apresentados os critérios utilizados para classificação das pequenas empresas, bem como as características próprias que as diferem das grandes organizações. Também são discutidos aspectos específicos do tema de pesquisa "orientação estratégica" aplicado ao universo das pequenas empresas.

\subsection{ESTRATÉGIA EMPRESARIAL}

A literatura de orientação estratégica emerge dentro do campo de estudo de estratégia empresarial. Ainda que essa última área seja relativamente recente, a teorização e sistematização do conhecimento sobre estratégia tem seu início a mais de 2.500 anos na China com a obra de Sun Tzu denominada "A Arte da Guerra", na qual, dentre outros ensinamentos, o autor pondera sobre a necessidade do conhecimento pessoal e do adversário para sair vitorioso nas diversas empreitadas (TZU, 2003). 
De forma análoga, transportando para o campo dos negócios, também é necessário, no momento de formulação das estratégias empresariais, o conhecimento próprio da organização (conhecimento de si mesmo) e do ambiente externo (conhecimento do adversário). Pode-se ver, portanto, dentre outros fatores, que os campos de estudo em estratégia militar e estratégia empresarial guardam muitas similaridades.

Tais similaridades se devem, sobretudo, ao fato de que a partir da segunda metade do século XX, o conceito de estratégia militar foi transportado para dentro do campo de estudos de administração empresarial. O ano de 1965 poderia ser lembrado como um marco com a publicação de "Corporate Strategy" de Igor Ansoff, na qual o autor apresenta quatro tipos de estratégia, que ficaram conhecidas como a "matriz produto/mercado" ou "matriz Ansoff" (ALDAY, 2000).

Ainda segundo Alday (2000) foi a partir da década de 1970 que o estudo de estratégia empresarial eclodiu dentro da literatura de administração aumentando a demanda por estudos e publicações acerca do tema.

Entretanto, apesar do interesse e da expansão do número de pesquisas sobre o campo da estratégia empresarial não há um consenso dentro da literatura do que se compreende por estratégia, ou seja, a definição de estratégia irá depender da abordagem escolhida pelo autor, uma vez que se trata de um tema abrangente e que, portanto, irá demandar uma grande integração de teorias e enfoques (CABRAL, 1998).

Não é o propósito deste trabalho discutir profundamente todas as abordagens dentro da literatura de estratégia empresarial, porém cabe destacar as definições dadas pelos principais autores em cada tema.

Andrews (1971) define a estratégia como um padrão de decisões adotado pela firma, de modo que a partir da análise detalhada destas decisões são revelados os 
objetivos perseguidos pela companhia, os planos necessários para que os objetivos sejam alcançados e modelo de negócios almejado pela empresa, de tal forma que a partir desses elementos, traduzidos a partir do padrão de decisões, é possível observar o tipo de organização que a empresa espera ser.

Hofer e Schendel (1978) caracterizam a estratégia como a união entre as capacidades, no sentido de aptidão, e recursos internos da própria organização com as oportunidades e riscos presentes no ambiente externo à firma, de tal forma que uma estratégia eficiente seja capaz de utilizar os recursos internos da firma na captação de oportunidades presentes no ambiente econômico em que a empresa opera.

Para Porter (1980) a estratégia é vista como a junção por um lado das metas e objetivos almejados pela organização e por outro das ações e esforços desprendidos para o alcance dos mesmos.

Mintzberg (2010) aponta a estratégia como um conceito amplo e que necessita de cinco definições para poder caracteriza-la. Essas cinco definições ficaram conhecidas como os 5 Ps. São eles:

- Padrão de decisões que surge a partir das próprias ações das empresas. Essas ações podem ser deliberadas ou emergentes.

- Plano como sinônimo de um curso pretendido pela empresa para lidar com objetivos pré estabelecidos.

- Posição pela qual a empresa localiza um segmento de mercado e busca estabelecer dentro dele um posicionamento que irá sustentar sua posição.

- Pretexto pelo qual a empresa busca direcionar uma mensagem ao mercado

- Perspectiva fundamentada nos valores e crenças da organização.

Em relação ao processe de formulação da estratégia, Mintzberg, Ahlstrand e Lampel (2000) identificaram dez escolas de pensamento estratégico. Através desse 
trabalho, os autores deixam claro que não há como entender a estratégia em sua totalidade, mas apenas alcançar o entendimento das distintas partes, ainda que mostrem a escola da configuração como uma tentativa de faltar do "todo". As partes as que os autores se referem são derivadas na figura de dez escolas. As escolas são apresentadas na tabela 1 .

Quadro 1 - Escolas do pensamento estratégico

\begin{tabular}{|l|l|}
\hline Escola & Processo estratégico \\
\hline Escola do Design & Estratégia como um processo de concepção \\
\hline Escola do Planejamento & Estratégia como um processo formal \\
\hline Escola do Posicionamento & Estratégia como um processo analítico \\
\hline Escola Empreendedora & Estratégia como um processo visionário \\
\hline Escola Cognitiva & Estratégia como um processo mental \\
\hline Escola do Aprendizado & Estratégia como um processo emergente \\
\hline Escola do Poder & Estratégia como um processo de negociação \\
\hline Escola Cultural & Estratégia como um processo coletivo \\
\hline Escola Ambiental & Estratégia como um processo reativo \\
\hline Escola de Configuração & Estratégia como um processo de transformação \\
\hline \multicolumn{1}{|c|}{ FONTE: MINTZBERG, AHLSTRAND E LAMPEL(2000) }
\end{tabular}

A partir das definições dos principais autores de estratégia empresarial, pode ser visto que não há uma definição única e precisa dentro do meio acadêmico para o conceito de estratégia. Isto em parte é explicado por Meirelles e Gonçalvez (2001) que destacam que o termo estratégia refere-se a um conceito amplamente utilizado e que carrega em si uma grande magnitude e diversificação.

Entretanto, ainda que não haja uma definição única e concisa sobre o conceito de estratégia, Mintzberg (1995) destaca sua importância ao apresentar o vértice 
estratégico como o responsável por assegurar o cumprimento dos objetivos da firma de forma eficaz e caracterizando a estratégia como uma força mediadora entre a organização e o ambiente externo à firma.

Com o desenvolvimento da literatura de estratégia empresarial vários campos de estudo emergiram decorrentes dela, cada qual tendo como base uma visão de estratégia. Um destes campos irá estudar a orientação estratégica adotada pelos dirigentes, o qual para Peng (2003) trata-se de um campo de estudo atual da administração e tem a sua visão de estratégia ligada a definição de Mintzberg (1995) como uma força moderadora entre a organização e o ambiente externo.

\subsection{CARACTERIZAÇÃO DA ORIENTAÇÃO ESTRATÉGICA}

De acordo com Noble, Sinha e Kumar (2002) há duas grandes vertentes dentro do campo de estudos em orientação estratégica: uma que irá abordar a orientação estratégica como sendo um processo de aprendizagem e cognição e outra vertente que abordará a orientação estratégica como valores que guiam as ações gerenciais, ou ainda, valores e crenças que orientam as ações dos dirigentes.

A primeira vertente é representada por Hitt et al. (1997) como um processo de aprendizagem e obtenção de conhecimento. Para o autor ao longo do tempo, os administradores das empresas passam a desenvolver modelos cognitivos essenciais para a tradução e processamento de todas as informações disponíveis a eles oriundas tanto do ambiente interno quanto ao ambiente externo à organização. A esses modelos cognitivos os autores denominam de orientação estratégica, sendo ela responsável por unir todas as informações em um único e conciso processo de decisão representativo de toda a organização. Outros trabalhos empíricos além de Hitt et al. (1997) fazem

parte dessa vertente como Hitt e Middlemist, (1979); Hitt e Tyler (1991); Calori, 
Johnson e Sarnin (1994);

A segunda vertente abordará a orientação estratégica como um conjunto de valores que ditam a filosofia da firma em gerir seus negócios, tendo como objetivo alcançar um desempenho superior aos seus concorrentes. Para os autores, o conceito de orientação estratégica ainda reflete um construto multidimensional que permite a empresa entender e gerenciar as forças do ambiente econômico em que está posicionada (GATIGNON; XUEREB, 1997).

A orientação estratégica de uma firma, nesse sentido, pode então ser compreendida como as direções, que uma organização irá seguir com o objetivo final de criar um comportamento inerente à ela e que a guiará em direção a um desempenho superior e continuo nos seus negócios, estando sempre pautada dentro de uma filosofia de negócios (NARVER; SLATER, 1990).

A filosofia de negócios da organização, compreendendo em seu interior o conjunto próprio de valores, de acordo com Day (1994), irá transcender as competências individuais, ou seja, não será pautado nas habilidades pessoais dos administradores, mas sim de toda a organização. Ela irá também unificar dentro de si todos os recursos e competências da firma dentro de um processo coeso de decisão. Sendo assim, a orientação estratégica de uma firma terá implicações diretas no tipo e existência das práticas gerenciais desempenhadas pelos dirigentes de uma firma (RAJAGOPALAN, 1996). Ainda sobre a filosofia de negócios, Machado da Silva e Nogueira (2001) também irão pontuar que ela compreende um conjunto de valores e mostram que esses valores podem ser compreendidos como concepções obtidas a partir de um processo de decisão racional e que irão expressar uma preferência por determinado curso de ações ao invés de outros.

Em relação a suas particularidades, Venkatraman (1985) aponta que a 
orientação estratégica adotada por uma firma tem por características:

- Serem estáveis dentro da empresa, ou seja, são mais duradouras do que simples iniciativas individuais para manter a posição de mercado, de tal forma que a orientação estratégica de uma empresa se mantém constante ao longo do tempo, demonstrando estar enraizada nas práticas gerenciais da companhia.

- São variáveis dentro de um mesmo segmento de mercado, ou seja, pode haver divergências de orientação estratégica em empresas operando em um mesmo setor.

Esta última característica apontada pelo autor é particularmente importante, pois permite que se façam comparações entre empresas inseridas em um mesmo setor da Indústria.

Uma próxima análise a ser feita dentro da literatura de orientação estratégica é a abordagem das correntes de estudo e, posteriormente, uma segunda análise é a relação com outros campos de estudo. Ambas as análises são motivos de estudo da próxima seção.

\subsection{LINHAS DE ESTUDO DA ORIENTAÇÃO ESTRATÉGICA}

Surgem dentro da literatura de orientação estratégia duas linhas de estudo distintas oriundas de dois campos de estudos igualmente distintos.

A primeira linha de estudo tem sua origem dentro do campo de estudos em marketing estratégico e irá definir o domínio focal de interesse, servindo, dessa forma, como um guia concreto no momento de definir a qual orientação estratégica uma firma segue (Zhou e Li, 2007). Seus principais autores são: Kholi e Jaworski (1990), Narver e Slater (1990) e Gatignon e Xuereb (1997) e compreendem cinco tipos de orientações estratégicas: orientação para o mercado (subdividida em orientação para o cliente e orientação para o concorrente), orientação para a 
tecnologia, orientação empreendedora, orientação para a produção e orientação para vendas (ZHOU; LI, 2007).

Empresas que adotam uma orientação estratégica voltada para o mercado têm enraizadas em sua cultura organizacional uma alta prioridade voltada para a criação de valor aos seus consumidores. Elas são subdivididas em duas dimensões: orientação para o consumidor e orientação para o concorrente. Para criar valor aos consumidores essas empresas despendem esforços consideráveis em monitorar e responder as necessidades de seus clientes, ao passo que também monitoram e respondem aos movimentos dos seus principais concorrentes (NARVER; SLATER, 1990).

Um segundo grupo dentro do marketing estratégico é composto por empresas que seguem uma orientação estratégica voltada para a tecnologia. Tais empresas, de acordo com Hurley e Hult (1998), são caracterizadas por apresentarem uma grande propensão a novas ideias e a adoção de novas tecnologias em seu processo produtivo. Sendo assim, empresas com essa orientação irão dar grande ênfase ao seu setor de pesquisa e desenvolvimento de produtos de forma a adquirir e introduzir as últimas inovações tecnológicas possíveis (GATIGNON; XUEREB, 1997).

Empresas com uma orientação empreendedora, de acordo com Hult e Ketchen (2001), terão em sua cultura corporativa a propensão em perseguir novas oportunidades de mercado além de sempre renovarem as ações desenvolvidas nas áreas de operação em que já atuam. Elas ainda têm como características serem tolerantes aos riscos inerentes de qualquer ação que vise novas oportunidades (MATSUNO; MENTZER; ÖZSOMER, 2002).

Firmas que adotam uma orientação estratégica voltada para a produção, tem 
como características: a busca por aumentar a eficiência produtiva, minimização dos custos de produção e desenvolvimento de uma rede de distribuição em massa dos seus produtos de forma a visar a obtenção de uma vantagem competitiva sobre seus concorrentes (NOBLE; SINHA; KUMAR, 2002).

Por último, dentro das orientações estratégicas emergentes da literatura em marketing estratégico, há as empresas que seguem uma orientação voltada para as vendas. Tais firmas apresentam uma postura agressiva em relação às suas vendas e despendem grandes esforços para obterem resultados imediatos. Além disso, elas têm como objetivo maximizar sua fatia de mercado (NOBLE; SINHA. KUMAR, 2002). De acordo com Zhou e Li (2007) firmas que adotam uma orientação estratégica voltada para as vendas priorizam um retorno em curto prazo, diferentemente das empresas que seguem uma orientação de mercado, as quais perseguem um retorno dos seus investimentos em longo prazo através da fidelização de seus clientes.

A segunda linha tem sua origem ligada ao campo da administração estratégica, que tem em sua essência ser uma tipologia mais abrangente, que não apenas descreve as orientações estratégicas, mas também as estruturas, processos e práticas organizacionais que são mais prováveis de se encaixar em uma dada orientação estratégica (RAJAGOPALAN, 1996). Essa linha tem como seu maior expoente a tipologia de Miles e Snow (1978). Ela compreende quatro tipos de orientações estratégicas: prospectoras, analistas, defensoras e reativos.

Prospectoras compreendem todas as firmas que adotam uma postura agressiva na busca por oportunidades de crescimento. Elas fazem isso através de desenvolvimento de novos mercados e produtos, assumindo uma postura de inovação. Além disso, ainda procuraram por tendências emergentes no mercado e desenvolvem novas tecnologias (MILES; SNOW, 1978). 
Defensores são definidos como as firmas que se estabelecem em um mercado e defendem essa posição. Elas se situam em mercados relativamente estáveis e limitados, os quais são marcados por apresentarem grupos particulares de consumidores e estruturas já estabelecidas. Ao passo que as firmas como uma orientação estratégica prospectora podem ser definidas como inovadoras e orientadas para o ambiente externo à empresa, os defensores são orientados para o ambiente interno da empresa e, por consequência, buscam a eficiência interna como forma de proteger sua posição. (MILES; SNOW, 1978).

Analistas por sua vez são firmas que defendem sua posição de mercado através de uma orientação voltada para a eficiência interna ao mesmo tempo em que cautelosamente adentram novos mercados através de inovações de produtos e mercados (MILES; SNOW, 1978). As empresas que adotam essa postura estratégica, portanto, exibem ao mesmo tempo as características estratégicas dos defensores e prospectores.

O último grupo dentro da tipologia de Miles e Snow (1978) são os reativos. As empresas que seguem essa orientação estratégica serão firmas que, ao contrário dos três primeiros tipos de orientação estratégica, não irão adotar uma postura proativa. Esses irão focar mais no movimento de reação frente às pressões do ambiente. Isso ocorre geralmente pela inaptidão dos dirigentes em articular uma direção estratégica clara e consistente com as oportunidades oferecidas pelo mercado (MILES; SNOW, 1978).

Apesar de serem tipologias distintas, para Zhou e Li (2007) as duas tipologias estão intimamente relacionadas. A tabela 2 apresenta as tipologias de Miles e Snow (1978) e as tipologias oriundas do marketing estratégico e suas características em comum. 
Quadro 2 - Tipologias e suas características

\begin{tabular}{|c|c|}
\hline Orientações estratégicas & Caracteristicas \\
\hline $\begin{array}{l}\text { Prospectora de Miles e Snow (1978) e } \\
\text { dirigentes com orientação voltada para o } \\
\text { desenvolvimento tecnológico ou } \\
\text { empreendedor na tipologia do marketing } \\
\text { estratégico. }\end{array}$ & $\begin{array}{l}\text { Grande capacidade de adaptação às } \\
\text { mudanças do ambiente e necessidade } \\
\text { constante de busca por novas tecnologias. }\end{array}$ \\
\hline $\begin{array}{l}\text { Analista de Miles e Snow (1978) e } \\
\text { dirigentes com visão para o mercado na } \\
\text { literatura de marketing estratégico. }\end{array}$ & $\begin{array}{l}\text { Empregam suas forças contra as fraquezas } \\
\text { dos rivais e tentam satisfazer as } \\
\text { necessidades dos seus consumidores }\end{array}$ \\
\hline $\begin{array}{l}\text { Defensora na tipologia de Miles e Snow } \\
\text { (1978) e empresas com orientação para a } \\
\text { produção ou vendas na tipologia do } \\
\text { marketing estratégico }\end{array}$ & $\begin{array}{l}\text { Buscam a eficiência interna, através da } \\
\text { alocação eficiente de recursos e retorno a } \\
\text { curto prazo como forma de defender sua } \\
\text { posição. }\end{array}$ \\
\hline
\end{tabular}

Ainda que para Zhou e Li (2007) as duas grandes tipologias guardem características em comum, como apresentadas no quadro 2, essa exposição serve apenas como ilustração, pois não há trabalhos empíricos dentro da literatura que a suportem.

\subsection{CATEGORIAS DE ESTUDO SOBRE ORIENTAÇÃO ESTRATÉGICA}

Dentro da literatura de orientação estratégica, há três grandes categorias gerais que podem ser encontradas a partir de uma análise de seu conteúdo. Essas categorias são apontadas por Morgan e Strong (2003) e apresentadas a seguir:

- Narrativa: os estudos narrativos de orientação estratégica descrevem a natureza holística da filosofia de negócios, a qual é única para o caso, para a situação e para 
a organização. A ênfase dessa abordagem quanto a sua metodologia é qualitativa e quase sempre assume a forma de estudo de caso.

- Classificatória: esses estudos classificam as filosofias de negócios em tipos já existentes, por isso mesmo as distintas classificações são conhecidas como tipologias (conceitual) ou taxonomias (empírica) de orientação estratégica.

- Comparativa: dentro dessa categoria são identificados combinações de atributos e dimensões estratégicas. Ela pretende descrever a orientação estratégica adotada por uma firma, portanto, por meio de múltiplas habilidades (ou atributos) e dimensões comuns a um conjunto de firmas. Nesse sentido, não é utilizada uma classificação restrita a priori, mas sim construídas tipologias com base no comportamento estratégico observado nas empresas.

Em estudos que utilizam a tipologia de Miles e Snow (1978), Morgan e Strong (2003) apontam que eles se enquadram dentro da categoria de estudos classificatórios. Outro ponto a destacar dentro dos estudos que utilizam essa tipologia é a relação que as orientações estratégicas estabelecem com outras variáveis, de tal forma que elas podem assumir duas formas distintas: ora se comportam como variáveis independentes e ora como variáveis dependentes. A seguir é feita uma revisão da literatura em orientação estratégica e a exposição do comportamento que as distintas tipologias apresentam. Os resultados estão expostos no quadro 3.

Quadro 3 - Relação das orientações estratégicas com outras variáveis

\begin{tabular}{|l|l|l|l|l|}
\hline Estudos & Ano & Amostra & $\begin{array}{l}\text { Variáveis } \\
\text { Independentes }\end{array}$ & Variáveis Dependentes \\
\hline Venkatraman & 1986 & $\begin{array}{l}39 \text { executivos de } \\
\text { diferentes setores } \\
\text { participantes do } \\
\text { programa de } \\
\text { desenvolvimento } \\
\text { gerencial }\end{array}$ & OE & DO \\
\hline Simons & 1991 & $\begin{array}{l}\text { 30 dirigentes do setor } \\
\text { de saúde }\end{array}$ & OE & $\begin{array}{l}\text { Sistemas de controle } \\
\text { gerencial }\end{array}$ \\
\hline
\end{tabular}




\begin{tabular}{|c|c|c|c|c|}
\hline $\begin{array}{l}\text { Rajagopalan e } \\
\text { Finkelstein }\end{array}$ & 1992 & $\begin{array}{l}50 \text { firmas do setor } \\
\text { elétrico }\end{array}$ & $\mathrm{OE}$ & $\begin{array}{l}\text { Sistemas de } \\
\text { remuneração dos } \\
\text { gerentes seniores. }\end{array}$ \\
\hline $\begin{array}{l}\text { Veliyath e } \\
\text { Shortel }\end{array}$ & 1993 & 406 hospitais & $\mathrm{OE}$ & $\begin{array}{l}\text { Planejamento } \\
\text { estratégico e DO }\end{array}$ \\
\hline Wright et al. & 1995 & $\begin{array}{l}79 \text { empresas do setor } \\
\text { automotivo }\end{array}$ & $\begin{array}{l}\text { Orientação } \\
\text { estratégica }\end{array}$ & $\begin{array}{l}\text { Desempenho } \\
\text { organizacional }\end{array}$ \\
\hline Rajagopalan & 1996 & $\begin{array}{l}50 \text { investidores do } \\
\text { setor de energia }\end{array}$ & $\begin{array}{l}\text { Planos de } \\
\text { incentivo }\end{array}$ & $\begin{array}{l}\text { Orientação estratégica e } \\
\text { Desempenho }\end{array}$ \\
\hline $\begin{array}{l}\text { Gatignon e } \\
\text { Xuereb }\end{array}$ & 1997 & $\begin{array}{l}3000 \text { executivos de } \\
\text { marketing de } \\
\text { diferentes setores }\end{array}$ & $\begin{array}{l}\text { Orientação } \\
\text { estratégica }\end{array}$ & Inovação \\
\hline Hitt et al. & 1997 & $\begin{array}{l}299 \text { executivos de } \\
\text { diferentes setores }\end{array}$ & $\begin{array}{l}\text { Indicadores } \\
\text { econômicos, } \\
\text { sociais e culturais }\end{array}$ & Orientação estratégica \\
\hline Chan et al. & 1997 & $\begin{array}{l}1200 \text { empresas do } \\
\text { setor industrial e } \\
\text { financeiro }\end{array}$ & $\begin{array}{l}\text { Sistemas de } \\
\text { informação }\end{array}$ & Orientação estratégica \\
\hline Berthon et al. & 1999 & Revisão da literatura & $\begin{array}{l}\text { Fatores } \\
\text { contingenciais }\end{array}$ & Orientação estratégica \\
\hline Voss e Voss & 2000 & $\begin{array}{l}128 \text { grupos de } \\
\text { comunição dos } \\
\text { teatros }\end{array}$ & $\begin{array}{l}\text { Orientação } \\
\text { estratégica }\end{array}$ & $\begin{array}{l}\text { Desempenho } \\
\text { organizacional }\end{array}$ \\
\hline $\begin{array}{l}\text { Durand e } \\
\text { Couerderoy }\end{array}$ & 2001 & $\begin{array}{l}582 \text { empresas de } \\
\text { manufatura }\end{array}$ & $\begin{array}{l}\text { Orientação } \\
\text { estratégica }\end{array}$ & $\begin{array}{l}\text { Desempenho } \\
\text { organizacional }\end{array}$ \\
\hline Noble et al. & 2002 & $\begin{array}{l}4 \text { grande empresas } \\
\text { do setor de varejo }\end{array}$ & $\begin{array}{l}\text { Orientação } \\
\text { estratégica }\end{array}$ & $\begin{array}{l}\text { Desempenho } \\
\text { organizacional }\end{array}$ \\
\hline $\begin{array}{l}\text { Morgan e } \\
\text { Strong }\end{array}$ & 2003 & $\begin{array}{l}149 \text { empresas do } \\
\text { setor de alta } \\
\text { tecnologia }\end{array}$ & $\begin{array}{l}\text { Orientação } \\
\text { estratégica }\end{array}$ & $\begin{array}{l}\text { Desempenho } \\
\text { organizacional }\end{array}$ \\
\hline Zhou et al. & 2005 & $\begin{array}{l}350 \text { marcas de } \\
\text { produtos de consumo }\end{array}$ & $\begin{array}{l}\text { Orientação } \\
\text { estratégica }\end{array}$ & $\begin{array}{l}\text { Inovação e } \\
\text { aprendizado } \\
\text { organizacional }\end{array}$ \\
\hline $\mathrm{Li}$ & 2005 & $\begin{array}{l}181 \text { firmas na China } \\
\text { que recebem } \\
\text { investimento } \\
\text { estrangeiro }\end{array}$ & $\begin{array}{l}\text { Orientação } \\
\text { estratégica }\end{array}$ & $\begin{array}{l}\text { Rede de } \\
\text { relacionamentos } \\
\text { (network) e DO }\end{array}$ \\
\hline $\begin{array}{l}\text { Sanchez e } \\
\text { Marin }\end{array}$ & 2005 & $\begin{array}{l}1351 \text { pequenas e } \\
\text { médias empresas }\end{array}$ & $\begin{array}{l}\text { Orientação } \\
\text { estratégica }\end{array}$ & $\begin{array}{l}\text { Desempenho } \\
\text { organizacional }\end{array}$ \\
\hline Zhou et al. & 2005 & $\begin{array}{l}2754 \text { empregados de } \\
180 \text { firmas de setores } \\
\text { diferentes }\end{array}$ & $\begin{array}{l}\text { Orientação } \\
\text { estratégica }\end{array}$ & $\begin{array}{l}\text { Satisfação e } \\
\text { comprometimento dos } \\
\text { funcionários e DO }\end{array}$ \\
\hline
\end{tabular}

A partir dos resultados da análise da literatura em orientação estratégica apresentados no quadro 3, pôde ser visto que as diversas orientações estratégicas se relacionam com distintas variáveis. Algumas considerações podem ser feitas a partir deste quadro: primeiramente a orientação estratégica se comporta como variável independente na maior parte dos estudos. E uma segunda análise deixa claro que 
a maioria dos estudos dentro do campo de orientação estratégica relaciona as distintas tipologias com o desempenho organizacional da empresa. Foram analisados 21 artigos obtidos através de uma busca sistemática Os artigos encontrados foram selecionados obedecendo algumas regras instituídas, tais quais número mínimo de citação e ano de publicação, de forma a manter apenas artigos tidos como referência dentro da área.

Sendo assim cabe, portanto, na seção 2.5 uma discussão sobre o conceito de desempenho organizacional e posteriormente na seção 2.6 uma discussão sobre o tema orientação estratégica e desempenho organizacional.

\subsection{DESEMPENHO ORGANIZACIONAL}

Para Dess e Robinson (1984) comumente quando há o estudo e análise de elementos organizacionais como estrutura, planejamento e estratégia é empregado o conceito de desempenho organizacional. Tal situação de acordo com os autores é explicada pelo fato de que o desempenho organizacional é considerado como parâmetro de validação no momento em que se pretende desenvolver uma teoria de administração estratégica baseada em investigações empíricas.

Dada, portanto, a relevância que o desempenho organizacional apresenta na tentativa de validação de desenvolvimento de estudos empíricos dentro do campo da administração estratégica, é necessário que se faça inicialmente uma análise do conceito de desempenho organizacional. Nesse sentido os autores apresentam três importantes quadros de análises desenvolvidos para definir o conceito de desempenho organizacional. Estudos empíricos publicados ao longo do tempo tem citado o trabalho desses autores (CONANT; MOKWA; VARADARJAN, 1990; GERINGER; HEBERT, 1991; HAMBRICK; GELETKANYCZ; FREDRICKSON， 1993; 
SLATER; NARVER, 1994; LYLES; SALK, 1996; BAKER; SINKULA, 1999; LUMPKIN; DESS, 2001; KAYNAK, 2003; CHO; PUCIK, 2005; HOBORG; BUCERIUS, 2005; LUBATKIN et al, 2006; ELBANNA; CHILD, 2007; LUTHANS; YOUSSEF, 2007; KAYNAK; HARTLER, 2008; WU, 2008; FURGATE; STANK; MENTZER, 2009; ROSENBUSCH; BRINCKMAN; BAUSCH, 2011) Abordagem das metas: desempenho organizacional entendido como a busca explicita por metas estabelecidas pela empresa ou então de metas que são emanadas do próprio comportamento da organização. Nesse sentido, o desempenho organizacional alcança um nível ideal quando há o cumprimento das metas e objetivos pré-estabelecidos pela empresa ou ainda quando há o alcance das metas estabelecidas de forma implícita, através do comportamento da empresa.

- Abordagem dos recursos do sistema: desempenho organizacional é compreendido como a busca e alcance de fatores chave presentes no ambiente interno e externo da empresa, de tal forma que para uma empresa apresentar um nível satisfatório de desempenho é fundamental que os dirigentes busquem alcançar estes fatores presentes no sistema.

- Abordagem da satisfação das necessidades dos membros da organização: o desempenho organizacional alcança um nível satisfatório quando a empresa consegue atender todas as necessidades dos membros internos e externos à organização. Sendo assim, por essa abordagem, o propósito final de uma empresa é visto como a capacidade de satisfazer as necessidades de todos os membros relacionados a ela.

Através da exposição dos três quadros clássicos de análise de desempenho organizacional, pode ser visto que não há uma única definição conceitual acerca do tema, de tal forma que a definição deste tema irá depender da abordagem utilizada 
pelos diversos autores. Para Richard et al. (2009), o desempenho organizacional é caracterizado por apresentar uma natureza multidimensional e, portanto, é necessário que o autor ao caracterizá-lo tenha a clareza de que estará incorrendo em apenas uma das possíveis abordagens para o tema.

Em pesquisas que consideram a relação do desempenho com outra variável de interesse, Kaynak (2003) pontua que a abordagem das metas é necessária, devido sua capacidade em traduzir em números o alcance da meta organizacional.

Após a definição conceitual acerca do desempenho organizacional, outro fator chave dentro dos estudos sobre este tema é como medi-lo. De acordo com Hong, Katerattanakul e Lee (2004), assim como não há uma definição única e concisa sobre o tema de desempenho organizacional, similarmente não há uma forma única de como medi-lo. Dentre as formas mais utilizadas se destacam o aumento do faturamento e a taxa de rotatividade. Essas medidas, de acordo com Walker e Ruekert (1997) não apenas se destacam pelo seu uso frequente em pesquisas, mas por traduzirem medidas de desempenho de primeira importância para gestores de empresas.

\subsection{ORIENTAÇÃO ESTRATÉGICA E DESEMPENHO ORGANIZACIONAL}

Sendo a orientação estratégica a forma como uma empresa decide competir, com base em uma filosofia de negócios, dentro do seu ambiente de negócios e tendo a firma, como fator chave dentro do atual contexto econômico, a busca, alcance e manutenção de uma vantagem competitiva da empresa sobre seus concorrentes (VARADARAJAN; CLARK, 1994), é fundamental, para que haja o alcance desta vantagem competitiva, que a empresa direcione seus esforços para o alcance de um desempenho organizacional satisfatório e continuo em seus negócios (NARVER; SLATER, 1990). 
Um dos primeiros autores a abordar esta temática da orientação estratégica relacionada com o desempenho organizacional da firma foi Venkatraman (1989). O autor vê a estratégia como os meios adotados ou ações e recursos necessários para o alcance de um dado objetivo.

Sendo assim, para Venkatraman (1989) o conceito de estratégia deve estar refletido no nível de negócios da companhia, de forma que haja a harmonização entre as oportunidades e ameaças do ambiente com a alocação eficiente dos recursos da empresa, portanto, influencias do ambiente devem ser respondidas através de decisões estratégicas.

Seguindo na mesma linha, Wright et al. (1995) apontam que a vantagem competitiva que uma firma busca adquirir leva a um desempenho organizacional superior. Esta vantagem competitiva de acordo com os autores, geralmente é alcançada através de duas formas: capacidade de adaptação e rigidez organizacional.

A capacidade de organização é adquirida através de uma orientação externa, pautada no comportamento dos prospectores de Miles e Snow (1978), ao passo que a rigidez organizacional é pautada no comportamento dos defensores de Miles e Snow (1978).

Para os autores a melhor forma de alcançar uma vantagem competitiva e, consequentemente, um desempenho organizacional superior é quando uma empresa faz o uso das duas orientações (externa e interna) ao mesmo tempo, o que pode assumir através dessa proposição que firmas pautadas no comportamento dos analistas de Miles e Snow (1978) teriam uma possibilidade maior de alcançar vantagem competitiva.

Já para Voss e Voss (2000), a relação entre orientação estratégica e desempenho organizacional é influenciada por fatores contingenciais presentes no 
ambiente próprio em que operam, uma vez que de acordo com os autores não há uma orientação estratégica que seja universalmente ótima, variando sua relação com o desempenho da firma, portanto, de empresa para empresa e de mercado para mercado. Dentre os fatores contingenciais citados pelos autores, os mais influentes são o comportamento dos fornecedores, dos clientes e dos concorrentes.

Ainda de acordo com Voss e Voss (2000) outra questão fundamental é a de que a relação entre a orientação estratégica e desempenho organizacional irá depender do tipo de medida de desempenho adotada.

Durand e Coeurderoy (2001) também adotam uma perspectiva contingencial e apontam que apenas a orientação estratégica sozinha não afeta o desempenho organizacional, portanto, de acordo com os autores é fundamental analisar fatores que influenciam esta relação. Para estes autores os fatores contingenciais mais influentes são as condições do ambiente em que a empresa opera, destacando-se: o estágio de desenvolvimento do ambiente, o grau de incerteza do ambiente e o nível de difusão tecnológica do ambiente.

Sendo assim para cada orientação estratégica irá existir também uma configuração de características organizacionais e extra organizacionais que permitem que a orientação estratégica adotada pela firma leve a um desempenho superior (SLATER et al., 2006).

O modo como os dirigentes operam seus negócios, como mobilizam seus recursos humanos e como reagem frente às mudanças no ambiente econômico podem ser caracterizados de diversas formas e para cada uma delas terá por trás a orientação estratégica adotada pelo dirigente. (GATIGNON; XUEREB, 1997). 


\subsection{PEQUENAS EMPRESAS}

\subsubsection{Classificação e definição da pequena empresa}

Pequenas empresas, apesar de alguns estudiosos considerarem como grandes empresas que ainda não cresceram, elas na verdade carregam em si especificidades próprias desse segmento. Dandridge (1979) faz uma analogia na qual da mesma forma que crianças não são pequenos adultos, pequenas empresas não são grandes empresas em miniatura e, portanto, necessitam de uma teoria organizacional própria, ainda que possam, no futuro, tornarem-se uma empresa de proporções maiores.

Julien (1993) apoia essa proposição ao afirmar que pequenas empresas são acentuadamente distintas das grandes empresas e que, portanto, devem ser estudas separadamente. Para o autor, um melhor entendimento dessas firmas como unidades produtivas dentro da economia possibilita não apenas um melhor entendimento da estrutura organizacional das pequenas empresas, mas também do seu dirigente.

Nesse sentido, algumas classificações de pequena empresa são encontradas dentro da literatura e que permitem que seja feita uma caracterização dessas organizações. Normalmente são adotados critérios quantitativos ou critérios qualitativos quando há a tentativa de classificar o que é uma pequena empresa.

De acordo com Leone (1991), critérios quantitativos são critérios econômicos e que podem, portanto, ser traduzidos em números. Dentro os principais a autora cita: ativo imobilizado que tem por finalidade observar o tamanho físico da empresa; o número de empregados que pode ser visto como além de um indicador 
econômico, também como um indicador social; o faturamento com vendas que reflete em última instancia o movimento das operações das empresas; há também a utilização do valor adicionado como forma de definir o tamanho de uma empresa e também seu capital social.

Amboise e Muldowney (1988) citam, no mesmo sentido, que para um grande número de pesquisadores, pequenas empresas também são geralmente consideradas como tendo menos que 500 empregados e que faturem menos de US\$20 milhões.

No caso específico do Brasil, há a classificação do porte da empresa pelo enquadramento tributário que faz referencia ao faturamento anual da empresa, sendo a microempresa a que tenha uma receita bruta anual igual ou inferior a $\mathrm{R} \$ 433.755,14 \mathrm{e}$ a empresa de pequeno porte a que tenha uma receita bruta anual superior a $\mathrm{R} \$$ 433.755,14 e igual ou inferior a $\mathrm{R} \$ 2.133 .222,00$.

O IBGE e o SEBRAE (1999) u s a m para classificar o porte das empresas o número de funcionários, que para a microempresa inserida no setor industrial e de construção é de até 19 funcionários e quando inserida no setor de comercio e serviços é nove funcionários. No caso da pequena empresa inserida na indústria ou construção o número de funcionários deve estar entre 20 e 99 funcionários e para as pequenas empresas inseridas no setor de comercio e serviços e número é de 10 a 49.

Apesar de os critérios quantitativos serem determinantes no momento de definir o porte de uma empresa e, além disso, serem fáceis de coletar, os critérios qualitativos são os que vão realmente traduzir uma imagem fiel da empresa visto que descrevem a estrutura, organização e a gestão da empresa (LEONE, 1991).

A visão de que a estrutura interna e administrativa está relacionada com o porte da organização também é partilhada por Drucker (1981) ao afirmar que cada porte 
de empresa requererá de seus dirigentes comportamentos e atitudes compatíveis com seu estágio de desenvolvimento, sendo assim parte importante da análise do tamanho de uma empresa é a análise da composição e das atividades gerenciais.

Peterson, Albaum e Kozmetsky (1986) consideram pequenas empresas aquelas que são operadas e gerenciadas independentemente e que não dominem o seu mercado. Carland et al (1984) caracterizam as pequenas empresas da mesma forma e ainda acrescenta que tais firmas raramente estão engajadas em uma mudança ou inovação de marketing e que são estudadas e tratadas como um setor a parte não por serem homogêneas, porque de fato elas não são, mas sim devido a um fator comum a todas elas: falta de recursos.

Ambas definições têm uma raiz comum que é a definição de pequenas empresas da Small Business Administration de 1978: negócio operado de forma independente e que não é dominante em seu campo de negócios. Tal definição ainda é recorrente e utilizada na literatura de pequenas empresas.

\subsubsection{Especificidades organizacionais da pequena empresa}

Mintzberg (1995) aponta algumas características organizacionais das pequenas empresas que as distingui dos demais tipos de organização, dentre elas há:

- Ausência de uma estratégia formalizada pelo dirigente-proprietário da pequena empresa;

- A estratégia concentrada na figura do dirigente;

- Baixa tecnologia incorporada na rotina de atividades da firma;

- Ausência de divisões de áreas funcionais na empresa. Normalmente há a figura do dirigente e dos empregados, sendo que eventualmente o dirigente também assume tarefas operacionais e administrativas; 
- Devido ao porte dessas firmas, há por parte dos funcionários uma visão global de todo o processo produtivo;

- Atividades e comunicação entre dirigente e funcionários são realizadas de maneira informal;

- Pouca qualificação técnica entre os funcionários;

- Comunicação entre proprietários e clientes, o que também facilita que os produtos e serviços oferecidos pela empresa sejam adaptados às necessidades individuais de cada consumidor ou grupo de consumidores.

Julien (1997) traça algumas características das pequenas empresas, entretanto o autor destaca que a intensidade que essas características ocorrem pode variar de pequena empresa para pequena empresa. São elas:

- Gestão centralizada, ou seja, a gestão fica concentrada na figura do dirigente da pequena empresa;

- Baixa especialização das atividades sejam elas gerenciais ou operacionais, de forma que essa baixa especialidade se encontra permeando todas as atividades da firma;

- Estratégia existente assume uma forma intuitiva ou então é pouco formalizada pelo dirigente;

- Baixa complexidade no sistema de informação interna, ou seja, entre dirigente e funcionários, sendo a comunicação nessas firmas apresentada de forma direta e ágil;

- Sistema de informação externo, de forma simples e direta de forma que os clientes e fornecedores da empresa guardam uma relação de proximidade com o proprietário-dirigente;

Para Leone (1999) as características próprias que diferem as pequenas empresas das grandes empresas, podem ser divididas em três grandes grupos:

- Especificidades individuais são características relacionadas com a figura de seu 
proprietário-dirigente. São elas: onipotência e forte influência do proprietário dirigente na condução dos negócios, dependência do dirigente ante certos empregados, junção de patrimônio pessoal do dirigente com patrimônio social da empresa.

- Especificidades decisionais são características próprias que se relacionam com o processo de decisão dessas firmas. Podem ser destacadas: decisões intuitivas, poucos dados quantitativos a disposição para o processo de tomada de decisão e racionalidade política, econômica e familiar nas decisões.

- Especificidades organizacionais são as características relacionadas com sua estrutura organizacional. São elas: baixo volume de recursos, gestão centralizada, pouco controle do ambiente organizacional externo, estrutura simples, pouca especialização e, especialmente relacionada a esse trabalho, a estratégia como sendo intuitiva e pouco formalizada, ainda que permeie a organização dessas firmas.

Com base nos três autores anteriores, as características próprias das pequenas empresas que as diferem das grandes organizações podem então ser resumidas conforme apresentado no quadro 4. Esse quadro procura fazer uma síntese das especificidades apresentadas pelos autores citados anteriormente: Mintzberg (1995), Julien (1997) e Leone (1999). 
Quadro 4-Características das pequenas empresas

\section{Especificidades das pequenas empresas}

- Estratégia não formalizada e centrada na figura do dirigente

- Gestão centralizada na figura do dirigente

- Baixa tecnologia nas atividades da empresa e baixa especialização dos funcionários e dirigentes

- Funcionários detém uma visão global do processo produtivo e há em alguns casos dependência do dirigente ante certos empregados

- Comunicação informal e de forma direta entre proprietários e funcionários

- Contato direto entre dirigente e consumidores

- Adaptação dos produtos e serviços às necessidades dos consumidores

- Baixo controle do mercado em que atua.

\subsubsection{Pequenas empresas e orientação estratégica}

Para Cooper (1981), ainda que haja uma grande heterogeneidade entre as pequenas empresas, tais como quantidade de recursos disponíveis, metas dos seus dirigentes, oportunidades e estágio de desenvolvimento, não se pode deixar de reconhecer algumas características próprias que as diferem das grandes organizações. Essas particularidades são responsáveis pela criação de ameaças e oportunidades diferentes das enfrentadas pelas grandes empresas.

Nesse sentido analisar o processo de formação estratégica na pequena empresa de forma separada da grande empresa é um aspecto fundamental, uma vez que de acordo com Hambrick (1983) a orientação estratégica pode ser considerada um fator fundamental e de importantes implicações no gerenciamento das pequenas empresas.

Brouthers et al (1998) destacam que há dentro da literatura estratégica diversos fatores que influenciam no processo de orientação estratégica e apontam os três 
principais deles: características gerenciais ligadas à figura do dirigente; relações entre membros da organização relacionadas à organização interna da empresa; e fatores externos relacionados ao ambiente.

Dentre as características gerenciais, Hambrick e Mason (1993) pontuam que a personalidade dos dirigentes responsáveis pela elaboração da estratégia irá influenciar nas decisões que eles tomam. Dentre os fatores que influenciam a personalidade, podem ser destacados: procedência econômica e social, grau de escolaridade, experiência profissional, dentre outras.

No caso específico das pequenas empresas, quem toma as decisões estratégicas é na maioria dos casos o próprio dirigente-proprietário, de tal forma que suas decisões tendem a ser menos racionais devido a forte influencia de suas características pessoais (BROUTHERS ET AL, 1998).

Gimenez (1999) ao analisar a literatura de estratégia em pequenas empresas destaca que há duas grandes correntes dentro dessa área. A primeira, de acordo com o autor, tem uma abordagem econômica e foi predominante até a década de 1980. A segunda corrente de orientação empreendedora é mais recente e é a predominante dentro da literatura e reconhece a influencia pessoal do dirigente no processo de desenvolvimento e aplicação da estratégica nessas empresas.

O segundo fator que influencia a orientação estratégica são as relações entre membros da organização. Essa perspectiva destaca que as decisões estratégicas são moderadas pelas relações recíprocas entre o dirigente e outros membros da organização, de forma que grupos dentro de uma empresa tentam influenciar as decisões feitas pela empresa de forma que através dos resultados obtidos eles possam se beneficiar de alguma forma (BROUTHERS et al., 1998).

Porém, no caso das pequenas empresas, esse fator tende a ser muito pouco 
significativo, uma vez que de acordo com Brouthers et al. (1998) nessas firmas não há separação de departamentos e há poucos níveis organizacionais. Adicionalmente o poder fica todo centralizado na figura do dirigente, o que torna as manobras políticas ineficientes nessas organizações e ficando o dirigente livre de qualquer pressão interna. Para Sanchez-Marín (2005), dada a simplicidade da organização interna das pequenas empresas, o dirigente desfruta de uma grande flexibilidade para se adaptar e assim, consequentemente, responder às mudanças no ambiente.

Por último a influência do ambiente no processo na orientação estratégica. Através dessa perceptiva há a influencia de grupos externos à empresa no processo de decisão estratégica, dentre esses grupos podem ser destacados: fornecedores, clientes, governo, e outros, ou seja, agentes externos ao ambiente organizacional. Nas pequenas empresas, ao contrário das duas perspectivas anteriores (características do dirigente e da organização) nas quais a primeira exerce grande influência na orientação estratégica e a segunda pouca, aqui a intensidade do efeito do ambiente externo irá ser variável de acordo com a situação. No caso da pequena empresa ter suas atividades atreladas a um único consumidor ou a um pequeno número de consumidores, a influencia do ambiente externo será forte na orientação estratégica da empresa, pois tem que se adaptar às necessidades de seu único cliente. No outro caso, quando há vários consumidores, a firma fica pouco depende dos seus consumidores e, portanto, goza de uma maior liberdade para orientar suas decisões (BROUTHERS, 1998).

Concluindo, pode ser visto que a formação da estratégia em pequenas empresas está sujeita a influencias, em menor ou maior grau, tanto da figura do dirigente proprietário, quanto da organização quanto do ambiente externo a ela, de tal forma que a orientação estratégica que uma firma segue é passível de sofrer influências destes 
atores. 


\section{MÉTODOS DE PESQUISA}

O objetivo desse capítulo é apresentar a fundamentação metodológica necessária para a realização do trabalho de campo. São discutidos inicialmente os principais métodos de pesquisa utilizados em pesquisas na literatura de orientação estratégica de forma a identificar o método de coleta de dados mais utilizado. Posteriormente há declaração dos métodos dessa pesquisa, seguido da apresentação das hipóteses, variáveis de pesquisa e técnicas de coleta e análise de dados. Por fim há uma seção sobre a ética na pesquisa e uma caracterização do setor metalmecânico.

\subsection{MÉTODOS DE PESQUISA NA LITERATURA DE ORIENTAÇÃO ESTRATÉGICA}

$\mathrm{Na}$ revisão sistemática da literatura realizada sobre o tema de orientação estratégica, alguns aspectos foram observados, sendo um dentre eles a fundamentação metodológica presente em cada um dos trabalhos. A partir dessa revisão foi possível levantar informações importantes relativas aos principais métodos de coleta de dados utilizados em pesquisas realizadas dentro desse tema. Os principais métodos de pesquisa utilizados dentro do tema "orientação estratégica" estão apresentados na figura 1. 


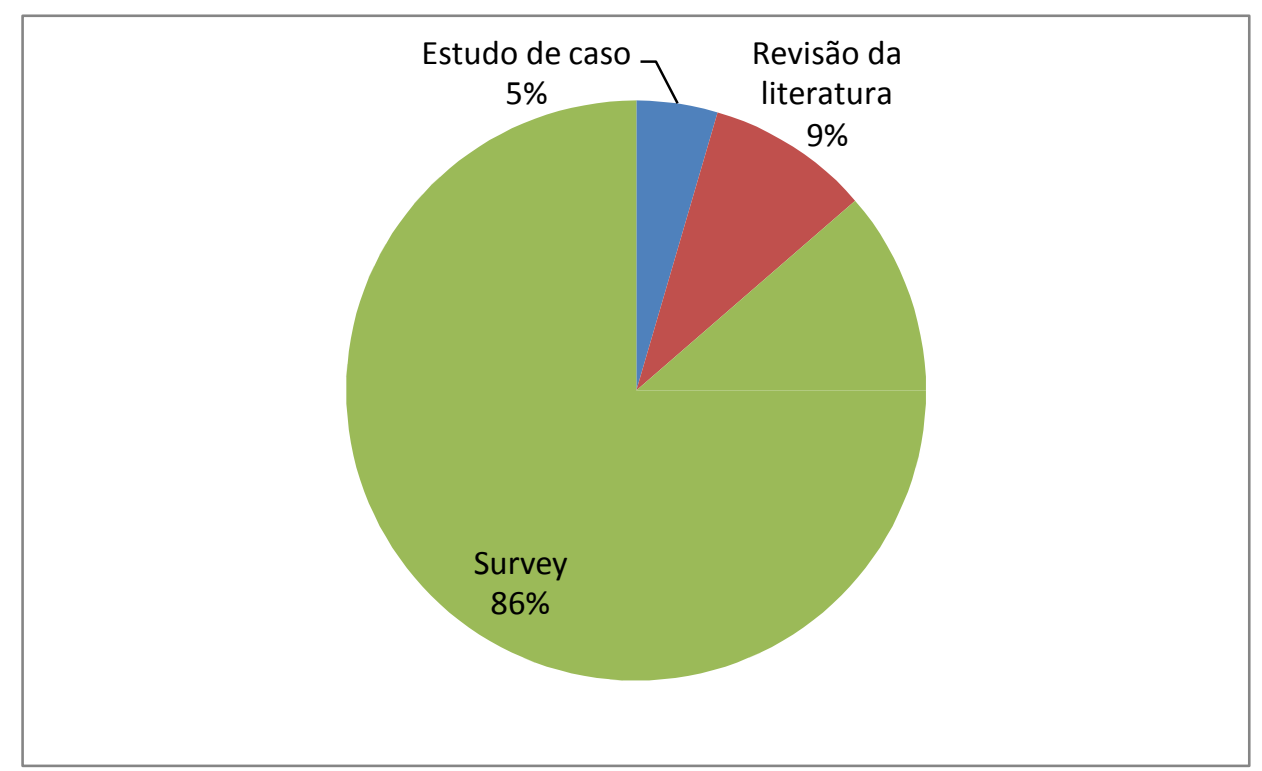

Figura 1 - Principais métodos de pesquisa em estudos sobre orientação estratégica

Como pode ser observado há uma grande preferência dos autores que trabalham no tema pela utilização do método de pesquisa conhecido como survey (ou levantamento), o qual tem como propósito identificar e descrever a relação entre variáveis. Esta afirmação é justificável visto que dentro do tema de estudo, o construto "orientação estratégica" está na maioria das vezes relacionado com outra(s) variável(is), de forma que ora ele se comporta como variável independente e ora como variável dependente.

\subsection{MÉTODOS DA PESQUISA}

Nessa seção será apresentada a escolha dos métodos que serão utilizados para que o objetivo da pesquisa, apresentado no capítulo 1, possa ser alcançado. Esta seção servirá, portanto, para guiar o pesquisador no que concerne a caracterização da pesquisa, suas hipóteses, variáveis e técnicas de coleta e análise de dados a serem utilizados. Essas considerações são importantes na medida em que permitem ao pesquisador ir a campo preparado e munido de instrumentos necessários e adequados para lidar com a realidade empírica. 


\subsubsection{Caracterização da pesquisa}

Quanto as suas características, essa pesquisa pode ser enquadrada dentro de alguns parâmetros, sendo eles o tipo de abordagem, natureza, objetivo e procedimento.

Essa pesquisa segue uma abordagem quantitativa, a qual segundo Fonseca (2002) tem suas raízes no pensamento positivista e considera que a realidade apenas pode ser compreendida se estiver fundamentada em uma análise de dados colhidos através de instrumentos padronizados e neutros. Sendo assim, a abordagem quantitativa irá recorrer à linguagem matemática na tentativa de descrever relações de causa e efeito entre variáveis (TURATO, 2005).

Como nessa abordagem a amostra utilizada pelo pesquisador tende a ser grande suficiente para representar a população estudada, os resultados obtidos são tomados como uma descrição real e fiel de toda a população alvo (FONSECA, 2002).

Em comparação com a pesquisa qualitativa, a quantitativa apresenta um menor enfoque na interpretação do objeto e no seu contexto, porém, há um alcance instantâneo do estudo no tempo e uma menor proximidade do pesquisador com o fenômeno, o que faz com que o ponto de vista do pesquisador seja externo ao objeto estudado. Por fim essa abordagem tem por característica ter um quadro teórico e hipóteses definidas rigorosamente (FONSECA, 2002).

Quanto a sua natureza essa pesquisa pode ser considerada como aplicada, a qual de acordo com Moresi (2003) tem por característica gerar novos conhecimentos passíveis de serem aplicados na solução de problemas específicos, no caso dessa pesquisa nos problemas específicos das pequenas empresas.

Em relação ao seu objetivo essa pesquisa pode ser definida como descritiva. Esse tipo de pesquisa tem como finalidade descrever fatos e fenômenos 
pertencentes a determinada realidade, buscando identificar eventos, situações, atitudes e opiniões presentes dentro de uma determinada população alvo (TRIVIÑOS, 1987; FREITAS et al., 2000).

Em relação ao seu procedimento, essa pesquisa irá utilizar como método, em concordância com a tendência encontrada dentro do tema de orientação estratégica (exposto na seção 3.1) e, sobretudo, em concordância com o objetivo principal dessa pesquisa que tem propósito identificar e descrever a relação entre variáveis, o survey.

A pesquisa survey irá procurar obter dados sobre as características de determinado grupo (amostra), representativo de uma população de interesse, através da aplicação de um questionário de perguntas e respostas (FONSECA, 2002).

Para Freitas et al. (2000), esse tipo de procedimento carrega duas características fundamentais: produção de descrição quantitativa de uma determinada população e uso de instrumentos pré-definidos. Por fim, nesse tipo de pesquisa o respondente não é identificável, o que faz com que o sigilo seja um traço imprescindível (FONSECA, 2002).

\subsubsection{Hipóteses de pesquisa}

A partir das discussões realizadas anteriormente, pode ser verificado que ao longo das últimas décadas o debate acerca da temática de orientação estratégica tem se intensificado e gerado um grande número de pesquisas. Dentre as importantes abordagens realizadas dentro do tema, destaca-se principalmente a que relaciona a orientação estratégica com o desempenho organizacional, contudo as pesquisas feitas com esse viés são predominantemente relacionadas com a grande empresa (ARAGON SANCHEZ e SANCHEZ MARÍN, 2005).

Sendo assim, surgem duas indagações principais quando há a tentativa de 
confrontar o tema orientação estratégica e desempenho organizacional com a realidade própria da pequena empresa:

- A abordagem predominante na literatura é suficiente para explicar, ainda que de forma parcial, a realidade enfrentada pelas pequenas empresas?

- Ou estaria tão intrinsecamente ligada à abordagem destacada com os eventos da grande empresa que a tentativa de relacioná-la com a realidade da pequena empresa e explica-la, ainda que de forma parcial, tornariam a tarefa improfícua?

Dado o que se tem destacado até aqui acerca das especificidades da pequena empresa e como seu modelo organizacional difere das grandes corporações, é de se esperar que o simples intercâmbio das realidades entre os dois tipos de organizações não seja possível de forma literal.

Sendo assim, surgem algumas formulações acerca do tema orientação estratégica e desempenho organizacional considerando o universo específico das pequenas empresas. Essas formulações se apresentam na forma de duas hipóteses apresentados a seguir:

- Hipóteses sobre as especificidades de gestão da pequena empresa e sua relação com a orientação estratégica e desempenho organizacional.

- Hipóteses sobre orientação estratégica e desempenho organizacional na pequena empresa

\subsubsection{Hipóteses sobre as especificidades de gestão da pequena empresa e sua relação com a orientação estratégica e desempenho organizacional.}

A partir da revisão da literatura feita no capítulo 2, pode ser visto que há na literatura sobre orientação estratégica duas tipologias predominantes: uma originária da administração estratégica e outra do marketing estratégico e que a orientação 
adotada pela direção, refletida no modo de gerenciar a empresa irá guardar uma relação direta com o desempenho organizacional obtido pela companhia. Identificouse também dentro deste capítulo que pequenas empresas possuem particularidades que as distinguem das grandes empresas em vários aspectos, com fundamental relevância nas suas especificidades de gestão.

Portanto, a partir das colocações preliminares, formulou-se o seguinte questionamento: estaria a pequena empresa condicionada a mesma relação observada nas grandes empresas no que diz respeito à influência da orientação estratégica no desempenho organizacional da firma?

A hipótese derivada desse questionamento é a seguinte: a pequena empresa, através das especificidades de gestão centradas na figura do dirigente, do ambiente e da organização, irá apresentar um comportamento distinto das grandes organizações no que diz respeito a influencia da orientação estratégica em seu desempenho organizacional.

H0-1: As especificidades da pequena empresa não irão ocasionar um comportamento distinto do observado nas grandes empresas no que concerne à relação entre orientação estratégica e desempenho organizacional.

H1: As especificidades da pequena empresa irão ocasionar um comportamento distinto do observado nas grandes empresas no que concerne à relação entre orientação estratégica e desempenho organizacional

As hipóteses descritas anteriormente podem ser observadas na figura 2. A partir dessa figura, pode ser observada que a relação entre orientação estratégica e desempenho organizacional será confrontada com a realidade específica das pequenas empresas, de forma que a partir do resultado será possível saber se no universo específico dessas empresas há uma alteração do padrão observado nas grandes 
empresas entre orientação estratégica e desempenho organizacional.

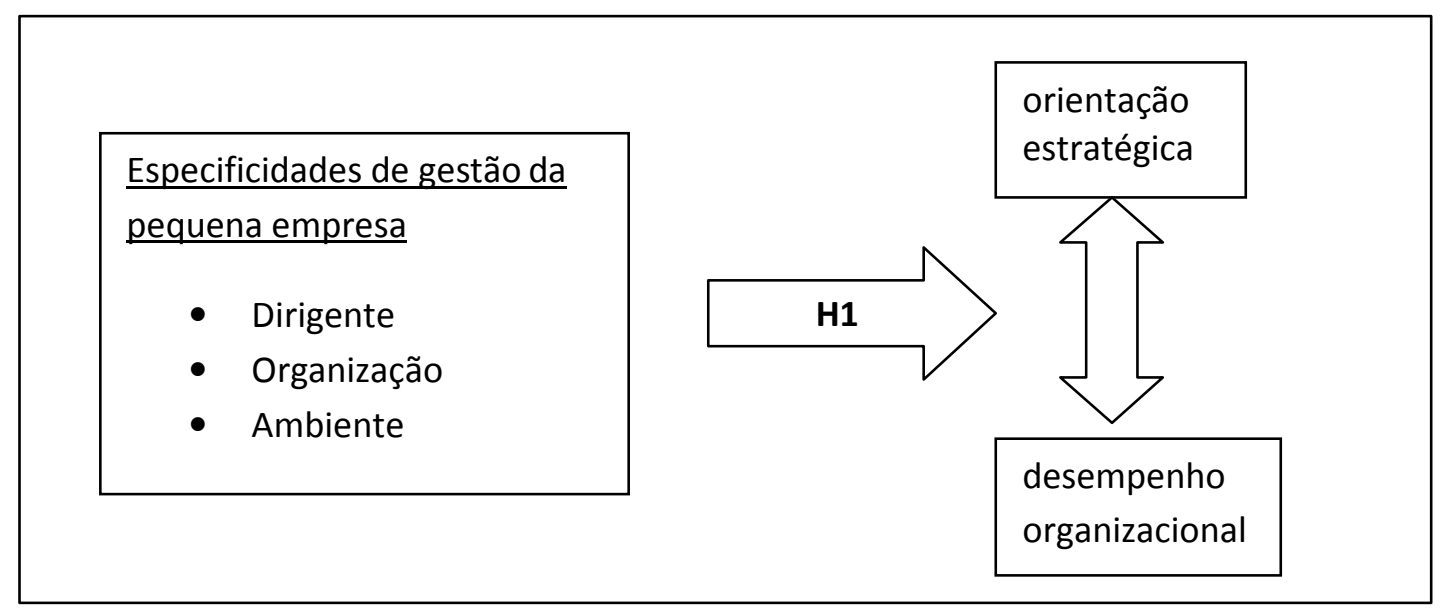

Figura 2 - Influência das especificidades de gestão da pequena empresa com a relação entre orientação estratégica e desempenho organizacional.

\subsubsection{Hipóteses sobre orientação estratégica e desempenho organizacional na pequena empresa}

Em continuidade com a discussão acerca das hipóteses, uma vez identificado se a relação entre orientação estratégica e desempenho organizacional nas pequenas empresas é significativa, é possível, portanto, descobrir a relação de cada uma das orientações estratégicas, apresentadas no capítulo 2, com o desempenho organizacional da pequena empresa.

Considerando o fato de que prospectores, na tipologia de Miles e Snow (1978), têm uma grande capacidade de adaptação às mudanças do ambiente e respondem a ela mais rapidamente do que analistas e também defensores, é esperado que empresas que possuem a primeira orientação estratégica descrita tenha uma relação positiva com o desempenho organizacional da firma. Sendo assim a hipótese derivada dessa colocação é a seguinte: Pequenas empresas com uma orientação prospectora irá ter um desempenho melhor do que pequenas empresas que adotem uma a 
orientação analista ou defensora, nessa ordem.

H0-2: Não há uma relação de melhor desempenho organizacional em pequenas empresas que adotam uma orientação prospectora em comparação com aquelas que adotam uma a orientação analista ou defensora, nessa ordem.

H2: Existe uma relação de melhor desempenho organizacional em pequenas empresas que adotam uma orientação prospectora em comparação com aquelas que adotam uma a orientação analista e defensora, nessa ordem.

\subsubsection{Síntese das hipóteses}

Concluindo a discussão sobre as hipóteses de pesquisa, pôde ser verificado que a primeira delas guarda uma relação de validação entre a relação orientação estratégica e desempenho organizacional a partir do confronto com a realidade própria das pequenas empresas. É esperado a partir da revisão da literatura que ocorra um comportamento distinto do observado nas grandes empresas no que concerne a essa relação apresentada, contudo é esperado que mesmo diversa, essa relação seja significativa. Uma vez confirmada a existência dessa relação, é esperado que se confirme, através da hipótese 2 , se a adoção de uma das orientações tipicamente voltadas para a inovação tecnológica, de mercados e produtos, que guardam como características uma grande capacidade de adaptação e respostas rápida às mudanças do ambiente, está relacionada com um melhor desempenho por parte das pequenas empresas.

\subsubsection{Variáveis de pesquisa}

Esta pesquisa aborda três variáveis de pesquisa: orientação estratégica, 
desempenho organizacional e especificidades de gestão da pequena empresa, as quais serão detalhadas a seguir.

- Orientação estratégica: orientação seguida pela firma e refletida na forma como uma empresa decide competir no mercado em que atua. Pode ser medida através do agrupamento, com base nas características de cada uma delas apresentada no capítulo 2, em tipos já existentes, sendo eles: prospectoras, analistas, defensoras e reativas.

- Desempenho organizacional: cumprimento das metas e objetivos préestabelecidos pela empresa. Pode ser medido através da receita operacional e o retorno sobre o investimento como apresentado no capítulo2.

- Especificidades de gestão da pequena empresa: características de gestão próprias que as diferem das grandes organizações. Podem ser constatadas verificando como ocorre a gestão das empresas em comparação com o que mostra a literatura descrita no capítulo 3.

As três variáveis de pesquisa descritas anteriormente estão representadas na figura 3 de forma a demonstrar o delineamento da pesquisa. É partir dessa disposição que se pretende descobrir como os fatores contingenciais da pequena empresa influenciam a relação entre orientação estratégica e desempenho organizacional, proposto no objetivo dessa pesquisa.

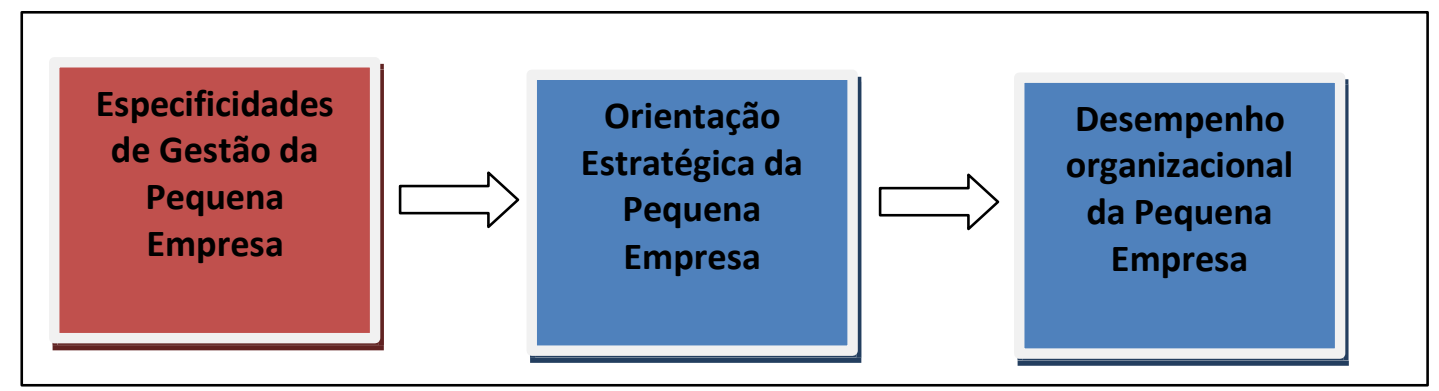

Figura 3 - Variáveis de pesquisa. 


\subsubsection{Técnica de coleta de dados}

Para a coleta de dados, em concordância com o método de pesquisa survey, o instrumento utilizado será um questionário. O questionário pode ser definido como um instrumento de pesquisa composto por um número determinado de questões e que através das respostas dos participantes é possível determinar qual o comportamento do grupo alvo (GIL, 1994).

$\mathrm{O}$ questionário utilizado nessa pesquisa, o qual se encontra no apêndice $\mathrm{C}$ e anexo A, terá duas características principais. Primeiro, irá apresentar um corte transversal, ou seja, a coleta de dados irá ocorrer apenas uma vez ao longo do tempo em contraposição ao corte longitudinal onde ocorre uma coleta de dados várias vezes ao longo do tempo (VIEIRA, 2002). Segundo, será um questionário estruturado, ou seja, será composto por questões formais e estruturadas em uma ordem pré-estabelecida (FONSECA, 2002).

\subsubsection{Técnica de análise de dados}

A partir dos dados gerados, por intermédio das respostas obtidas com o questionário, os mesmos necessitam que se aplique uma técnica específica para que seus resultados possam ser analisados e interpretados.

No caso dessa pesquisa é utilizada a análise de variância (ANOVA), visto que uma das finalidades da pesquisa, em relação ao uso dos dados, é verificar se existe uma diferença significativa entre as médias das respostas e também se os fatores analisados exercem influência na variável resposta (BOX; HUNTER; HUNTER, 2005).

Conjuntamente com o a análise variância (ANOVA) é utilizado também o teste 
de Fischer, o qual segundo Box, Hunter e Hunter (2005) irá comparar todos os pares de médias das respostas com o objetivo de encontrar quais destes pares exercem uma diferença significativa entre as variáveis. Para geração dos dados será utlizado o software SAS 9.2

\subsubsection{Definição da amostra}

Para a escolha da amostra foram contatadas todas as empresas do setor metal mecânico das cidades de São Carlos, Araraquara, Matão, Américo Brasiliense e Sertãozinho, provenientes de uma lista gerada pelo Ministério do Trabalho.

Para a geração desta lista foi utilizado o CNAE (Classificação Nacional de Atividades Econômicas) como critério de inclusão das empresas. A utilização de um CNAE em específico ou de um conjunto de CNAE é importante na medida em que ela captura todas as unidades produtivas pertencentes a um determinado setor de interesse. No caso desta pesquisa ela capturou todas as empresas do setor metal-mecânico, que contabilizaram ao final 171 empresas escolhidas como população alvo do estudo, sendo 7 empresas da cidade de Américo Brasiliense, 33 da cidade de Araraquara, 21 da cidade de Matão, 50 da cidade de São Carlos e 60 da cidade de Sertãozinho, conforme mostra a figura 4 


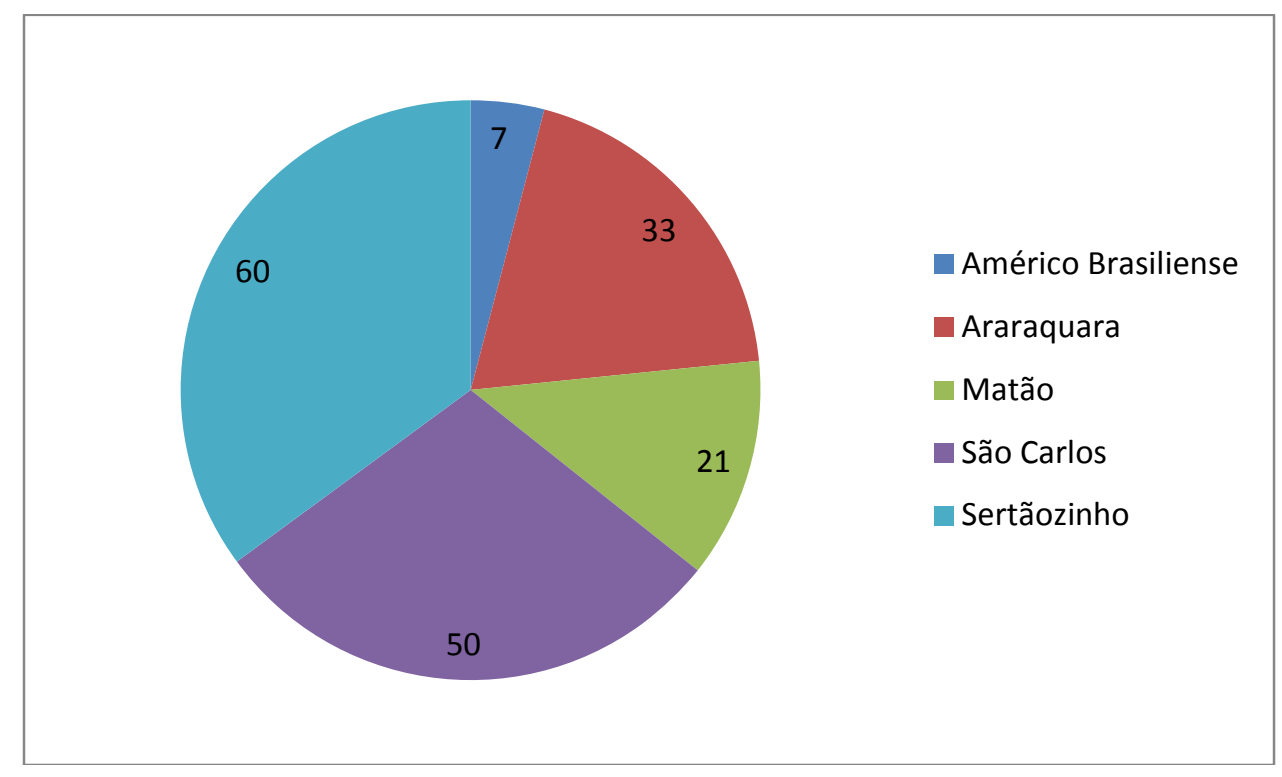

Figura 4 - Número de empresas participantes

Para a seleção das empresas participantes foram realizados contatos telefônicos com os dirigentes de todas as empresas explicando os objetivos da pesquisa e solicitando a participação. A amostra gerada a partir das empresas da população alvo que aceitaram participar da pesquisa, sendo que para conseguir uma quantidade representativa da população todas que concordaram em participar foram incluídas. No final 37 empresas constituíram a amostra, o que em relação a população alvo representa uma taxa de $21 \%$, número acima da média de empresas que participam das pesquisas acadêmicas do tipo survey (GIBBONS; O'CONNOR, 2005).

Neste processo de seleção algumas dificuldades foram encontradas. A maior delas foi conseguir o contato direto com o dirigente, uma vez que poucas atendentes das empresas se dispuseram a passar a ligação para eles. A maioria delas alegava que os dirigentes não estavam presentes na empresa ou estavam em reunião. Entretanto, em $100 \%$ dos casos em que foi possível o contato direto com o proprietário ou com o dirigente principal das empresas eles toparam participar da pesquisa. Outra dificuldade encontrada foi a conciliação de horários mais próximos na agenda dos dirigentes para a aplicação dos questionários, caso não houvesse essa questão, o período de coleta de 
dados poderia ter sido mais curto. Outras dificuldades menores podem ser incluídas como: o deslocamento até empresas fora do perímetro de São Carlos; a localização destas empresas, uma vez que a maioria se concentra em distritos industriais, os quais, por sua vez, são afastados dos centros urbanos; e por fim, algumas vezes, durantes as entrevistas, a fragmentação do processo de preenchimento dos questionários, uma vez que alguns dirigentes pausavam as respostas para atender ao telefone ou outros funcionários da empresa.

\subsection{CARACTERIZAÇÃO DO SETOR E COLETA DE DADOS}

\subsubsection{Setor metal mecânico}

Para Macedo e Campos (2001) podem ser consideradas empresas pertencentes ao setor metal mecânico aquelas que destinam suas atividades à produção de bens intermediários e/ou bens finais que se utilizem de metais e seus derivados dentro de sua cadeia produtiva.

No estado de São Paulo essas empresas estão concentradas principalmente na região metropolitana, mas apresentam também grandes concentrações em algumas regiões do interior, como no vale do Paraíba (região de São José dos Campos) e região central que engloba São Carlos, Araraquara, Matão e Sertãozinho (Investe São Paulo, 2012).

Rosenthal (1999) destaca que devido ao fato do setor metal-mecânico compreender uma grande diversidade de atividades relacionadas à transformação de metal, ela por muitas vezes podem ser designada de complexo metal-mecânico. Ainda para o autor, fazem parte desse complexo as indústrias pertencentes aos seguintes segmentos: indústrias metalúrgicas, ou seja, aquelas que trabalham com a 
conversão de minérios em produtos metalúrgicos; indústrias de máquinas e equipamentos que desempenham atividades relacionadas à fabricação de componentes mecânicos (partes e peças) para as atividades industriais; indústrias de bens finais e indústrias que trabalhem com a produção de artefatos metálicos.

Essa grande heterogeneidade presente dentro do setor metal-mecânico não está apenas refletida na diversidade de atividades, mas também no tipo de tecnologia empregada e também ao porte dessas empresas (MACEDO; CAMPOS, 2001).

Em relação à qualificação dos administradores das pequenas empresas do setor metal-mecânico, Moioli, Escrivão Filho e Oliveira (2007) constataram que a maioria possui ensino técnico ou médio, mas que não é incomum que eles persigam uma formação superior. Ainda para os autores, em relação ao planejamento, essas empresas realizam algum tipo de plano formal, porém eles ainda são essencialmente voltados para o curto prazo de forma a servirem mais como um mecanismo de apoio aos negócios.

\subsubsection{Caracterização da amostra}

A amostra utilizada para a obtenção dos dados pode ser caracterizada em relação à empresa pela divisão dentro do setor metal-mecânico e em relação ao dirigente pelo seu sexo (masculino ou feminino), grau de escolaridade, raça, religião e tempo de experiência.

Das empresas pertencentes à amostra, $37 \%$ se dedicam à fabricação de estruturas metálicas e obras de caldeiraria pesada, 34\% à fabricação de motores, bombas, compressores e equipamentos de transmissão, $12 \%$ à fabricação de máquinas e equipamentos de uso geral, $5 \%$ à produção de ferro-gusa e de ferroligas e os outros $12 \%$ restantes se dividem igualmente em: fabricação de cabines, carrocerias e reboques 
para veículos automotores; fabricação de peças e acessórios para veículos automotores; fabricação de tanques, reservatórios metálicos e caldeiras; e siderurgia.

Em relação aos dirigentes respondentes do questionário, algumas características podem ser evidenciadas. São elas:

- $80 \%$ dos dirigentes do sexo masculino e $20 \%$ do sexo feminino;

- $51 \%$ possuem pós-graduação, $31 \%$ graduação, $15 \%$ ensino médio e $3 \%$ possuem apenas ensino fundamental;

- $95 \%$ se declararam pertencer à raça branca, enquanto 5\% à raça negra;

- $77 \%$ professam a religião católica, $15 \%$ são protestantes e os outros $8 \%$ se dividem em ortodoxos, espíritas e ateus;

- $45 \%$ trabalham na empresa a mais de 10 anos, $32 \%$ entre 5 e 10 anos e $23 \%$ a menos de 5 anos.

\subsubsection{Coleta de dados}

Em relação à coleta de dados foi deliberado que esta seria feita pessoalmente e em apenas uma visita às empresas. A coleta teve início no dia 7 de abril de 2015 e encerrou-se no dia 02 de junho de 2015. A coleta foi feita em etapas, sendo realizada inicialmente na cidade de São Carlos, posteriormente Araraquara, Américo Brasiliense, Matão e foi finalizada em Sertãozinho. A quantidade de questionários respondidos por cidade pode ser observado na figura 5. 


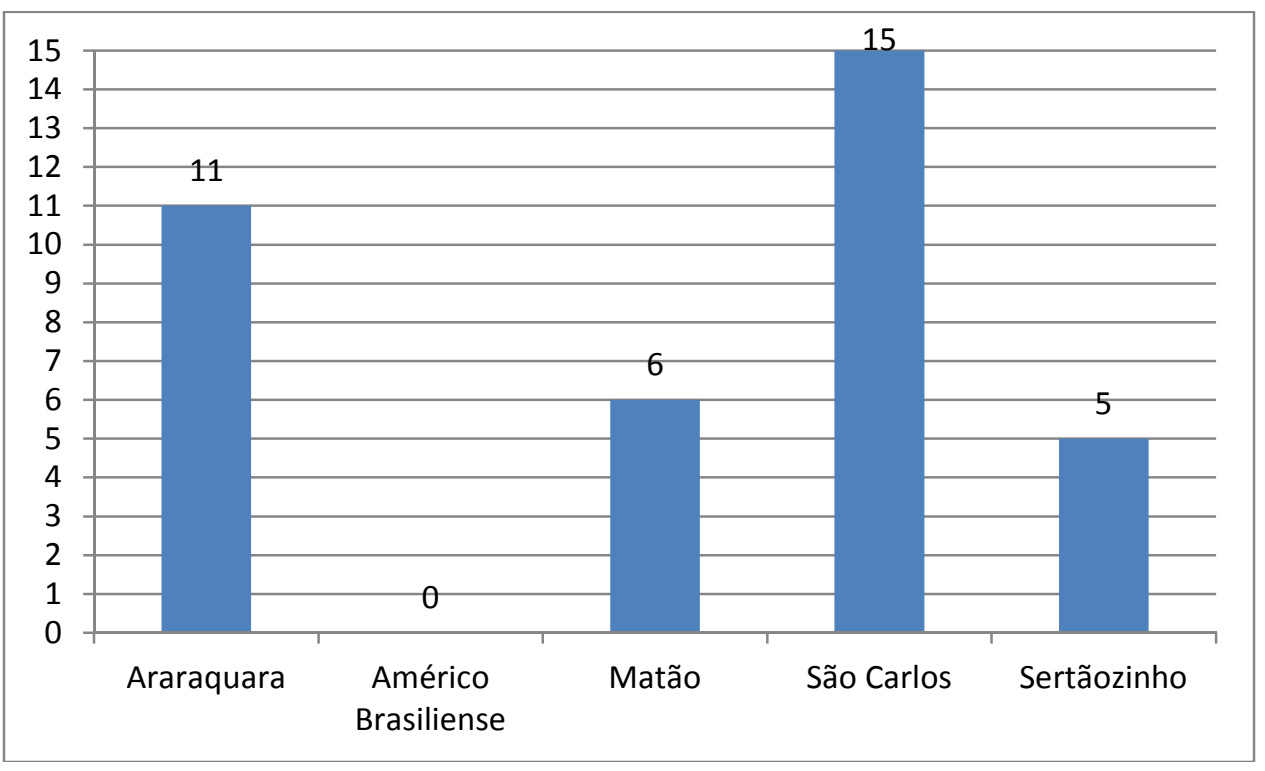

Figura 5 - Questionários respondidos por cidade

Sobre a coleta podem ser destacados os seguintes pontos: primeiramente nenhuma empresa da cidade de Américo Brasiliense se disponibilizou a participar da pesquisa. Uma possível razão pode ser o baixo número de empresas desta cidade dentro da população alvo quando comparado com as demais cidades, o que torna mais difícil conseguir um número significativo para a amostra. Um segundo ponto a ser destacado é a grande participação de empresas da cidade de São Carlos na composição da amostra. Isto pode ser devido ao fato de que a USP está inserida na cidade e isto, de certa forma, aumenta a percepção dos dirigentes em relação à importância das pesquisas acadêmicas, uma vez que boa parte destes empresários veio das universidades da cidade.

\subsection{CONSIDERAÇÕES ÉTICAS}

Para Du Mont (1991) a ética pode ser compreendida como um conjunto de regras a serem seguidas com vistas a alcançar o bem geral da sociedade. Porém, como as mesmas não implicam em nenhuma sanção legal ao individuo que 
quebrá-las, a característica fundamental da ética é apelar à consciência de cada um, de forma que os interesses pessoais não se sobreponham aos valores morais.

Para Kremer (1982), quando contextualizada dentro do universo das investigações científicas, a ética tem como papel direcionar os pesquisadores a dar o crédito corresponde aos colaboradores das pesquisas, sendo assim, dentro de uma pesquisa científica, a ética é responsável por nortear procedimentos considerados como corretos, de forma que guiado por ela seja solicitado às pessoas envolvidas na investigação seu consentimento e também lhes seja garantido proteção a qualquer espécie de dano (BOGDAN; BIKLEN, 1994).

Portanto, apesar dessa pesquisa seguir uma abordagem qualificada como quantitativa, a qual segundo Bogdan e Biklen (1994) é marcada por apresentar uma menor relação pessoal entre o pesquisador e o experimento, na prática, tais questões éticas, pontuadas inicialmente, foram traduzidas em uma carta entregue aos participantes da pesquisa que continha obrigatoriamente: objetivos da pesquisa, método, compromisso declarado de manter o anonimato de cada empresa, confidencialidade dos dados, relatos e possíveis observações e a declaração que posteriormente será disponibilizado os resultados aos participantes ao final do trabalho de pesquisa. Esta carta pode ser vista no apêndice D. 


\section{APRESENTAÇÃO E ANÁLISE DOS RESULTADOS}

O objetivo desse capítulo é a apresentação e análise dos dados coletados através do trabalho de campo. Inicialmente há uma análise de como ocorre a gestão das pequenas empresas e sua relação com o ambiente externo. Posteriormente há uma análise descritiva por quebras de análise, relacionando as especificidades de gestão da pequena empresa com sexo do dirigente, religião, raça, grau de escolaridade, tempo de experiência e cidade. Na sequencia há a classificação das empresas por orientação estratégica e a relação da mesma com as quebras mencionadas anteriormente. Por fim há verificação da relação entre orientação estratégica e desempenho organizacional medido em termos de aumento do faturamento e rotatividade.

\subsection{ESPECIFICIDADES DA PEQUENA EMPRESA}

A primeira análise realizada foi a verificação de como os dirigentes enxergam as características próprias das pequenas empresas apontadas pela literatura. Os dados nessa etapa foram coletados através de um questionário fechado utilizando a escala Likert em cinco pontos, sendo 1 referente à "discordo totalmente" e 5 à "concordo totalmente". O questionário sobre especificidades encontra-se no apêndice C. Os dados foram gerados através de estatística descritiva. O gráfico representado na figura 6 mostra os resultados obtidos. 


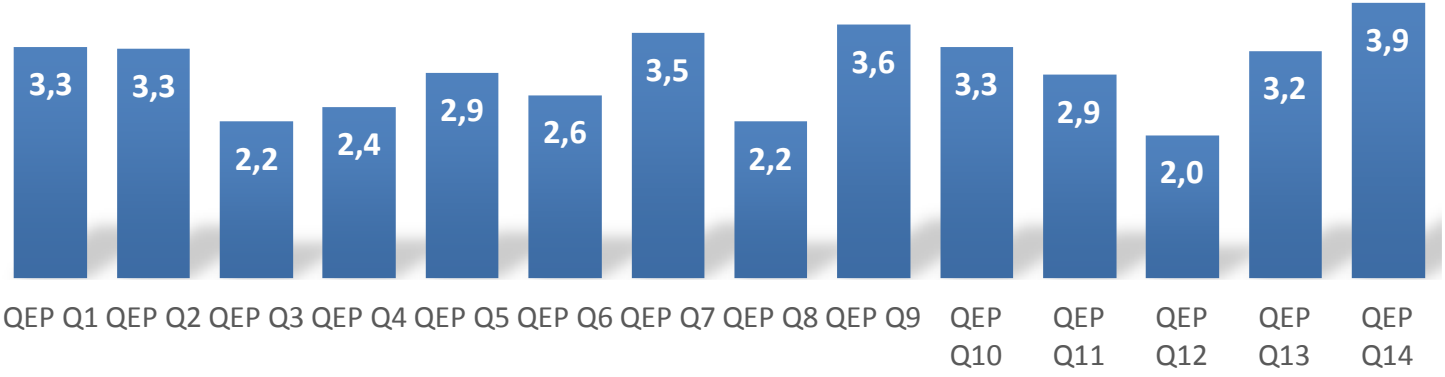

Figura 6 - Média das respostas

Através do gráfico pode ser visto que de uma forma geral os entrevistados concordam com as afirmações sobre as especificidades da pequena empresa apresentada pela literatura, uma vez que a maioria das questões está acima de 2,5, ou seja, mais próximas de cinco do que de um.

Detalhando melhor essa questão, pode ser verificado na tabela 1 e 2 as quantidades de respostas por pontuação e seu percentual respectivamente.

Tabela 1 - Quantidade de resposta por pontuação

\begin{tabular}{cccccc}
\hline Questão & $\mathbf{1}$ & $\mathbf{2}$ & $\mathbf{3}$ & $\mathbf{4}$ & $\mathbf{5}$ \\
\hline QEP Q1 & 6 & 7 & 0 & 15 & 7 \\
QEP Q2 & 6 & 6 & 4 & 11 & 8 \\
QEP Q3 & 21 & 1 & 2 & 6 & 5 \\
QEP Q4 & 16 & 6 & 1 & 6 & 6 \\
QEP Q5 & 10 & 6 & 4 & 7 & 8 \\
QEP Q6 & 15 & 6 & 1 & 4 & 9 \\
QEP Q7 & 4 & 10 & 2 & 3 & 16 \\
QEP Q8 & 19 & 5 & 1 & 4 & 6 \\
QEP Q9 & 5 & 5 & 3 & 8 & 14 \\
QEP Q10 & 7 & 8 & 1 & 6 & 13 \\
QEP Q11 & 9 & 9 & 3 & 5 & 9 \\
QEP Q12 & 17 & 10 & 1 & 4 & 3 \\
QEP Q13 & 11 & 3 & 3 & 3 & 15 \\
QEP Q14 & 5 & 3 & 3 & 3 & 21 \\
\hline
\end{tabular}


Tabela 2 - Percentual de resposta por pontuação

\begin{tabular}{cccccc}
\hline Questão & $\mathbf{1}$ & $\mathbf{2}$ & $\mathbf{3}$ & $\mathbf{4}$ & $\mathbf{5}$ \\
\hline QEP Q1 & $17 \%$ & $20 \%$ & $0 \%$ & $43 \%$ & $20 \%$ \\
QEP Q2 & $17 \%$ & $17 \%$ & $11 \%$ & $31 \%$ & $23 \%$ \\
QEP Q3 & $60 \%$ & $3 \%$ & $6 \%$ & $17 \%$ & $14 \%$ \\
QEP Q4 & $46 \%$ & $17 \%$ & $3 \%$ & $17 \%$ & $17 \%$ \\
QEP Q5 & $29 \%$ & $17 \%$ & $11 \%$ & $20 \%$ & $23 \%$ \\
QEP Q6 & $43 \%$ & $17 \%$ & $3 \%$ & $11 \%$ & $26 \%$ \\
QEP Q7 & $11 \%$ & $29 \%$ & $6 \%$ & $9 \%$ & $46 \%$ \\
QEP Q8 & $54 \%$ & $14 \%$ & $3 \%$ & $11 \%$ & $17 \%$ \\
QEP Q9 & $14 \%$ & $14 \%$ & $9 \%$ & $23 \%$ & $40 \%$ \\
QEP Q10 & $20 \%$ & $23 \%$ & $3 \%$ & $17 \%$ & $37 \%$ \\
QEP Q11 & $26 \%$ & $26 \%$ & $9 \%$ & $14 \%$ & $26 \%$ \\
QEP Q12 & $49 \%$ & $29 \%$ & $3 \%$ & $11 \%$ & $9 \%$ \\
QEP Q13 & $31 \%$ & $9 \%$ & $9 \%$ & $9 \%$ & $43 \%$ \\
QEP Q14 & $14 \%$ & $9 \%$ & $9 \%$ & $9 \%$ & $60 \%$ \\
\hline
\end{tabular}

Através dos dados pode ser visto que a questão com média maior $(3,9)$, a questão 14, é também onde há o maior percentual (60\%) de escolha da resposta cinco. Essa questão se refere à seguinte afirmação "O crescimento financeiro da empresa não é a motivação principal para ter meu próprio negócio”, o que demonstra que dirigentes de pequenas empresas têm outras motivações, que não necessariamente financeiras, para gerenciar seu próprio negócio.

Ainda através dos dados das tabelas 1 e 2 , pode ser visto também que a questão com menor média $(2,0)$ é a questão 12 , visto que mais da metade das empresas $(77 \%)$ marcaram as respostas 1 e 2 para esta questão. A questão 12 faz referencia à seguinte afirmação "Os meus fornecedores e clientes se encontram, em sua maioria, na mesma região geográfica da empresa", demonstrando que pequenas empresas estão fortemente inseridas no atual contexto econômico, onde as barreiras de distância entre as empresas, clientes e fornecedores foram reduzidas drasticamente.

Quando consideradas as médias das outras questões, pode ser verificado que as 
demais questões, com exceção das número3 e 8, ficaram mais próximas de cinco, o que significa que as empresas participantes apresentam muitas características descritas pela literatura como próprias das pequenas empresas, confirmando dessa forma as proposições feitas pelos autores desta área e apresentadas no capítulo 2. Sendo assim, pode-se dizer que nesta amostra, de uma forma geral, as empresas realizam o planejamento estratégico de maneira informal, não seguindo uma metodologia prédefinida, a qual demandaria um esforço de tempo maior. Isso é justificado, sobretudo, pela quantidade de atividades que os dirigentes de pequenas empresas têm que realizar diariamente, o que impossibilitaria despender uma parcela de tempo muito grande para a estruturação formal do planejamento. Além disso, os dirigentes dessas empresas concentram em torno de si uma grande influencia sobre todas as atividades da firma, sejam elas operacionais, ou também negociando com clientes e fornecedores. De uma forma geral pode ser visto que os dirigentes nessas empresas são peças fundamentais para o funcionamento da firma, de tal forma que suas motivações, valores e objetivos pessoais estão refletidos nas atividades da empresa.

Pode-se dizer também que essas empresas possuem funcionários aptos para compreender todas as etapas do processo produtivo, ou seja, não há uma grande especialização das atividades.

Já em relação às questões 3 e 8 que ficaram mais próximas de 1 , significando que algumas características próprias de pequenas empresas apontadas na literatura não traduzem fortemente a realidade encontradas nessas empresas. Essas características pouco presentes são: a divisão em departamentos da firma, mostrando que ao contrário do apresentado por estudos nessa área, as empresas da amostra utilizam divisões departamentais em marketing, finanças, recursos humanos, mesmo que supervisionando diretamente pelo dirigente. Além dessa questão, outra igualmente 
contrária ao mostrado pela literatura de pequenas empresas é que há pouca utilização do patrimônio pessoal do dirigente nas atividades da empresa e/ou o patrimônio da empresa para arcar com despesas pessoais. Esse resultado é importante, pois mostra que as firmas pertencentes à amostra tem uma clara distinção entre pessoa física e pessoa jurídica, de tal forma que a saúde financeira dessas empresas não ficam comprometidas pela vida pessoal do dirigente.

\subsubsection{Análise das especificidades por quebras}

Uma segunda análise realizada foi a verificação do reconhecimento das especificidades por parte dos dirigentes, analisando-as através de quebras. Inicialmente, através de estatística descritiva, foram feitas as médias das respostas para cada uma das quebras e em seguida, para verificar se existe uma diferença significativa entre as médias, foi realizada a análise de variância. Os resultados são apresentados a seguir.

\subsubsection{Sexo}

A primeira quebra realizada foi em relação ao sexo do dirigente. Do total da amostra sete respondentes são do sexo feminino e 28 do sexo masculino. A média das respostas pode ser vista na tabela 3

Tabela 3 - Média das repostas por sexo

\begin{tabular}{|c|c|c|}
\hline Questão & F & M \\
\hline QEP Q1 & 2,3 & 3,5 \\
\hline QEP Q2 & 3,4 & 3,2 \\
\hline QEP Q3 & 2,0 & 2,3 \\
\hline QEP Q4 & 1,9 & 2,6 \\
\hline QEP Q5 & 2,7 & 2,6 \\
\hline QEP Q6 & 3,7 & 2,7 \\
\hline
\end{tabular}




\begin{tabular}{|c|c|c|}
\hline QEP Q7 & 3,6 & 3,5 \\
\hline QEP Q8 & 2,6 & 2,1 \\
\hline QEP Q9 & 2,9 & 3,8 \\
\hline QEP Q10 & 3,1 & 3,3 \\
\hline QEP Q11 & 3,1 & 2,8 \\
\hline QEP Q12 & 1,3 & 2,2 \\
\hline QEP Q13 & 3,1 & 3,3 \\
\hline QEP Q14 & 3,1 & 4,1 \\
\hline
\end{tabular}

A partir dos resultados obtidos, pode ser visto que a questão com média maior $(4,1)$ é a questão 14 e está relacionada ao sexo masculino. Essa questão se refere a seguinte afirmação "O crescimento financeiro da empresa não é a motivação principal para ter meu próprio negócio", demonstrando que há uma motivação não financeira para ter e gerenciar o próprio negócio muito maior entre dirigentes do sexo masculino do que do sexo feminino.

Já a questão com menor média (1,3) é a questão 12, e esta, por sua vez, está relacionada ao sexo feminino. A questão 12 se refere à seguinte afirmação "Os meus fornecedores e clientes se encontram, em sua maioria, na mesma região geográfica da empresa", demonstrando que dirigentes do sexo feminino operam seus negócios em uma base de relacionamento com clientes e fornecedores muito mais ampla quando comparado aos dirigentes do sexo masculino. Isto talvez possa indicar uma maior facilidade entre as mulheres de se relacionar com agentes externos das mais diversas localidades em comparação aos homens.

De uma forma geral, dirigentes do sexo masculino se destacaram na média das respostas dos dirigentes do sexo feminino, nas seguintes questões: 1,4 e 9 . Isso siginifica que homens realizam o planejamento estratégico de uma maneira muito mais informal que os dirigentes do sexo oposto, indicando uma clara preferência das mulheres por seguirem um metodologia pré-definida e serem menos guiadas por sua experiência no momento da formulação da estratégia. Além disso, dirigentes do sexo 
masculino se relacionam de forma muito mais informal com seus funcionários do que os dirigentes do sexo feminino, demonstrando que há uma abertura muito menor por parte das mulheres com seus operários, os quais são em sua maioria do sexo masculino. Por último os dirigentes do sexo masculino se destacam do sexo feminino quando considerado o grau em que suas motivações, valores e objetivos pessoais estão refletidos nas atividades da empresa. Dirigentes homens têm essas características mencionadas de forma muito mais clara em suas empresas, demonstrando que os homens projetam muito mais sua personalidade em suas firmas do que as mulheres.

Já em relação à dirigentes do sexo feminino, essas se destacaram nas questões 2 e 6. Isso demonstra que os funcionários de empresas gerenciadas por mulheres são menos especializados em suas tarefas do que empresas administradas pelo sexo oposto, de tal forma que há uma preferência por parte das mulheres por operários que consigam desempenhar várias tarefas, se necessário, quando comparado aos dirigentes do sexo masculino. Outro ponto a ser destacada é que entre os dirigentes do sexo feminino, há uma maior preferência por executar todas as tarefas administrativas do que entre dirigentes do sexo masculino, o que pode indicar que mulheres delegam menos tarefas aos seus subordinados, quando comparada aos homens.

Já as demais questões se mantiveram sem diferenças consideráveis entre os dirigentes de ambos os sexos, o que significa as outras características das pequenas empresas não são influenciadas pelo fato do dirigente ser homem ou mulher.

Após a verificação das médias, com o objetivo de analisar a significância das respostas, foi realizada a análise de variância. Os resultados são apresentados na tabela 4. 
Tabela 4 - ANOVA por sexo

\begin{tabular}{cccccc}
\hline Questão & GL & SQ & QM & $\mathbf{F}$ & Valor $\mathbf{p}$ \\
\hline QEP Q1 & 1 & 8,8 & 8,8 & 4,63 & $0,03{ }^{*}$ \\
QEP Q2 & 1 & 0,3 & 0,3 & 0,12 & 0,731 \\
QEP Q3 & 1 & 0,5 & 0,5 & 0,17 & 0,684 \\
QEP Q4 & 1 & 2,9 & 2,9 & 1,10 & 0,302 \\
QEP Q5 & 1 & 5,6 & 5,6 & 2,34 & 0,136 \\
QEP Q6 & 1 & 0,1 & 0,1 & 0,04 & 0,847 \\
QEP Q7 & 1 & 0,1 & 0,1 & 0,03 & 0,875 \\
QEP Q8 & 1 & 1,0 & 1,0 & 0,39 & 0,537 \\
QEP Q9 & 1 & 4,8 & 4,8 & 2,23 & 0,145 \\
QEP Q10 & 1 & 0,2 & 0,2 & 0,06 & 0,801 \\
QEP Q11 & 1 & 0,6 & 0,6 & 0,22 & 0,639 \\
QEP Q12 & 1 & 4,8 & 4,8 & 2,84 & 0,101 \\
QEP Q13 & 1 & 0,1 & 0,1 & 0,0 & 0,889 \\
QEP Q14 & 1 & 5,2 & 5,2 & 2,27 & 0,141 \\
\hline
\end{tabular}

Para as questões serem significativas o valor $\mathrm{p}$ deveria ser significativo em 5\% ou significativo em 10\%. Das respostas obtidas, a única significativa é a questão número 1 , que se refere à seguinte afirmação "A visão sobre onde minha empresa deve estar no longo prazo é realizada com base na minha experiência e de maneira informal (não segue uma metodologia pré-definida)", portanto há indícios que para esta questão o sexo tenha associação com a variável resposta (escala Likert). Ou seja, isto quer dizer que, as outras questões mencionadas anteriormente apenas indicam uma diferença entre os sexos, mas apenas a quesão 1, a qual menciona que homens realizam o planejamento estratégico de uma maneira muito mais informal que os dirigentes do sexo oposto, é significativa, indicando uma clara preferência das mulheres por seguirem um metodologia pré-definida e serem menos guiadas por sua experiência no momento da formulação da estratégia

\subsubsection{Religião}

A segunda quebra realizada se refere à análise do reconhecimento das 
especificidades considerando a religião dos dirigentes. Os resultados são apresentados no gráfico representado na figura 7.

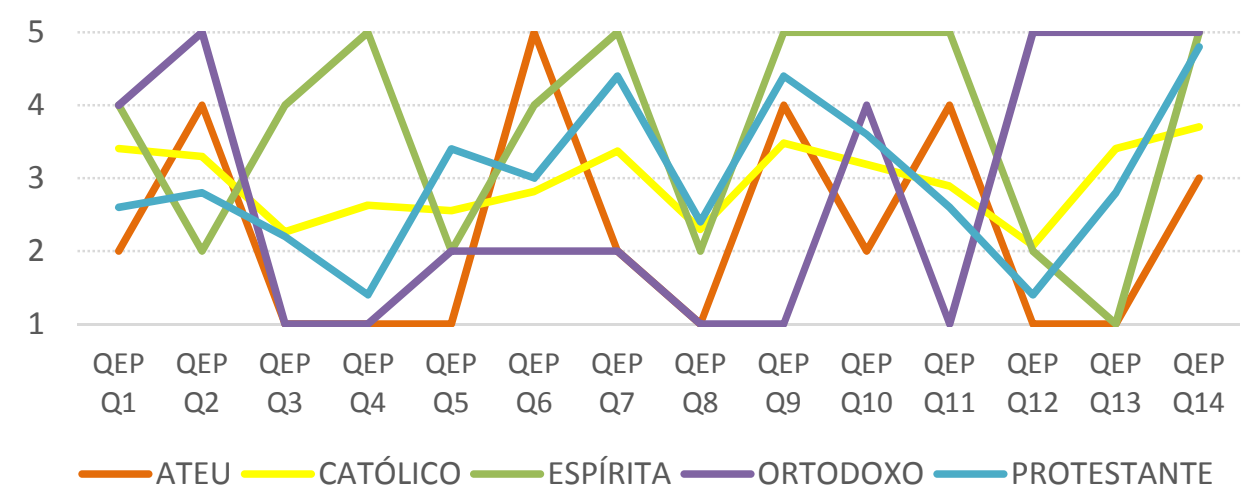

Figura 7 - Média das respostas por religião

Através dos dados pode ser visto que não há um padrão de resposta por religião que seja concentrando mais próximo de 1 ou mais próximo de 5 , de tal forma que não é possível tirar uma conclusão ou um indicativo de comportamento quando considerada a fé professada pelos dirigentes. Da mesma forma que não é possível estabelecer um padrão de resposta, também não foi possível verificar a significância das respostas, pois há concentração de respondentes (mais de 90\%) em um só tipo de religião.

\subsubsection{Raça}

A próxima quebra realizada foi em relação à raça declarada pelos dirigentes. $\mathrm{O}$ objetivo dessa quebra é verificar como os dirigentes de raças diferentes compreendem as especificidades, verificando se há diferenças nas percepções de cada um deles. Os resultados são apresentados na figura 8 . 


\section{Média das respostas}

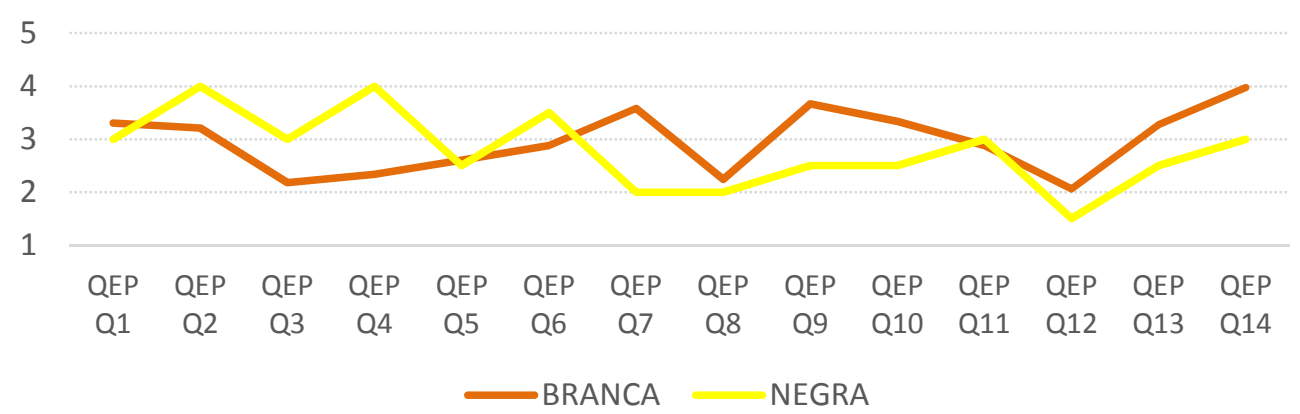

Figura 8 - Média das respostas por raça

A partir dos resultados pode ser visto que não há uma diferença muito grande entre as respostas dos dirigentes que se declararam pertencer à raça branca em contraposição com os que se declararam pertencer à raça negra. De forma análoga à religião, aqui também não é possível verificar a significância das respostas, pois há uma concentração muito grande de respondentes (em torno de 95\%) na raça branca.

\subsubsection{Escolaridade}

Seguindo a análise por quebras, posteriormente foi verificada a média das respostas dos dirigentes considerando seu grau de escolaridade. Os resultados podem ser visualizados na figura 9.

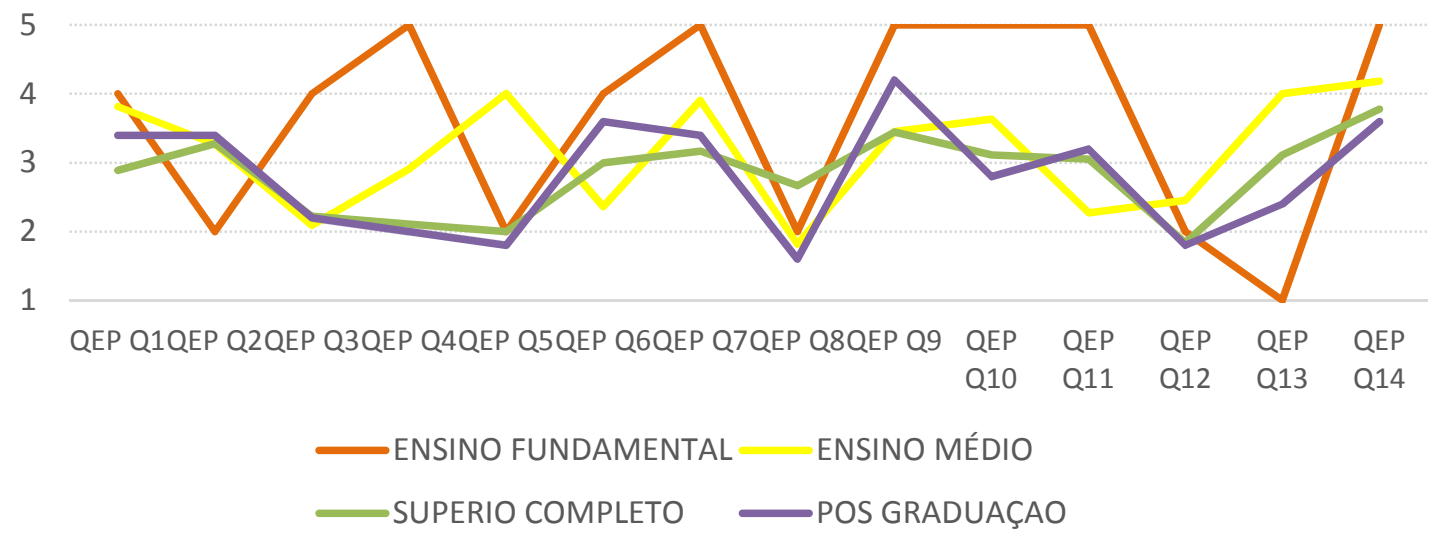

Figura 9 - Média das respostas por escolaridade 
Com base nos resultados representados na figura 9 pode ser visto que de uma forma geral empresas em que os dirigentes têm apenas o ensino fundamental destoam da média de respostas das demais empresas. Elas se comportam, na maioria das repostas, mais próximas de cinco quando comparada com as demais empresas, indicando que as firmas administradas por esses dirigentes guardam características próprias mais próximas ao que é mencionado pela literatura em relação a outras firmas administradas por dirigentes com ensino médio, superior ou pós-graduação.

Após a análise das médias, com o objetivo de verificar a significância das respostas, foi realizada a análise de variância. Os resultados são apresentados na tabela 5.

Tabela 5 - ANOVA por escolaridade

\begin{tabular}{cccccc}
\hline Questão & GL & SQ & QM & $\mathbf{F}$ & Valor $\mathbf{p}$ \\
\hline QEP Q1 & 3 & 6,5 & 2,2 & 1,04 & 0,387 \\
QEP Q2 & 3 & 1,7 & 0,6 & 0,25 & 0,858 \\
QEP Q3 & 3 & 3,4 & 1,1 & 0,40 & 0,755 \\
QEP Q4 & 3 & 11,9 & 4,0 & 1,60 & 0,209 \\
QEP Q5 & 3 & 7,0 & 2,3 & 0,93 & 0,438 \\
QEP Q6 & 3 & 31,6 & 10,5 & 4,75 & $0,008 *$ \\
QEP Q7 & 3 & 6,1 & 2,0 & 0,81 & 0,500 \\
QEP Q8 & 3 & 7,3 & 2,4 & 0,94 & 0,434 \\
QEP Q9 & 3 & 4,4 & 1,5 & 0,64 & 0,598 \\
QEP Q10 & 3 & 6,0 & 2,0 & 0,73 & 0,542 \\
QEP Q11 & 3 & 9,6 & 3,2 & 1,31 & 0,289 \\
QEP Q12 & 3 & 2,9 & 1,0 & 0,52 & 0,669 \\
QEP Q13 & 3 & 15,2 & 5,1 & 1,69 & 0,19 \\
QEP Q14 & 3 & 2,8 & 0,9 & 0,37 & 0,775 \\
\hline
\end{tabular}

Para as questões serem significativas o valor p deveria ser significativo em 5\% ou significativo em 10\%. Das respostas obtidas, a única significativa é a questão número 6 , a qual teve sua significância em 5\%. Tal questão se refere à seguinte afirmação "Eu, como dirigente da empresa, sou responsável por todas as tarefas administrativas (gestão financeira, de marketing, de pessoas entre outras).", portanto 
há indícios que para esta questão a escolaridade tenha associação com a variável resposta (escala Likert).

Para identificar onde está a diferença das médias utilizou-se o teste de comparação de Fisher, o qual é comumente utilizado em amostras com mais de 30 elementos (BOX; HUNTER; HUNTER, 2005). Pelo gráfico representado na figura 10, observa-se que a diferença significativa foi entre ter superior completo e ensino médio, uma vez que para ser significativo o intervalo não deve conter zero.

Fisher Individual 95\% Cls

Differences of Means for QEP Q6

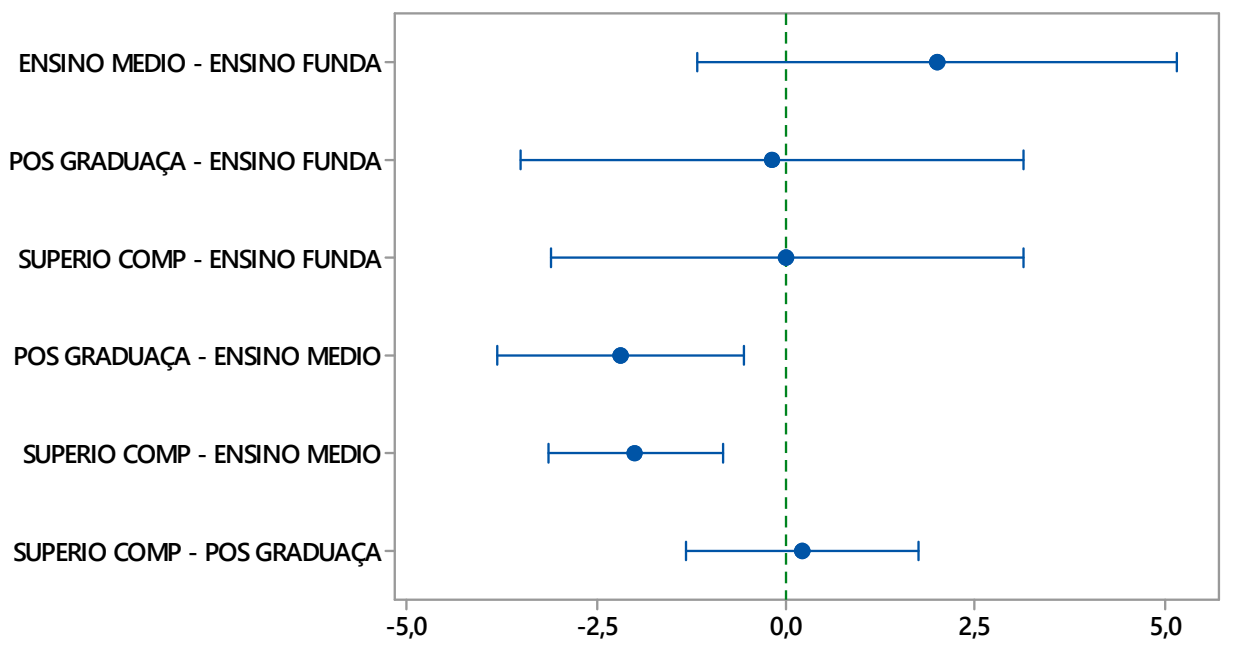

If an interval does not contain zero, the corresponding means are significantly different.

Figura 10 - Teste Fisher para escolaridade

Com base na figura 10 , pode ser concluído, portanto, que a diferença significativa ocorreu na questão 06 e entre dirigentes com ensino médio e dirigentes com ensino superior e também entre dirigentes com ensino médio e dirigentes com pós-graduação. Analisando a média das respostas através da tabela 6, pode ser verificado que em ambos os casos dirigentes com apenas o ensino médio desempenham menos tarefas administrativas quando comparada aos dirigentes com ensino superior e pós-graduação. Isso pode ser justiçado pelo fato de que dirigentes com menos grau de instrução necessita que outras pessoas executem tarefas que ele 
sozinho, pelo seu nível de escolaridade, não seria capaz.

Tabela 6 - Valor das médias das repostas por tempo de escolaridade

\begin{tabular}{ccccc}
\hline \multicolumn{5}{c}{ Média das respostas } \\
\hline Questão & ENSINO FUNDAMENTAL & ENSINO MÉDIO & SUPERIO COMPLETO POS GRADUAÇAO \\
\hline QEP Q1 & 4,0 & 3,8 & 2,9 & 3,4 \\
QEP Q2 & 2,0 & 3,3 & 3,3 & 3,4 \\
QEP Q3 & 4,0 & 2,1 & 2,2 & 2,2 \\
QEP Q4 & 5,0 & 2,9 & 2,1 & 2,0 \\
QEP Q5 & 2,0 & 4,0 & 2,0 & 1,8 \\
QEP Q6 & 4,0 & 2,4 & 3,0 & 3,6 \\
QEP Q7 & 5,0 & 3,9 & 3,2 & 3,4 \\
QEP Q8 & 2,0 & 1,8 & 2,7 & 1,6 \\
QEP Q9 & 5,0 & 3,5 & 3,4 & 4,2 \\
QEP Q10 & 5,0 & 3,6 & 3,1 & 2,8 \\
QEP Q11 & 5,0 & 2,3 & 3,1 & 3,2 \\
QEP Q12 & 2,0 & 2,5 & 1,8 & 1,8 \\
QEP Q13 & 1,0 & 4,0 & 3,1 & 2,4 \\
QEP Q14 & 5,0 & 4,2 & 3,8 & $\mathbf{5}$ \\
\hline Quantidade respondentes & $\mathbf{1}$ & $\mathbf{1 1}$ & $\mathbf{1 8}$
\end{tabular}

\subsubsection{Tempo de experiência}

A próxima quebra verificada foi verificar a média das respostas dos dirigentes tomando como base o tempo de experiência destes dirigentes na condução da empresa. Com base nas respostas dados pelos entrevistados foi feito um agrupamento em três categorias, a primeira com dirigentes com tempo de experiência menor que cinco anos, a segunda com tempo de experiência entre cinco e dez anos e a terceira, e última, com tempo de experiência maior que dez anos. Os resultados podem ser verificados na figura 11 . 


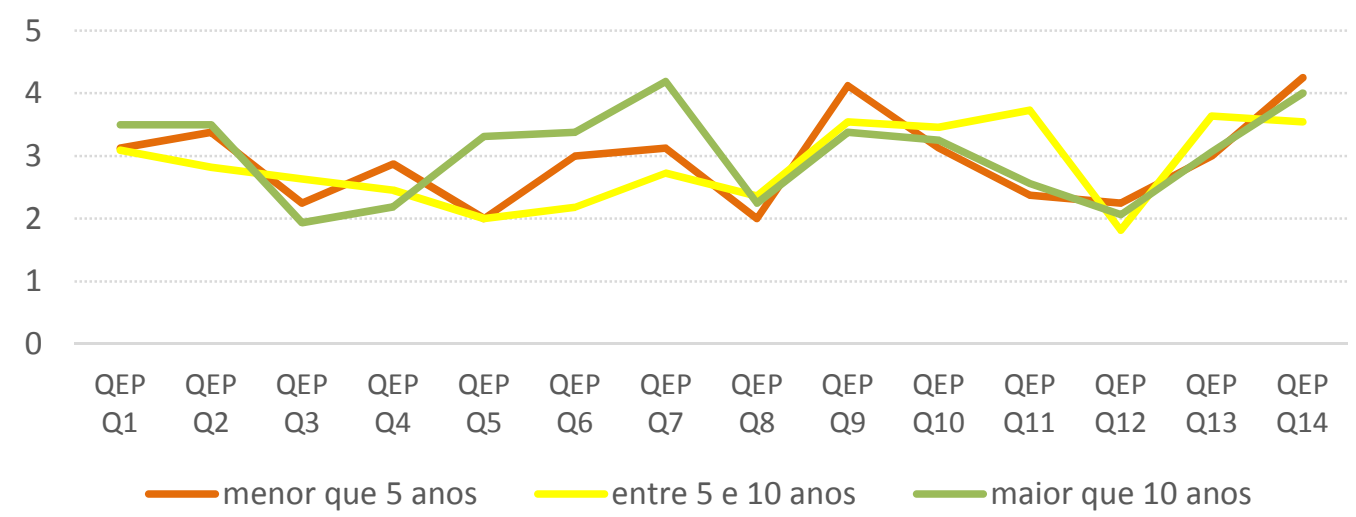

Figura 11 - média por tempo de experiência

De uma forma geral, com base na figura 11, pode ser visto que as médias das respostas dos dirigentes mantém de uma forma geral o mesmo padrão, o que significa que a variável tempo de experiência não exerce uma influencia muito grande nas respostas dos entrevistados. Isto torna-se mais evidente quando comparada o valor das médias por respostas na tabela 6 .

Tabela 7 - Valor das Médias das respostas por tempo de experiência

\begin{tabular}{cccc}
\hline \multicolumn{4}{c}{ Média das respostas } \\
\hline Questão & menor que 5 anos & entre 5 e 10 anos maior que 10 anos \\
\hline QEP Q1 & 3,1 & 3,1 & 3,5 \\
QEP Q2 & 3,4 & 2,8 & 3,5 \\
QEP Q3 & 2,3 & 2,6 & 1,9 \\
QEP Q4 & 2,9 & 2,5 & 2,2 \\
QEP Q5 & 2,0 & 2,0 & 3,3 \\
QEP Q6 & 3,0 & 2,2 & 3,4 \\
QEP Q7 & 3,1 & 2,7 & 4,2 \\
QEP Q8 & 2,0 & 2,4 & 2,3 \\
QEP Q9 & 4,1 & 3,5 & 3,4 \\
QEP Q10 & 3,1 & 3,5 & 3,3 \\
QEP Q11 & 2,4 & 3,7 & 2,6 \\
QEP Q12 & 2,3 & 1,8 & 2,1 \\
QEP Q13 & 3,0 & 3,6 & 3,1 \\
QEP Q14 & 4,3 & 3,5 & 4,0 \\
\hline Quantidade respondentes & $\mathbf{8}$ & 11 & 16 \\
\hline
\end{tabular}

Com o objetivo de verificar a significância das respostas, foi realizada a análise 
de variância e, posteriormente para verificar onde se encontravam as diferenças foi realizado o teste de Fisher. A tabela com os resultados da analise de variância para o tempo de experiência e o teste de Fisher para essa quebra pode ser identificados, respectivamente, na tabela 7 e figura 12, 13 e 14.

Na tabela 7 pode ser verificado que a questão número sete que se refere à seguinte afirmação "Eu, como dirigente da empresa exerço uma grande influencia nas atividades da empresa (supervisiono pessoalmente todas as atividades da empresa)." é significativa em $5 \%$, enquanto as questões seis e onze que se referem às seguintes afirmações, respectivamente, "Eu, como dirigente da empresa, sou responsável por todas as tarefas administrativas (gestão financeira, de marketing, de pessoas entre outras)" e "Não temos grande influência sobre os fornecedores da empresa" são significativas em $10 \%$.

Tabela 8 - ANOVA para tempo de experiência

\begin{tabular}{cccccc}
\hline Questão & GL & SQ & QM & $\mathbf{F}$ & Valor $\mathbf{p}$ \\
\hline QEP Q1 & 2 & 1,4 & 0,7 & 0,31 & 0,735 \\
QEP Q2 & 2 & 3,2 & 1,6 & 0,75 & 0,479 \\
QEP Q3 & 2 & 3,2 & 1,6 & 0,59 & 0,562 \\
QEP Q4 & 2 & 2,5 & 1,3 & 0,47 & 0,629 \\
QEP Q5 & 2 & 9,4 & 4,7 & 1,99 & 0,154 \\
QEP Q6 & 2 & 15,0 & 7,5 & 2,80 & $0,076^{* *}$ \\
QEP Q7 & 2 & 15,3 & 7,62 & 3,510 & $0,042^{*}$ \\
QEP Q8 & 2 & 0,6 & 0,3 & 0,11 & 0,892 \\
QEP Q9 & 2 & 3,0 & 1,5 & 0,66 & 0,521 \\
QEP Q10 & 2 & 0,5 & 0,3 & 0,10 & 0,909 \\
QEP Q11 & 2 & 11,6 & 5,77 & 2,5 & $0,098^{* *}$ \\
QEP Q12 & 2 & 0,9 & 0,4 & 0,24 & 0,789 \\
QEP Q13 & 2 & 2,7 & 1,3 & 0,41 & 0,669 \\
QEP Q14 & 2 & 2,5 & 1,3 & 0,51 & 0,603 \\
\hline
\end{tabular}




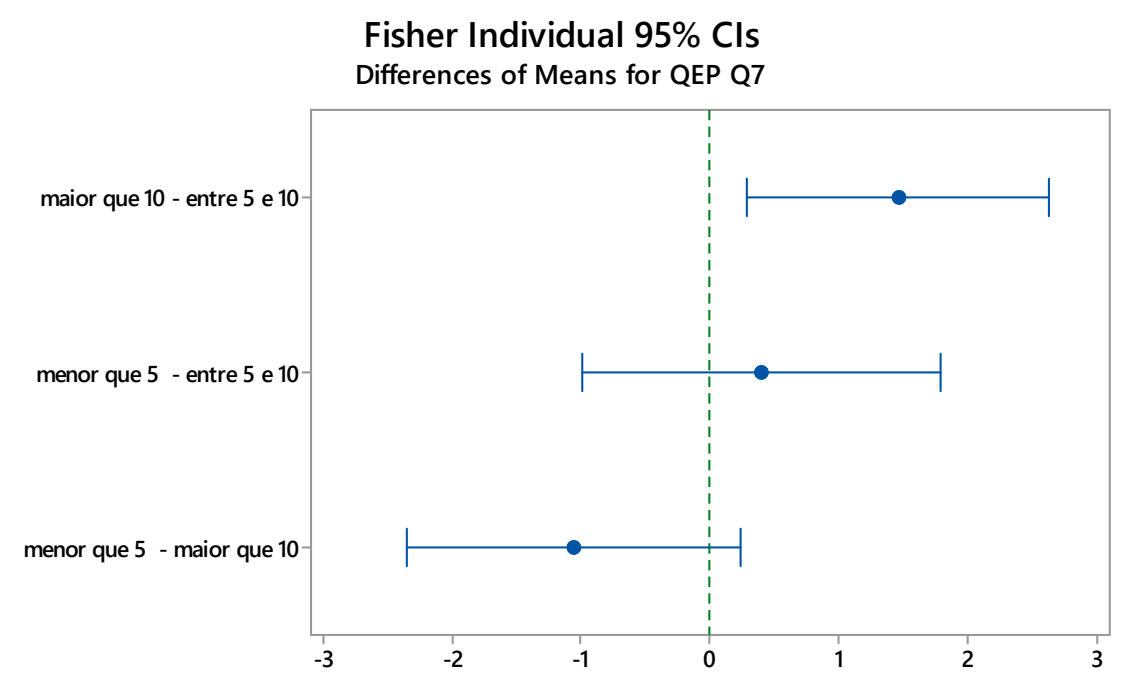

If an interval does not contain zero, the corresponding means are significantly different.

Figura 12 - Teste de Fisher da questão 07 relacionada ao tempo de experiência

De acordo com a figura 12, a diferença significativa encontrada na questão 07 se refere à diferença das respostas entre dirigentes com tempo de experiência maior que 10 anos e dirigentes com tempo de experiência entre 5 e 10 anos. Isso significa que dirigentes com mais de 10 anos de experiência supervisionam e exercem uma influencia direta nas atividades da empresa de uma forma significantemente maior que dirigentes com menos experiência do que eles.

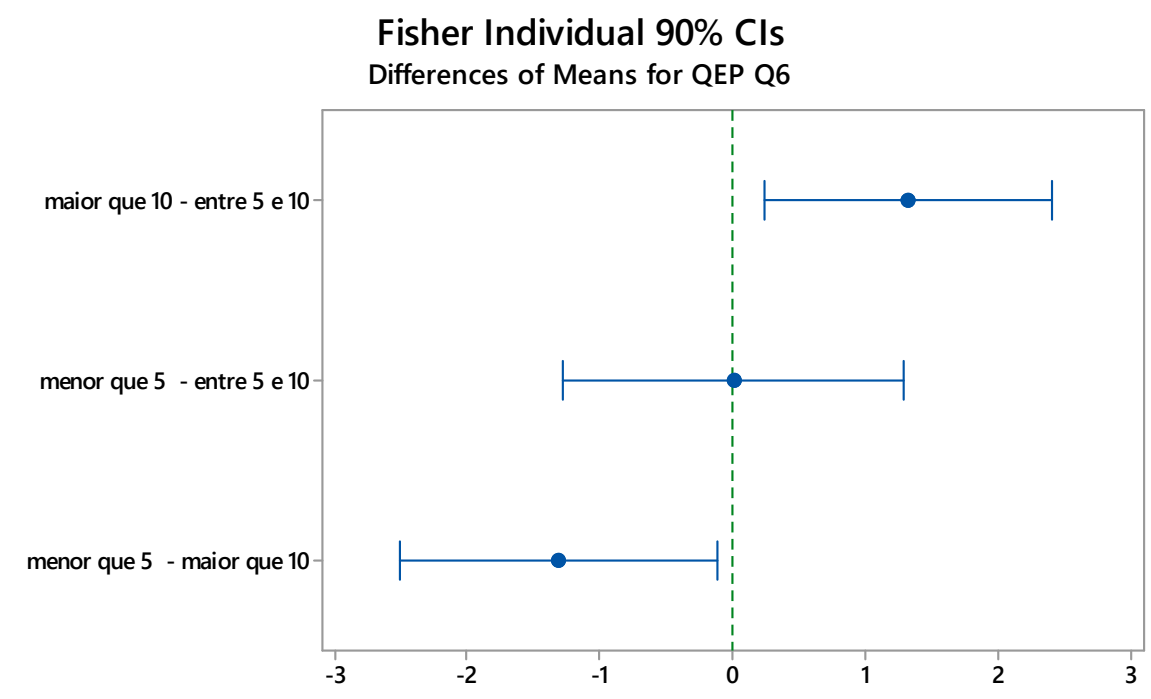

If an interval does not contain zero, the corresponding means are significantly different.

Figura 13 - Teste de Fisher da questão 06 relacionada ao tempo de experiência 
Novamente a diferença encontrada se refere aos dirigentes com tempo de experiência maior que 10 anos e dirigentes com tempo de experiência entre 5 e 10 anos. Essa diferença associa-se à significância encontrada na questão anterior, uma vez que dirigentes com mais tempo de experiência, além de supervisionarem diretamente as atividades da empresa, eles também realizam todas as tarefas administrativas de forma muito mais acentuada do que dirigentes com menos tempo de experiência.

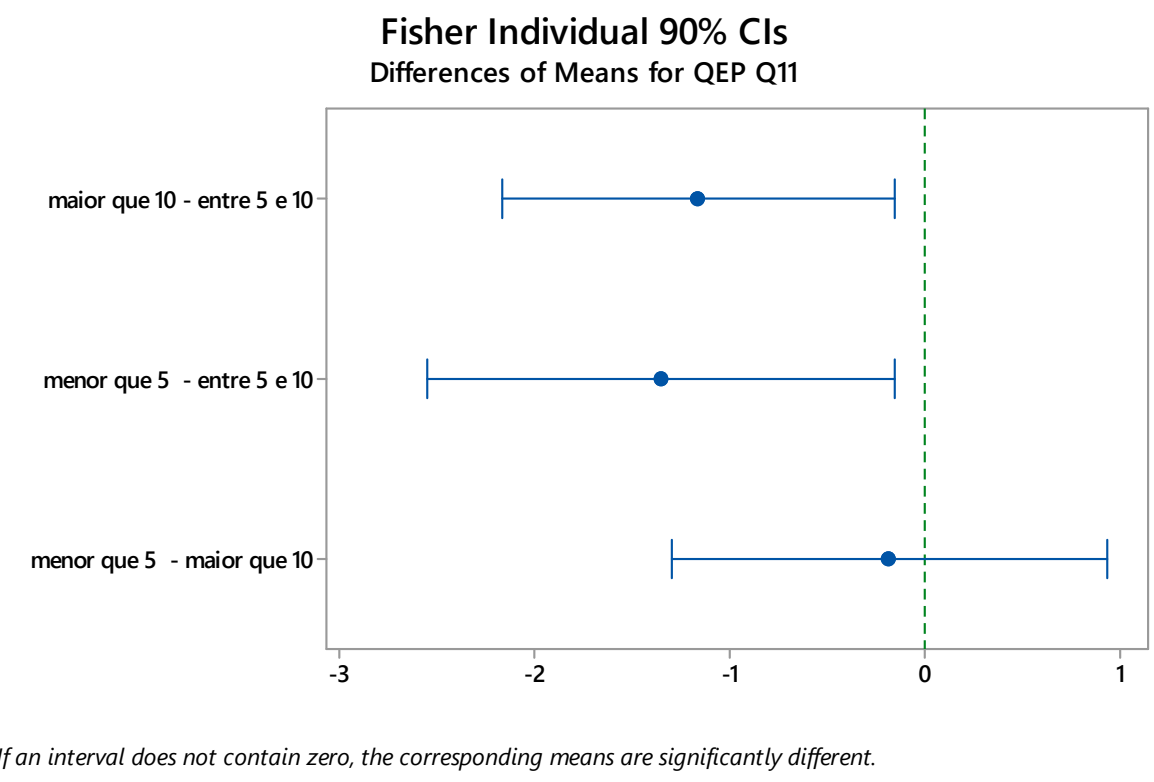

Figura 14 - Teste de Fisher da questão 11 relacionada ao tempo de experiência

Já na questão 11, diferentemente das duas anteriores, além da diferença significativa encontrada entre dirigentes com tempo de experiência maior que 10 anos e dirigentes com tempo de experiência entre 5 e 10 anos, também foi identificada diferença significativa nas respostas de dirigentes com tempo de experiência menos que 5 anos e com tempo de experiência entre 5 e 10 anos. Com base nessa inferência, pode ser destacado que dirigentes com tempo de experiência entre 5 e 10 anos exercem menos influencia em seus fornecedores quando comparado a dirigentes já estabelecidos a mais de dez anos e também quando comparada a dirigentes que desempenham suas atividades a menos de cinco anos. Isso pode indicar que empresas 
já estabelecidas possuem um relacionamento de longa data com seus fornecedores, o que possibilita a sua influencia sobre esses últimos e também pode indicar que empresas as quais seu dirigente principal tem pouco tempo de experiência a frente da firma consegue articular melhor seus relacionamento e parcerias.

\subsubsection{Cidade}

A última quebra verificada foi a média das respostas quando analisada a cidade onde as empresas estavam inseridas. $\mathrm{O}$ valor das médias e os resultados podem ser analisados, respectivamente, na tabela 9 e na figura 15.

Tabela 9 - Valor das médias das repostas por cidade

\begin{tabular}{ccccc}
\hline & \multicolumn{4}{c}{ Média das respostas } \\
\hline Questão & ARARAQUARA & MATÃo & SÃo CARLOS & SERTÃOZINHO \\
\hline QEP Q1 & 3,7 & 3,2 & 2,8 & 3,8 \\
QEP Q2 & 3,5 & 3,6 & 2,6 & 4,2 \\
QEP Q3 & 2,5 & 2,4 & 2,1 & 1,8 \\
QEP Q4 & 2,5 & 2,8 & 2,3 & 2,2 \\
QEP Q5 & 3,5 & 2,6 & 1,9 & 2,6 \\
QEP Q6 & 2,8 & 2,2 & 3,1 & 3,2 \\
QEP Q7 & 3,5 & 3,2 & 3,4 & 4,0 \\
QEP Q8 & 2,2 & 2,6 & 2,4 & 1,4 \\
QEP Q9 & 3,5 & 2,8 & 3,7 & 4,4 \\
QEP Q10 & 3,7 & 3,4 & 2,8 & 3,6 \\
QEP Q11 & 2,9 & 3,6 & 2,3 & 3,8 \\
QEP Q12 & 2,2 & 2,6 & 1,8 & 1,8 \\
QEP Q13 & 2,6 & 3,6 & 3,6 & 3,2 \\
QEP Q14 & 4,8 & 2,6 & 3,7 & 3,8 \\
\hline Quantidade respondentes & $\mathbf{1 1}$ & $\mathbf{5}$ & $\mathbf{1 4}$ & $\mathbf{5}$ \\
\hline
\end{tabular}




\section{Média das respostas}

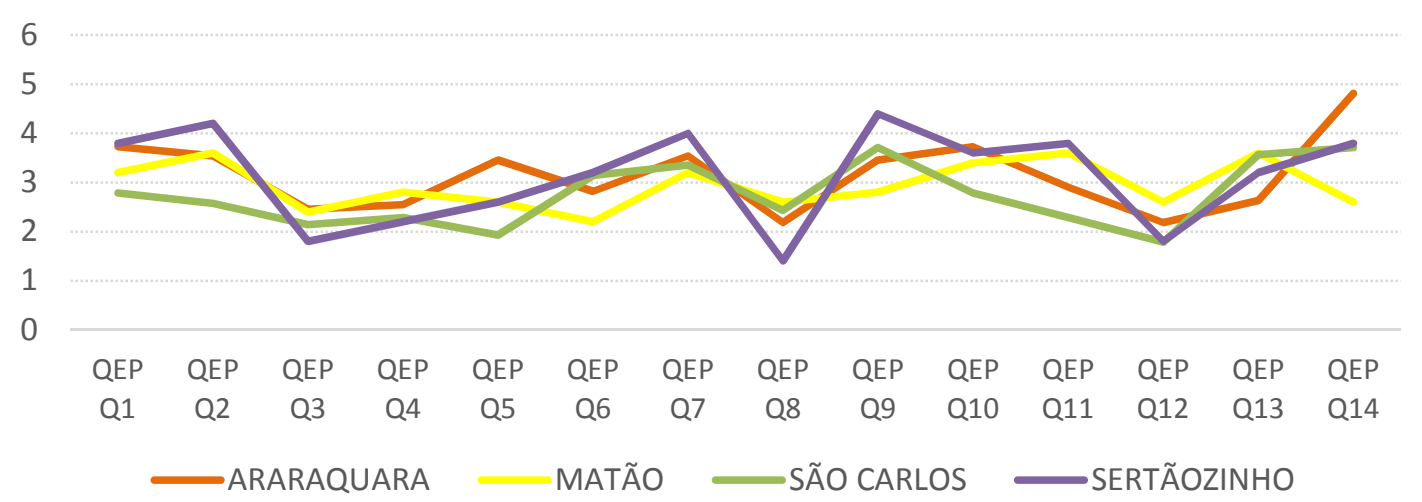

Figura 15 - Média das respostas por cidade

Assim como a quebra anterior, que relacionou a experiência do dirigente com a percepção das especificidades, as médias das respostas dos dirigentes mantém, de uma forma geral, o mesmo padrão, o que significa que a variável cidade não exerce uma influencia muito grande nas respostas dos entrevistados.

Com o objetivo de verificar a significância da diferença das médias, foi rodado um teste de analise variância para esta quebra. Os resultados obtidos são apresentados na tabela 10 .

Tabela 10 - ANOVA por cidade

\begin{tabular}{|l|l|l|l|l|l|}
\hline Questão & GL & SQ & QM & $\mathbf{F}$ & Valor $\mathbf{p}$ \\
\hline QEP Q1 & 3 & 7,0 & 2,3 & 1,13 & 0,353 \\
\hline QEP Q2 & 3 & 12,5 & 4,2 & 2,23 & 0,105 \\
\hline QEP Q3 & 3 & 1,7 & 0,6 & 0,20 & 0,894 \\
\hline QEP Q4 & 3 & 1,4 & 0,5 & 0,16 & 0,92 \\
\hline QEP Q5 & 3 & 3,8 & 1,3 & 0,48 & 0,696 \\
\hline QEP Q6 & 3 & 14,3 & 4,78 & 1,72 & 0,183 \\
\hline QEP Q7 & 3 & 2,0 & 0,67 & 0,25 & 0,861 \\
\hline QEP Q8 & 3 & 4,7 & 1,6 & 0,58 & 0,631 \\
\hline QEP Q9 & 3 & 6,8 & 2,3 & 1,01 & 0,401 \\
\hline QEP Q10 & 3 & 6,2 & 2,1 & 0,75 & 0,528 \\
\hline QEP Q11 & 3 & 11,8 & 3,9 & 1,65 & 0,198 \\
\hline QEP Q12 & 3 & 3,0 & 1,0 & 0,53 & 0,665 \\
\hline QEP Q13 & 3 & 6,2 & 2,1 & 0,6 & 0,602 \\
\hline QEP Q14 & 3 & 18,3 & 6,1 & 3,02 & $0,045 *$ \\
\hline
\end{tabular}


De acordo com a tabela 10, a única diferença com significância encontrada foi na questão 14 , sendo esta significativa em 5\%. Tal questão se refere a seguinte afirmação "O crescimento financeiro da empresa não é a motivação principal para ter meu próprio negócio". Para poder verificar onde se encontra essa diferença foi realizado novamente o teste de Fisher. O resultado está representado na figura 16.

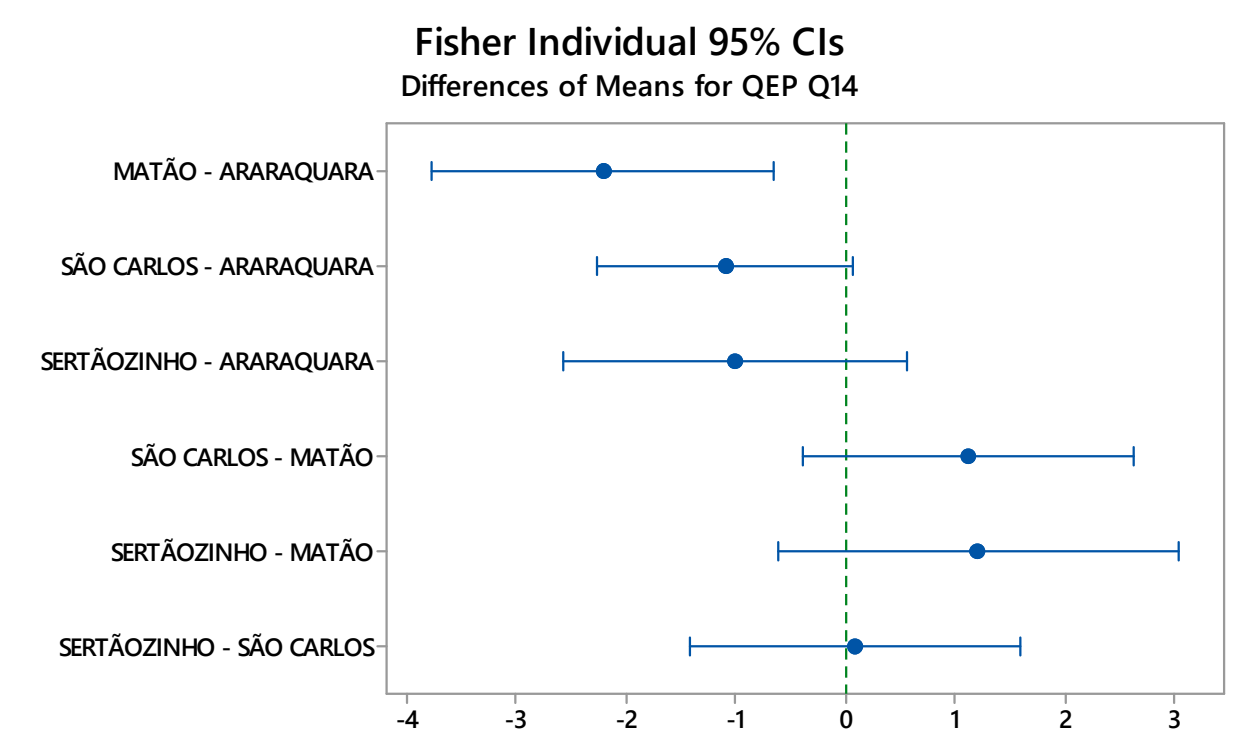

If an interval does not contain zero, the corresponding means are significantly different.

Figura 16 - Teste de Fisher para cidade

Com base na figura 16 pode ser identificado que a diferença significativa na questão 14 ocorre entre os dirigentes da cidade de Matão e de Araraquara. Isso significa que dirigentes da cidade de Matão são motivados muito mais por questões financeiras quando comparado aos dirigentes da cidade de Araraquara, os quais dentre os demais dirigentes da amostra são os que são menos motivados por questões financeiras.

\subsection{ORIENTAÇÃO ESTRATÉGICA}


Da amostra de 35 empresas, quando analisada as respostas do questionário de orientação estratégica (presente no anexo A), quatro empresas foram identificadas como pertencentes a mais de uma orientação estratégica. Sendo assim, para fins do estudo, considerando o objetivo de analisar as orientações estratégicas individualmente, essas empresas foram desconsideradas no momento da analise. A classificação final das empresas e a quantidade de cada uma delas podem ser vista na tabela 11 .

Tabela 11 - Classificação por orientação estratégica

\begin{tabular}{|l|l|}
\hline Classificação & $\begin{array}{l}\text { Quantidade } \\
\text { empresas }\end{array}$ \\
\hline Analistas & 10 \\
\hline Defensoras & 10 \\
\hline Prospectoras & 8 \\
\hline Reativas & 3 \\
\hline Total & $\mathbf{3 1}$ \\
\hline
\end{tabular}

Com base nos resultados apresentados na tabela 11 pode ser verificado que as orientações estratégicas, com exceção da reativas, apresentam uma distribuição muito próxima uma das outras. A seguir são realizadas análises descritivas por quebras, relacionando as orientações estratégicas das empresas com sexo do dirigente, religião, raça, grau de escolaridade, tempo de experiência e cidade.

\subsubsection{Análise das orientações estratégicas por quebras}

A análise estatística para esta etapa será o Teste exato de Fisher. O teste exato de Fisher será utilizado para verificar se há associação entre cada covariável com a variável orientação estratégica. Para gerar os dados foi utilizado o software SAS 9.2. 
A seguir são apresentados nas figuras 17, 18, 19 e 20, respectivamente, os resultados das quebras para as covariáveis sexo, escolaridade, cidade e tempo de experiência. Para verificar se há evidencias de associação entre cada covariável de interesse e a orientação estratégica, o p-value deve ser menor que 5\%.

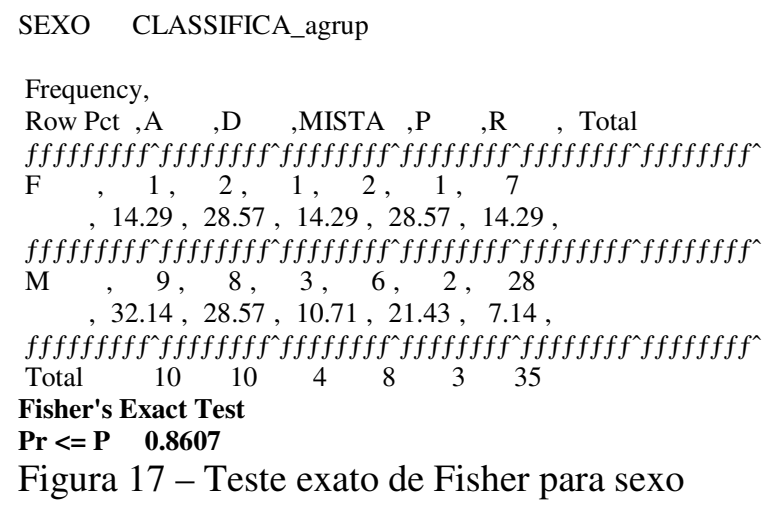

Figura 17 - Teste exato de Fisher para sexo

Com base nos resultados apresentados na figura 17, pode ser verificado que o p-value é de $86 \%$ o que significa, portanto, que não há evidências de associação entre a covariável sexo dos dirigentes e a orientação estratégica.

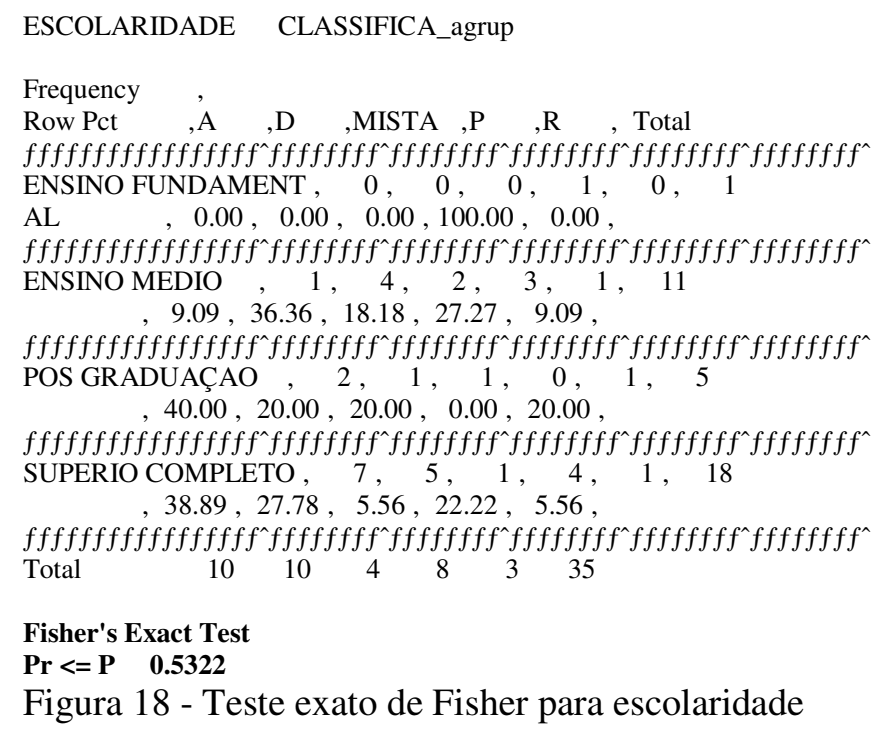

Figura 18 - Teste exato de Fisher para escolaridade

Com base nos resultados apresentados na figura 18 , pode ser verificado que o 
p-value é de $53 \%$ o que significa, portanto, que não há evidências de associação entre a covariável grau de escolaridade dos dirigentes e a orientação estratégica.

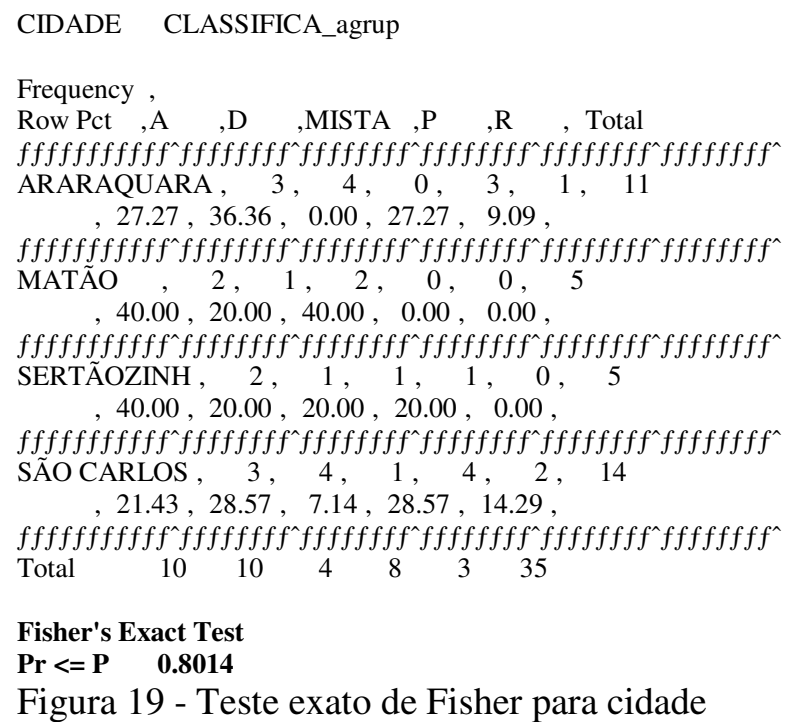

Com base nos resultados apresentados na figura 19 , pode ser verificado que o p-value é de $80 \%$ o que significa, portanto, que não há evidências de associação entre a covariável cidade onde as empresas estão localizadas e a orientação estratégica.

A última quebra realizada foi em relação ao tempo de experiência do dirigente e a orientação estratégica adotada pela empresa. Essa quebra, como pode ser verificado na figura 20 , foi a única em que o p-value ficou menor que $5 \%$ e, portanto, houve indícios de associação entre elas. Porém, como uma restrição deste teste, não foi possível determinar onde ocorre essa associação, ou seja, se é entre dirigentes com mais de 10 anos de experiência, entre dirigentes entre 10 e 5 anos de experiência ou entre dirigentes com menos de 5 anos de experiência e tampouco com qual orientação estratégica, seja ela prospectora, analista, defensora ou reativa 


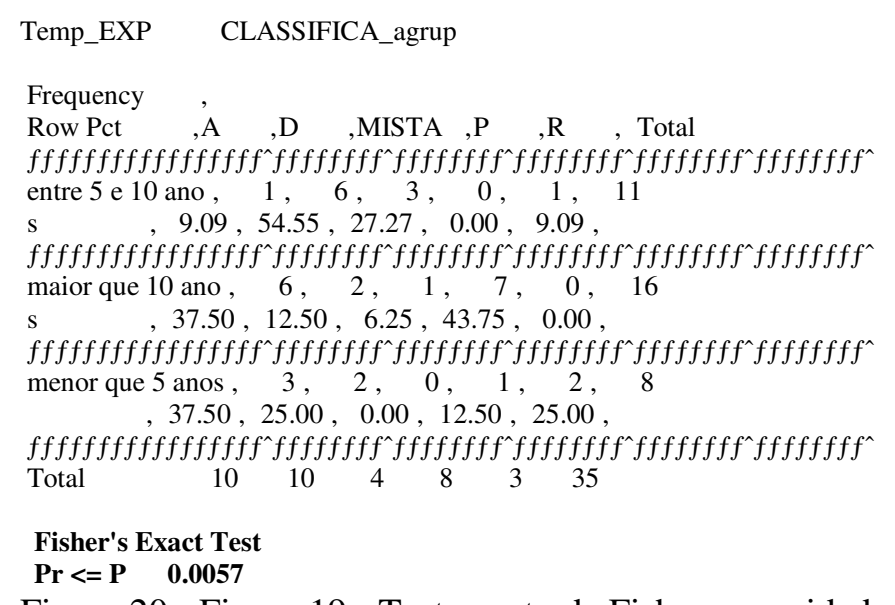

Figura 20 - Figura 19 - Teste exato de Fisher para cidade

$\mathrm{Na}$ sequência desta seção há a verificação da relação entre orientação estratégica e desempenho organizacional, sendo este medido em termos de aumento do faturamento e rotatividade.

\subsubsection{Orientação estratégica e desempenho organizacional}

Para verificar se há relação entre a orientação estratégica e desempenho organizacional, foram selecionadas duas medidas de desempenho com base na literatura sobre o tema. Os valores foram fornecidos pelos respondentes em termos percentuais, com base na variação do faturamento de suas empresas em relação aos anos de 2011, 2012, 2013 e 2014 e com base na variação da rotatividade de pessoal para esses mesmos anos.

\subsubsection{Desempenho em termos de faturamento}

A primeira medida de desempenho considerada foi a variação do faturamento. Na tabela 12 pode ser vista a média da variação do faturamento (DRF) dentro do período considerado para cada grupo de empresas classificadas de acordo com sua 
orientação estratégica.

Tabela 12 - Média de Desempenho de Faturamento

\begin{tabular}{ccccc}
\hline Classificação & A & D & P & R \\
\hline Média de DRF 11-12 & $\mathbf{0 , 0 4}$ & $\mathbf{0 , 1 1}$ & $\mathbf{B , 2 7}$ & $\mathbf{0 , 2 2}$ \\
Média de DRF 12-13 & $\mathbf{0 , 2 2}$ & $\mathbf{0 , 1 1}$ & $\mathbf{0 , 7 1}$ & $\mathbf{0 , 1 4}$ \\
Média de DRF 13-14 & $\mathbf{0 , 1 6}$ & $\mathbf{0 , 1 5}$ & $\mathbf{1 , 5 5}$ & $\mathbf{0 , 1 2}$ \\
\hline Quantidade respondentes & $\mathbf{1 0}$ & 10 & 8 & $\mathbf{3}$ \\
\hline
\end{tabular}

Com base na tabela acima pode ser visto que as empresas classificadas como prospectaras possuem as maiores médias de faturamento quando comparadas às demais empresas que seguem outros tipos de orientação estratégica.

Entretanto, este resultado se deve a presença de uma empresa, classificada como prospectora, dentro da amostra que por conta do seu resultado de faturamento muito acima da média acabou por alterar a percepção do conjunto de empresas com orientação prospectora dentro do grupo. Essa empresa pode ser detectada como o outliers em relação ao faturamento, conforme mostra o bloxplot nas figuras 21 e 22 , onde A são empresas analistas, D são empresas defensoras, R são empresas reativas e P são empresas prospectoras. 


\section{Boxplot of DRF 12-13}

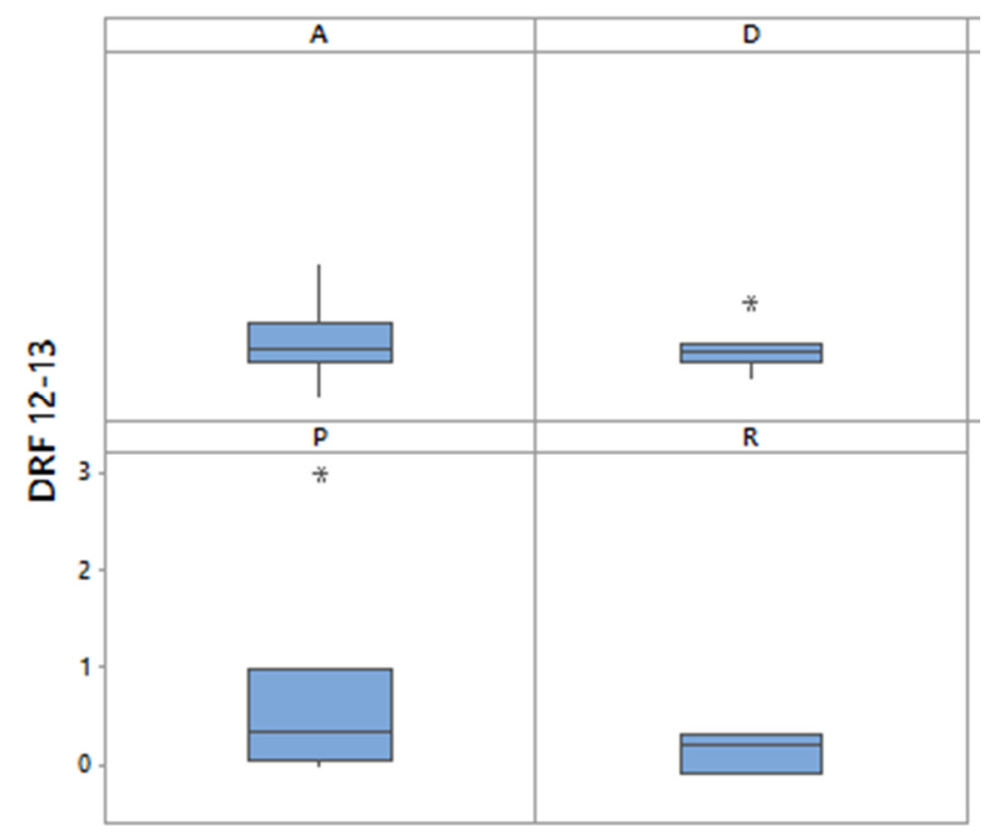

Panel variable: CLASSIFICA_agrup

Figura 21 - Boxplot para faturamento entre 2012-2013

O ponto acima da caixa dentro do quadrante referente às empresas classificadas como prospectoras representa a empresa outlier, ou seja, a empresa dentro da amostra que apresenta dados discrepantes. Tal empresa apresentou dentro do período de 2012 a 2013 um aumento de faturamento em torno de 300\%, muito acima das demais empresas. Para o período seguinte a discrepância ficou maior ainda, quando a mesma empresa aumentou seu faturamento em $1000 \%$. Essa diferença pode ser vista na figura 22. 


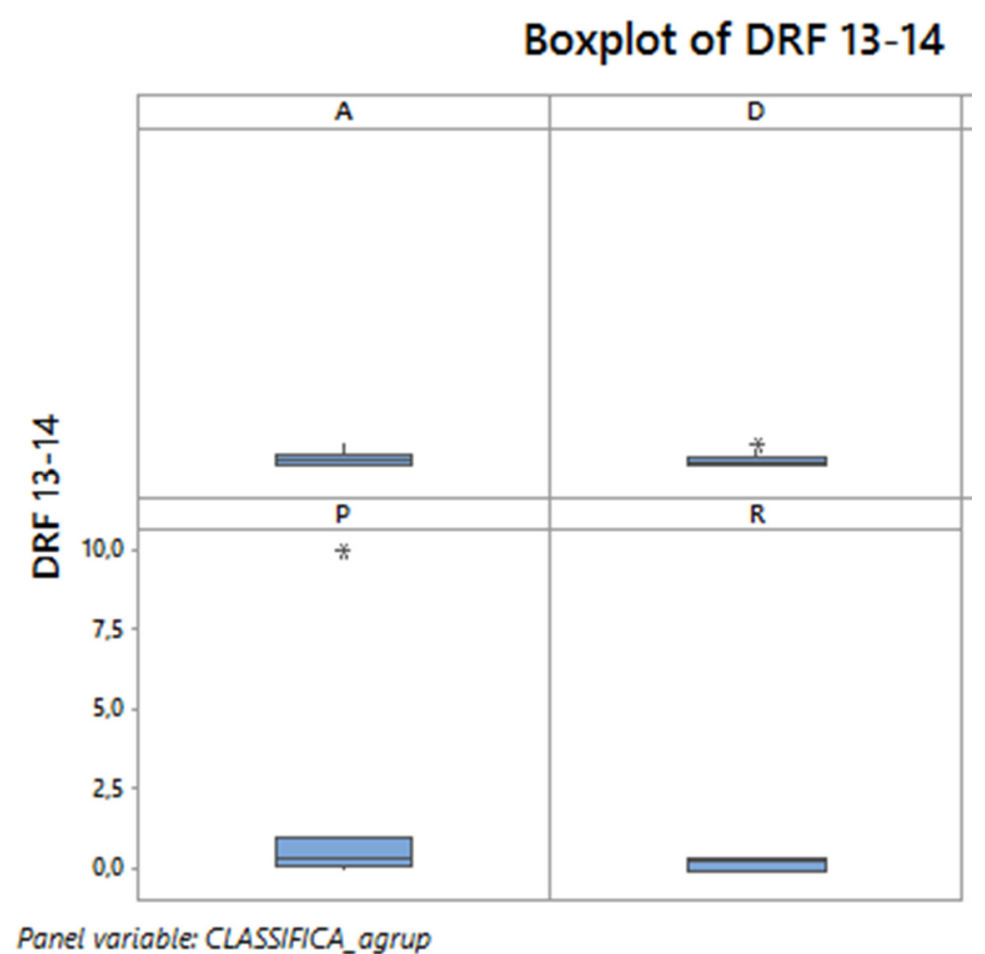

Figura 22 - Boxplot para faturamento entre 2013-2014

Sendo assim, quando desconsiderada a presença da empresa outlier, a média das variações dos faturamentos das empresas pertencentes à amostra ficam muito semelhantes, porém mesmo assim as prospectoras apresentam um faturamento pouco maior que as demais, indicando que de uma forma geral firmas que seguem essa orientação estratégica apresentam melhor desempenho organizacional quando este é entendido em termos de aumento de faturamento.

\subsubsection{Desempenho em termos de rotatividade}

A segunda medida de desempenho considerada no estudo foi a variação da rotatividade de pessoal (Turnover) dentro dos períodos de 2011 a 2012, 2012 a 2013 e 2013 a 2014. Na tabela 13 pode ser visto a média de variação das empresas em relação a rotatividade (DRT), no período mencionado, para cada grupo de empresa classificada 
de acordo com sua orientação estratégica.

Tabela 13 - Média de desempenho de rotatividade

\begin{tabular}{|c|c|c|c|c|}
\hline Classificação & A & D & $\mathbf{p}$ & $\mathbf{R}$ \\
\hline Média de DRT 11-12 & 6,18 & $\mathbf{B}, \mathbf{1 3}$ & 0,11 & 0,17 \\
\hline Média de DRT 12-13 & 8,11 & $\mathbf{0 , 6 8 8}$ & 0,15 & 0,13 \\
\hline Média de DRT 13-14 & $\mathbf{0 , 1 3}$ & $\mathbf{0 , 1 1}$ & $\mathbf{0}, 23$ & 0,10 \\
\hline Quantidade respondentes & 10 & 10 & 8 & 3 \\
\hline
\end{tabular}

As empresas classificadas como prospectoras possuem novamente as maiores médias, indicando que firmas que seguem essa orientação estratégica apresentam os melhores índices de desempenho quando este é entendido em termos de rotatividade, posicionando-as, como as que se relacionam mais positivamente com o desempenho organizacional, conforme pode ser verificado nas figuras 23, 24 e 25 .

\section{Boxplot of DRT 11-12}

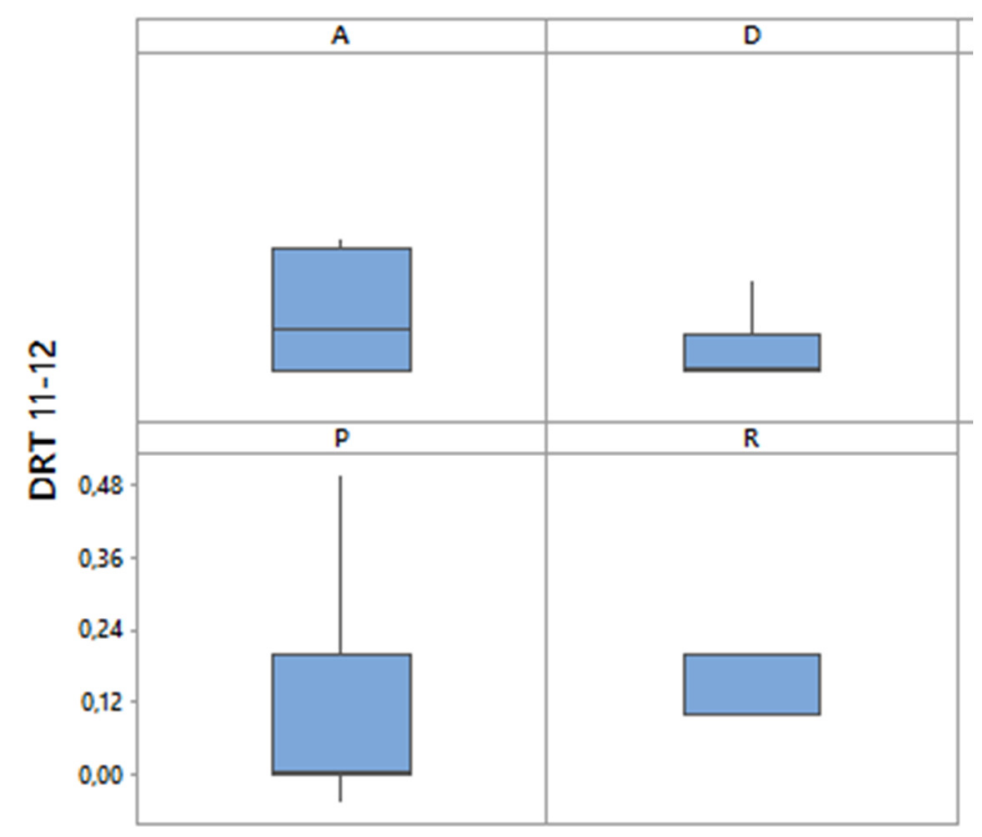

Panel variable: CLASSIFICA_agrup

Figura 23 - Boxplot para rotatividade entre 2011-2012 


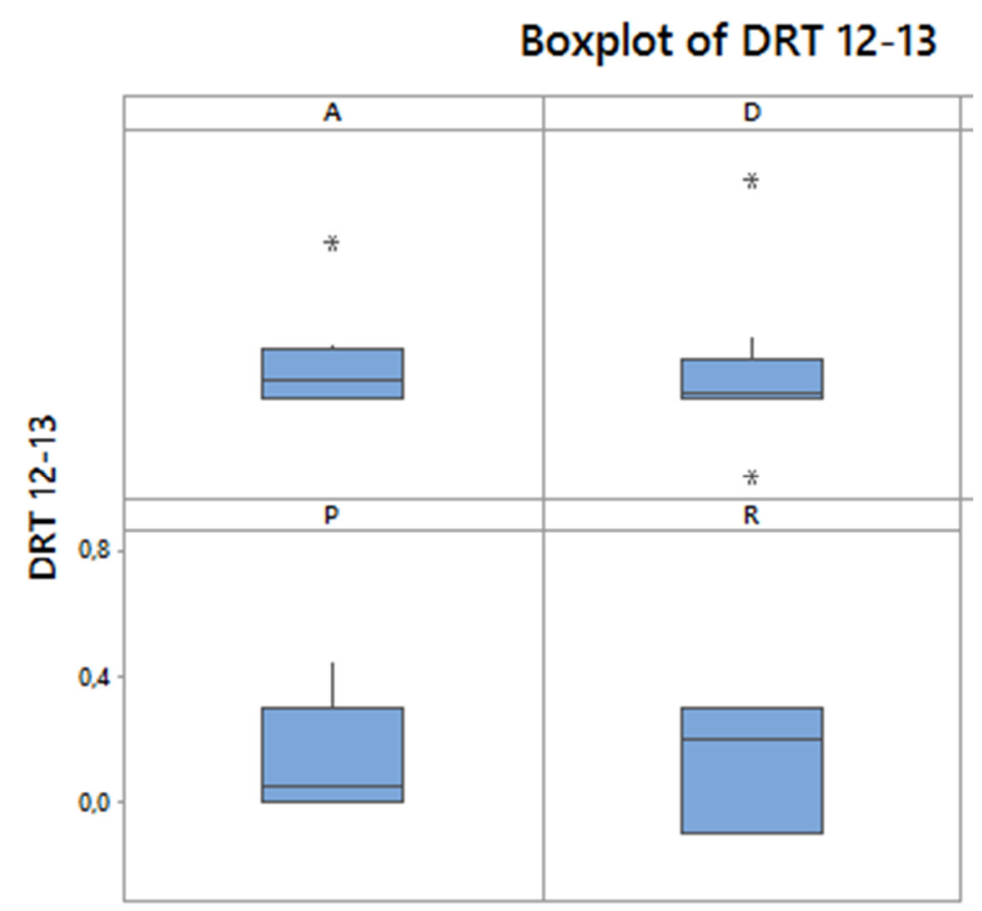

Panel variable: CLASSIFICA_agrup

Figura 24 - Boxplot para rotatividade entre 2012-2013

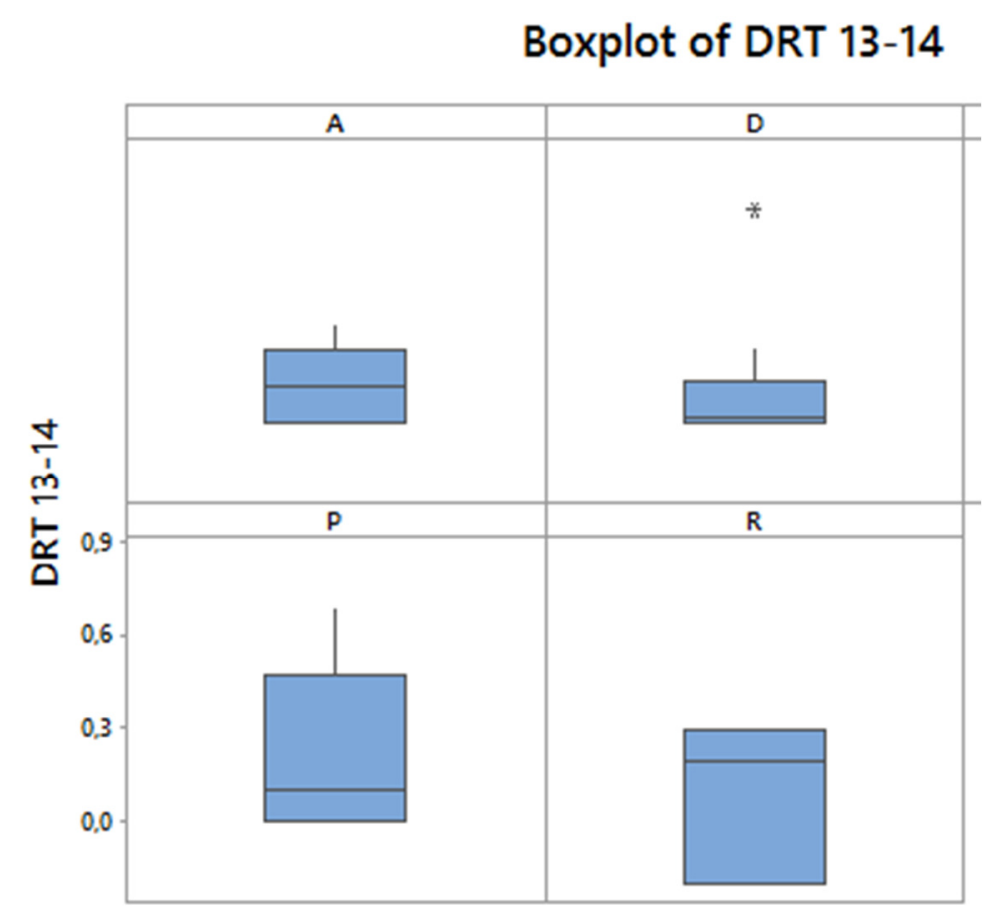

Panel variable: CLASSIFICA_agrup

Figura 25 - Boxplot para rotatvidade entre 2013-2014

Com o objetivo de verificar a existência de correlação entre as covariáveis de interesse faturamento e rotatividade e a variável orientação estratégica, foi realizada o 
teste de analise de variância (ANOVA). O resultado pode ser visto na tabela 14.

Tabela 14 - ANOVA para desempenho e OE

\begin{tabular}{|l|l|l|l|l|l|}
\hline Questão & GL & SQ & QM & F & Valor $\mathbf{p}$ \\
\hline $\begin{array}{l}\text { DRF 11- } \\
12\end{array}$ & 4 & 0,5 & 0,1 & 1,45 & 0,243 \\
\hline $\begin{array}{l}\text { DRF 12- } \\
13\end{array}$ & 4 & 1,0 & 0,2 & 1,22 & 0,323 \\
\hline $\begin{array}{l}\text { DRF 13- } \\
14\end{array}$ & 4 & 1,3 & 0,3 & 1,11 & 0,370 \\
\hline $\begin{array}{l}\text { DRT 11- } \\
12\end{array}$ & 4 & 0,3 & 0,1 & 2,70 & 0,500 \\
\hline $\begin{array}{l}\text { DRT 12- } \\
13\end{array}$ & 4 & 0,3 & 0,1 & 1,35 & 0,273 \\
\hline $\begin{array}{l}\text { DRT 13- } \\
14\end{array}$ & 4 & 0,3 & 0,1 & 1,44 & 0,244 \\
\hline
\end{tabular}

Para que a correlação entre as variáveis seja significativa o valor p deve ser menor que $5 \%$ ou menor que $10 \%$. Através dos resultados apresentados na tabela 14 pode ser visto que dentro da amostra estudada não houve correlação entre as covariáveis faturamento e rotatividade e a variável orientação estratégica, de tal forma que não é possível estabelecer uma relação com significância estatística entre desempenho organizacional e orientação estratégica.

\subsection{CONSIDERAÇÕES SOBRE O CAPÍTULO 4}

Inicialmente foi verificada se as características próprias das pequenas empresas indicadas na literatura estão presentes nas empresas estudadas e, posteriormente, se nessas empresas a relação entre desempenho organizacional e orientação estratégica é significativa. A primeira hipótese dessa pesquisa contemplava a seguinte afirmação "Pequenas empresa irão apresentar um comportamento distinto do observado nas grandes empresas no que concerne à relação entre orientação estratégica e desempenho organizacional". Com base nos resultados encontrados nesse estudo, pode-se concluir 
que a hipótese 1 não foi rejeitada, uma vez que os dirigentes concordam com as afirmações sobre as especificidades da pequena empresa apresentada pela literatura, de tal forma que nas empresas estudas as características próprias das pequenas empresas estavam presentes e influenciavam as atividades de gestão das mesmas. Conjuntamente com esse resultado há a verificação da não existência de correlação entre orientação estratégica e desempenho organizacional na amostra, resultado contrário ao encontrado em estudos com grandes empresas ((HAMBRICK, 1983; WRIGHT et al, 1995; GIMENEZ, 1999; COEURDEROY, 2001; DURAND; NOBLE; RAJIV; KUMAR, 2002; SLATER et al, 2006; ACQUAHH, 2007; ZHOU E LI, 2007), os quais mostram uma associação positiva entre essas variáveis. Sendo assim, há um comportamento distinto do observado nas grandes empresas no que concerne à relação entre orientação estratégica e desempenho organizacional nas pequenas empresas.

Em consequência dos resultados encontrados, pode-se dizer que a hipótese 2, que tratava da seguinte afirmação "Existe uma relação de melhor desempenho organizacional em pequenas empresas que adotam uma orientação prospectora em comparação com aquelas que adotam uma a orientação analista e defensora, nessa ordem" foi rejeitada, uma vez que os dados mostraram que não houve diferença significativa entre as medias de desempenho das empresas com orientações estratégicas distintas. 


\section{CONSIDERAÇÕES FINAIS}

Este capítulo tem por finalidade discutir como ocorreu o alcance dos objetivos desta pesquisa, apresentar as contribuições e limitações do estudo bem como relatar o aprendizado ocorrido e oferecer sugestões para pesquisas futuras.

\subsection{CONSIDERAÇÕES SOBRE OS OBJETIVOS}

Inicialmente em relação ao objetivo principal de "verificar a relação entre as orientações estratégicas de Miles e Snow (1978) com o desempenho organizacional nas pequenas empresas à luz de suas especificidades", pode-se dizer que este objetivo foi alcançado uma vez que foi mostrado não haver relação entre essas variáveis. Isso indica que dentro das pequenas empresas há outros fatores mais determinantes em relação ao desempenho organizacional do que a orientação estratégica.

Quanto ao primeiro objetivo específico de verificar qual é a orientação estratégica seguida por firmas que apresentam os melhores índices de desempenho organizacional, quando este é entendido em termos de aumento do faturamento, podese afirmar, com base nos resultados apresentados no capítulo anterior, que este objetivo foi igualmente alcançado, sendo que empresas que seguem uma orientação estratégica prospectora apresentam os melhores índices quando considerado o desempenho em termos de aumento do faturamento.

Em relação ao segundo objetivo específico, cujo propósito era verificar qual é a orientação estratégica seguida por firmas que apresentam os melhores índices de desempenho organizacional, quando este é entendido em termos de rotatividade, podese afirmar que este objetivo foi alcançado, de tal forma que quando considerado o desempenho em termos de rotatividade, as empresas que seguem uma orientação 
prospectora novamente serão as empresas que irão apresentar os melhores índices de desempenho, assim como quando considerado o desempenho em termos de faturamento.

Com relação ao terceiro objetivo específico que tinha como propósito verificar se as orientações estratégicas identificadas nas empresas que apresentam os melhores índices de faturamento e de rotatividade são as mesmas empresas ou distintas, pode-se afirmar que este objetivo, assim como demais, também foi alcançado, uma vez que foi identificado, a partir dos dois objetivos específicos anteriores, que as orientações estratégicas são as mesmas, ou seja, para ambos os casos o grupo de empresas classificado como prospectores apresentam os melhores índices de desempenho.

Considerando o quarto objetivo específico, o qual tinha por propósito verificar qual especificidade da pequena empresa estava mais evidente dentro da amostra estudada, ou seja, verificar qual ou quais especificidades apresentaram as maiores médias do questionário de especificidades. Após a análise dos dados, pode-se dizer que este objetivo foi concluído, uma vez que foi identificada a especificidade de número 14, que se tratava da seguinte afirmação "O crescimento financeiro da empresa não é a motivação principal para ter meu próprio negócio”, como a que apresenta a maior média dentre todas as afirmações. Esse dado é importante na medida em que indica que a maioria dos dirigentes das pequenas empresas não é motivada por fatores financeiros no momento de gerenciar seu negocio, mostrando que fatores não financeiros são mais importantes para os mesmos.

Finalmente, em relação ao último objetivo específico que tinha por objetivo verificar qual especificidade da pequena empresa estava menos evidente dentro da amostra estudada, pode-se afirmar que ele foi concluído, uma vez que foi identificada a especificidade de número 12 como a que apresentou a menor média dentre as demais 
questões. Tal questão se referia a seguinte afirmação “Os meus fornecedores e clientes se encontram, em sua maioria, na mesma região geográfica da empresa”, o que demonstra que as empresas estudadas na amostra, de uma forma geral, discordam dessa especificidade, uma vêz que os resultados indicam uma mudança no ambiente econômico em que as pequenas empresas estão inseridas, de tal forma que gradualmente elas vão avançando para mercados geograficamente mais distantes de sua localização, bem como buscando parceiros cada vez mais afastados de sua cidade de origem. Um motivo para esta situação é o aumento do uso da internet para fins comercias, o que diminui as barreiras de distâncias entre os agentes, como também o desenvolvimento do setor de logística vivenciado nos últimos anos, o que possibilitou o escoamento de produtos por todo o território nacional.

Sendo assim, ao final desse trabalho pode-se afirmar que tanto o objetivo geral quanto os objetivos específicos foram alcançados, pois ambos foram verificados e validados empiricamente.

\subsection{CONTRIBUIÇÃO DA PESQUISA}

A principal contribuição do trabalho foi mostrar que em pequenas empresas a orientação estratégica seguida por uma firma não tem relação direta com o desempenho organizacional, ao contrário dos estudos realizados sistematicamente ao longo do tempo com grandes empresas que mostraram a existência dessa relação. Este estudo também mostrou que apesar de não haver significância estatística que suporte essa relação, há indicadores de que a orientação estratégica prospectora tenha um maior efeito no desempenho organizacional quando comparada as demais orientações estratégicas.

Em relação às especificidades da pequena empresa, esse trabalho também 
apresentou algumas contribuições referentes ao comportamento dos dirigentes, mostrando que os homens, demonstrando que há uma motivação não financeira para ter e gerenciar o próprio negócio muito maior entre dirigentes do sexo masculino do que do sexo feminino. Outras contribuições se referem à verificação de que empresas administradas por dirigentes que possuem apenas o ensino fundamental guardam características próprias mais próximas ao que é mencionado pela literatura em relação a outras firmas administradas por dirigentes com ensino médio, superior ou pósgraduação e também que dirigentes que possuem apenas o ensino médio desempenham menos tarefas administrativas quando comparada aos dirigentes com ensino superior e pós-graduação, demonstrando que dirigentes com menos grau de instrução necessita que outras pessoas executem tarefas que ele sozinho, pelo seu nível de escolaridade, não seria capaz.

\subsection{LIMITES DA PESQUISA}

A principal limitação deste estudo se refere ao número de respondentes da pesquisa. Ainda que em termos relativos o estudo esteja com um número de participantes da amostra em torno $21 \%$, número acima da média de empresas que participam das pesquisas acadêmicas do tipo survey (GIBBONS; O'CONNOR, 2005), em termos absolutos a quantidade de respondentes é baixa quando comparada a estudos realizados com pequenas empresas no exterior, onde o número da amostra é em torno de 300 respondentes (ARAGON-SANCHEZ; SANCHEZ-MARIN, 2005). Acredita-se que com um número maior de participantes talvez pudesse ser encontradas mais relações estatísticas significantes. 


\subsection{O TREINAMENTO A NIVEL DE POS GRADUAÇÃO E A}

\section{APRENDIZAGEM EM PESUISA}

Ao final do estudo, o pesquisador considera que teve todo o preparo necessário para conduzir inicialmente a revisão sistemática da literatura, de tal forma que foi possível selecionar os artigos mais importantes dentro da área, bem como interpretá-los e partir disto realizar a formulação dos construtos de pesquisa que guiaram todo o trabalho empírico através da aplicação dos questionários.

Em relação às técnicas de análise de dados, utilizando estatística descritiva, bem como análise de variância e os testes de Fischer, pode afirmar que elas foram fundamentais para que a análise dos dados fosse realizada com sucesso.

Ao final do processo o maior aprendizado para o pesquisador foram os conhecimentos obtidos através do contato direto com a realidade vivida pelas pequenas empresas e seus dirigentes e o confronto da mesma com a teoria aprendida na literatura sobre o tema. Portanto, há o reconhecimento por parte do pesquisador de que a vivência dentro das empresas durante o trabalho de campo torna-se um fator de valiosa influencia para o aprendizado e de grande importância para a condução da pesquisa.

\subsection{SUGESTÕES DE PESQUISAS FUTURAS}

Após a conclusão da pesquisa, alguns pontos são sugeridos para trabalhos futuros.

Devido ao fato de que a principal limitação da pesquisa foi um número absoluto baixo de empresas, quando comparado com outras pesquisas realizadas com pequenas empresas, propõe-se que seja considerado no planejamento um número maior de empresas a serem contatadas, ou seja, tentar aumentar a população do estudo, bem como considerar igualmente um aumento do tempo destinado ao contato 
telefônico com estas empresas, de forma a tentar conseguir uma taxa maior de respondentes para aumentar a amostra.

Ainda que a hipótese 1 tenha sido não rejeitada, o que significa que com os dados obtidos ela não pode ser considerada falsa, com um número maior de empresas participantes talvez em uma segunda análise, os resultados possam ser diferentes e igualmente importantes para a construção de uma teoria organizacional para pequenas empresas.

De forma análoga, com um número maior de participantes é possível que a hipótese 2, que foi rejeitada no momento, possa apresentar um comportamento distinto e, também, igualmente importante para a verificação da influencia da orientação estratégica no desempenho organizacional.

Por fim, como última sugestão, é importante que estudos futuros analisem a relação conjunta da orientação estratégica com outras variáveis no desempenho organizacional das pequenas empresas, de tal forma que não apenas a orientação estratégica seja considerada a variável independente, mas também outras igualmente importantes evidenciadas pela literatura de estratégia. 


\section{REFERÊNCIAS}

ACQUAAH M. Managerial social capital, strategic orientation, and organizational performance in an emerging economy. Strategic Management Journal, vol 28(12), p. 1235-1255, 2007.

AMBOISE, G.; MULDOWNEY, M. Management theory for small business: attempts and requirements. Academy of Management Review, vol. 13, n.2, p. 226-240, 1988.

ANDREWS, K. The Concept of Corporate Strategy. Homewood: Irwin, 1971.

ALDAY, H.C.E. O Planejamento Estratégico dentro do Conceito de Administração Estratégica. Revista FAE, v.3, n.2, p.9-16, 2000.

ARAGON-SACHEZ, A.; SANCHEZ-MARIN, G. Strategic Orientation, Management Characteristics, and Performance: A Study of Spanish Smes. Journal of Small Business Management, n.43, p. 287-308, 2005.

ARAÚJO, C. A. Bibliometria: evolução histórica e questões atuais. Revista Em Questão, v.12, n.1, p.11-32, 2006.

BERTHON, P; HULBERT, J. M; PITT, L. F. To serve or create? Strategic orientation towards customers and innovation. California Managerial Review, vol. 42, p. 37- 58, 1999.

BAKER, W. E.; SINKULA, J. M. The synergistic effect of market orientation and learning orientation on organizational performance. Journal of the Academy of Marketing Science. N. 27, p. 411-427, 1999.

BOGDAN, R.; BIKLEN, S. - Características da investigação qualitativa. In: Investigação qualitativa em educação: uma introdução à teoria e aos métodos. Porto, Porto Editora, 1994.

BORTOLI NETO, A. A virada dos pequenos. Revista PEGN, n. 100, p. 37, 1997.

BOX, G. E. P., HUNTER, J. S., Statistics for Experimenters: Design, Innovation, and Discovery, $2^{\circ}$ ed., New York, Wiley, 2005.

BROUTHERS, K; ANDRIESSEN, F; NICOLAES. Driving Blind: Strategic DecisionMaking in Small Companies, Long Range Planning, vol. 31, p. 130-138, 1998.

BURRELL, G.; MORGAN, G. Sociological paradigms and organizational analyses. London: Heinemann, 1979.

CABRAL, A. C. A. A evolução da estratégia: em busca de um enfoque realista. In: XXIIENANPAD, 22º , Anais. Foz do Iguaçu: ANPAD set. 1998.

CALORI, R.; LUBATKIN, M.; VERY, P. Control mechanisms in cross-border acquisitions: An international comparison. Organization Studies, n 15 pp. 361379, 1994.

CARLAND, J. W; HOY, F; BOULTON, W. R; CARLAND, J. C. Differentiating entrepreneurs from small business owners. Academy of Management Review, vol.9 p. 354-359, 1984.

CHAUI, M. Convite à filosofia. São Paulo: Editora Ática, 2002.

CHO, H. J.; PUCIK, V. Relationship between innovativeness, quality, growth, profitability, and market value. Strategic Management Journal, n.26, p. 555$575,2005$.

CHUNG, M. L. The Emerging Strategic Balance in Northeast Asia. Seoul: Research Center for Peaceful Unification, 1989

CONANT, J. S.; MOKWA, M.; VARADARJAN, P. R. Strategic Types, Distinctive Marketing Competencies and Organizational Performance: A Multiple-MeasuresBased Study. Strategic Management Journal, n.11, p. 365-383, 1990. 
COOPER, A. Strategic management: new ventures and small businesses. Long Range Planning, vol. 14, p.39-45, 1981.

COOPER, H. Synthesizing Research. Thousand Oaks: Sage, 1998.

COUTINHO, L.; FERRAZ, J. C. Estudo da competitividade da indústria brasileira. 4a ed. Campinas: Papirus Editora, 2002.

DANDRIDGE, T.C. Children are not little grown-ups: small business needs its own organizational theory. Journal of Small Business Management, p.53, 1979.

DAY, G. S. The capabilities of market-driven organizations. Journal of Marketing, vol. 58, p.31-44, 1994.

DEMO, P. Metodologia científica em ciências sociais. São Paulo: Atlas, 1981.

DESS, G. G.; ROBINSON, R. B. Measuring organizational performance in the absence of objective measures: the case of privately- held firm and conglomerate business unit. Strategic Management Journal, n.5, p. 265-273, 1984.

DU MONT, R. R. Ethics in librarianship: a management model. Library Trends, v. 40, n. 2, p. 201-215, 1991.

DURAND, R; COEURDEROY, R. Age, order of entry, strategic orientation, and organizational performance, Journal of Business Venturing, 16 (5), p. 471-494, 2001

DRU, J. M., LEMBERG, R. Drisrupt your business. Journal of Business Strategy,

vol. 18, no3, p. 24-30, 1997.

DRUCKER, P. F. A prática de administração de empresas. São Paulo: Pioneira, 1981.

ELBANNA, S.; CHILD, J. The influence of decision, environmental and firm characteristics on the rationality of strategic decision-making. Journal of Management Studies, n.44, p. 122-146, 2007.

FONSECA, J. J. S. Metodologia da pesquisa científica. Fortaleza: UEC, 2002.

FORD, J. D.; SCHELlENBERG, D. A. Conceptual issues of linkage in the assessment of organizational performance. Academy of Management Review, January, p. 49-58, 1982.

FREITAS, H. M. R. Análise de dados qualitativos: aplicação e tendências mundiais em sistemas de informação. Revista de Administração - RAUSP, v.35, n.4, p.84-102, 2000.

FURGATE, B. S.; STANK, P.; MENTZER, J. T. Linking improved knowledge management to operational and organizational performance. Journal of Operation Management, n.27, p. 247-264, 2009.

GAO, G. Y; ZHOU, K. Z; YIM, C. K. On what should firms focus in transitional economies? A study of the contingent value of strategic orientations in China. International Journal of Research in Marketing, vol. 24, p. 3-15, 2007.

GATIGNON, H.; XUEREB, J. M. Strategic orientation of the firm and new product performance. Journal of Marketing Research, n. 34, p. 77-90, 1997.

GERINGER, J. M.; HEBERT, L. Measuring Performance of International Joint Ventures. Journal of International Business Studies, n. 22, p. 249-263, 1991.

GIMENEZ, F. A. P.; PELISSON, C.; HAYASHI JR., P.; KRÜGER, E. Estratégia em pequenas empresas: uma aplicação do modelo de Miles e Snow. Revista de Administração Contemporânea, v. 3, n. 2, p. 53-74, 1999.

GINSBERG, A; VENKATRAMAN, N. Contingency perspectives of organizational strategy: a critical review of the empirical research. Academy Managerial Review, vol.10, p.421 - 4341985.

HAGUENAUER, L., FERRAZ, J. C., KUPFER, D. S. Competição e 
internacionalização na indústria brasileira. In: BAUMANN, R. (Org.). $O$ Brasil e a Economia Global. Rio de Janeiro: Campus, 1996.

HAMBRICK, D. C. Some tests of the effectiveness and functional attributes of Miles and Snow's strategic types. Academy of Management Journal, v. 26, n. 1, p. 05-26, 1983.

HAMBRICK, D. C; MASON, P. Upper Echelons: The Organization as a Reflection of its Top Managers, The Academy of Management Review, 9: 193-206, 1993.

HAMBRICK, DC; GELETKANYCZ, MA; FREDRICKSON, JW. Top Executive Commitment to the Status-Quo - Some Tests of its Determinants. Strategic Management Journal, n.14, p. 401-418, 1993.

HITT, M. A.; MIDDELEMIST R. D. A methodology to develop the criteria and criteria weightings for assessing subunit effectiveness in organizations, Academy of Management Journal, 22, pp. 356-374, 1979

HITT, M. A.; TYLER, B. B. Strategic decisions models: Integrating different perspectives. Strategic Management Journal. n.12, p. 327-351, 1991.

HITT, M. A; DACIN, M.T; TYLER, B.B.; PARK, D. Understand the differences in Korean and U.S. executive's strategic orientations. Strategic Management Journal, n. 18:2, p. 159-167, 1997.

HITT, M A.; IRELAND, R. S; HOSKISSON, R. Administração Estratégica. 2. ed. São Paulo: Cengage Learning, 2008.

HOFER, C. W.; SCHENDEL, D. Strategy Formulation: Analytic Concepts. St. Paul: West, 1978.

HOMBORG, C.; BUCERIUS, M. A marketing perspective on mergers and acquisitions: How marketing integration affects postmerger performance. Journal of Marketing, n.69, p. 95-113, 2005.

HONG, S.; KATERATTANAKUL, P.; LEE, S. M. Impact of data warehousing on organizational performance of retailing firms. International Journal of Information Technology \& Decision Making.v. 3, n. 1, p. 61-79, 2004.

HULT, G. T; KETCHEN, D. Does market orientation matter? A test of the relationship between positional advantage and performance. Strategic Management Journal, vol. 22 p. 899-906, 2001.

HURLEY, R; HULT, T. Innovation, market orientation and organizational learning: an integration and empirical examination. Journal of Marketing, vol. 62, p. 42-54, 1998.

INVESTE SÃO PAULO. Agencia Paulista de Promoção de Investimento e Competitividade. Bens de Capital, 2012. Disponível em $<$ http://www.dc.itamaraty.gov.br/imagens-e-textos/Industria07MaquinasEquipamentos.pdf > Acesso em: 8 de Julho de 2014.

JULIEN, P. A. Small business as a research subject: some reflections on knowledge of small business and its effects on economic theory. Small Business Economics, vol.5 pp. 157-166, 1993.

JULIEN, P. A. Lês PME bilan et perspectives. Quebec: econômica, 1997.

KAPLAN, R. S.; NORTON, D. P. A estratégia em ação. Balanced Scorecard. Rio de Janeiro: Editora Campus, 1997.

KAYNAK, H. The relationship between total quality management practices and their effects on firm performance. Journal of Operation Management, n.21, p. 405-435, 2003.

KAYNAK, H.; HARTLER, J. L. A replication and extension of quality management into the supply chain. Journal of Operation Management, n.26, p. 
468-489, 2008.

KOHLI, A. K.; JAWORSKI, B. J. Market orientation: the construct, research propositions, and managerial implications. Journal of Marketing, v.54, n.2, p.1$18,1990$.

KREMER. J. M. Ética em pesquisa: um tema para reflexão. Revista da Escola de Biblioteconomia da UFMG, Belo Horizonte, v. 11, n. 12, p. 158-179, 1982.

LANG, L.E.; OFEK, E.; STULTZ, R. Leverage, investment, and firm growth. Journal of Financial Economics, Vol. 40, pp. 3-29, 1996.

LAVERTY, S. M. Hermeneutic phenomenology and phenomenology: A comparison of historical and methodological considerations. International Journal of Qualitative Methods, v.2, n. 3, p. 1-29, 2003.

LEONE, N.M.C.P.G. A dimensão física das pequenas e médias empresas: a procura de um critério homogeneizador. Revista de Administração de Empresas. vol. 31, n.2, p. 53-59, 1991.

LEONE, N. M. C. P. G. As especificidades das pequenas e médias empresas. Revista de Administração, v.34, n.2, p.91-94, abril/junho, 1999.

LI, J. J. The formation of Managerial networks of foreign firms in China: The effects of strategic orientations. Asia Pacific Journal of Management, vol. 22, p.423443, 2005.

LUBATIKIN, M. H.; SIMSEK, Z. LING, Y. Ambidexterity and performance in smallto medium-sized firms: The pivotal role of top management team behavioral integration. Journal of Management, n.32, p. 646-672, 2006.

LUMPKIN, G. T.; DESS, G. G. Linking two dimensions of entrepreneurial orientation to firm performance: The moderating role of environment and industry life cycle. Journal of Business Venturing, n.16, p. 429-441, 2001.

LUTHANS, F.; YOUSSEF, C. A. Emerging positive organizational behavior. Journal of Management, n.33, p. 321-349, 2007.

LYLES, M. A.; SALK, J. E. Knowledge acquisition from foreign parents in international joint ventures: An empirical examination in the Hungarian context. Journal of International Business Studies, n.27,p. 877-903, 1996.

MACEDO, A.L.O.; CAMPOS, R.R. Diagnóstico do complexo metal-mecânico: Brasil e Santa Catarina. Revista de Tecnologia e Ambiente, v.7, n.2 , p. 9-37, 2001.

MATSUNO K, MENTZER J. T, OZSOMER, A. The effects of entrepreneurial proclivity and market orientation on business performance. Journal of Marketing, vol. 66, p. 18-32, 2002.

MEIRELLES, A.M.; GONÇALVES, C.A.; BERNARDES, P. Strategy and Organizational Theory: What the Latter tells about the Former. In: BALAS, 2001, 2001, San Diego, Annals, 2001.

MILES, R. E.; SNOW, C. C. Organizational Strategy, Structure, and Process. NewYork: West, 1978.

MILLER, D; FRIESEN, P. H. Strategy-Making and Environment: The Third Link. Strategic Management Journal, vol. 4(3) p. 221-235, 1983

MINTZBERG, H. Patterns in strategy formation. Management Science, v.29, n. 9, p.934-48, 1978.

MINTZBERG, H. Criando organizações eficazes - estruturas em cinco configurações. São Paulo: Atlas, 1995.

MINTZBERG, H. Estrutura e Dinâmica das Organizações. Lisboa: Publicações Dom Quixote, 1995.

MINTZBERG, H; AHLSTRAND, B; LAMPEL, J. Safari de Estratégia: um roteiro pela selva do planejamento estratégico. Porto Alegre: Bookmam, 2000. 
MOIOLI, B. C.; OLIVEIRA, J.; DELGADO, M. J.; ESCRIVÃO FILHO, E. Planejamento estratégico e operacional na pequena empresa: um estudo sobre sua influência no desempenho dos empreendimentos do setor de tecnologia convencional (metal-mecânico) de São Carlos - SP. In.: XXII Reunião Anual da Rede PYMES Mercosul e $5^{\circ}$ Conferencia de Investigação em Entreprenurship na América Latina - CIELA. Campinas. Anais. Campinas: 2007.

MORGAN, R.E; STRONG, C. A. Business Performance and Dimensions of Strategic Orientation. Journal of Business Research, vol.56, p.163-176, 2003.

NARVER, J C.; SLATER, S F. The effect of a market orientation on business profitability. Journal of Marketing, v.54, n.4, p.20-35, 1990.

NOBLE, C. H, SINHA, R.K; Kumar, A. Market orientation and alternative strategic orientations: A longitudinal assessment of performance implications. Journal of Marketing, vol 66, p.25-39, 2002.

PAULA, A. P. P.; MARANHÃO, C. M. S. A.; BARRETO, R. O.; KLECHEN, C. F. A tradição e a autonomia dos Estudos Organizacionais Críticos no Brasil. Revista de Administração de Empresas (RAE), v. 50, n. 1, 2010.

PENG, M.W. Institutional transitions and strategic choices. Academy of Management Review, vol. 28, p.275-296, 2003.

PETERSON, R. A.; ALBAUM, G.; KOZMETSKY, G. The public's definition of small business. Journal of Small Business Management, vol. 24 (3), 1986.

PORTER, M. E.Competitive Strategy: Techniques for Analyzing Industries and Competitors. New York: Free Press, 1980.

RAJAGOPALAN, N. FINKELSTEIN, S. Effects of Strategic Orientation and Environmental Change of Senior Management Reward Systems. Strategic Management Journal; vol.13, p.127-142, 1992.

RAJAGOPALAN, N. Strategic orientations, incentive plan adoption, and firm performance: evidence from the electric utility industry. Strategic Management Journal, vol.18, p.761-786, 1997.

RAUCH, A.; WIKLUND, J.; LUMPKIN, G. T.; FRESE, M. Entrepreneurial orientation and business performance: an assessment of past research and suggestions for the future. Entrepreneurship Theory and Practice, vol. 34, p.761-787, 2009

RICHARD, P. J.; DEVINNEY, T. M.; YIP, G. S.; JOHNSON, G. (2009). Measuring organizational performance: towards methodological best practices. Journal of Management, vol 35(3), p. 718- 804, 2009.

ROSENBUSCH, N.; BRINCKMAN, J.; BAUSCH, A. Is innovation always beneficial? A meta-analysis of the relationship between innovation and performance in SMEs. Journal of Business Venturing, n.26, p. 441-457, 2011.

ROSENTHAL, David. Aprendizado Competitivo e Oportunidades da Indústria Metal-Mecânica no Nordeste, Fortaleza: Banco do Nordeste, 1999.

SEBRAE - Serviço Brasileiro de Apoio às Micro e Pequenas Empresas. Anuário do trabalho na micro e pequena empresa, 2011.

SEBRAE - SP - Serviço Brasileiro de Apoio às Micro e Pequenas Empresas de São Paulo. Estudo da mortalidade das empresas paulistas, 1999.

SIMONS, R. Strategic orientation and top management attention to control systems. Strategic Management Journal, vol. 12, p.49 -62, 1991.

SLATER, S. F.; NARVER, J. C. Product-market strategy and performance: an analysis of the Miles and Snow strategy types. European Journal of Marketing, vol.27, p. 33-35, 1993.

SLATER, E.M; OLSON, G.T.M; HULT.The moderating influence of strategic 
orientation on the strategy formation capability- performance relationship. Strategic Management Journal,vol 27, pp. 1221-1231 2006.

STOREY, D.J. Understanding the small business sector, London: International Thomson Business Press, 1994.

TORRES, O; JULIEN, P. A. Specificity and denaturing of small business. International Small Business Journal vol. 23(4) p.355-377, 2005.

TRIVIÑOS, A. N. S. Introdução à Pesquisa em Ciências Sociais: a pesquisa qualitativa em educação. São Paulo: Editora Atlas, 1992

TSU, S. A Arte da Guerra, São Paulo: Madras, 2007.

TURATO E. R. Métodos qualitativos e quantitativos na área da saúde: definições, diferenças e seus objetos de pesquisa. Revista de Saúde Pública, Jun. 39(3) p.507-14, 2005.

UPRICHARD, E.; BURROWS, R.; BYRNE, D. SPSS as an 'Inscription Device': From causality to description? Sociological Review, vol.56(4) p.606 - 622, 2008.

VARADARAJAN. P. R; CLARK, T. Delineating the scope of corporate, business, and marketing strategy. Journal of Business Research vol.31, p. 93-105, 1994.

VELIYATH, R.; SHORTELL, S. M. Strategic Orientations, Strategic Planning System Characteristics and Performance. Journal of Management Studies, n.30, p. 359-381, 1993.

VENKATRAMAN, N. Strategic orientation of business enterprises: the construct and its measurements. Ph.D. dissertation. University of Pittsburgh. Pittsburgh, 1985.

VIEIRA, S. Como Elaborar Questionários. São Paulo: Atlas, 2009.

VOSS, G.; VOSS, Z. Strategic orientation and firm performance in an artistic environment. Journal of Marketing, n. 64, p. 67 - 83, 2000.

WIKLUND, J. The sustainability of the entrepreneurial orientation-performance relationship. Entrepreneurship Theory and Practice, vol. 24, p. 37-48, 1999.

WRIGHT P; KROLL M; PRAY B; LADO A. Strategic orientations, competitive advantage, and business performance. $J$ Business Research, vol. 33, p.143- 51, 1995.

WU, W. P. Dimensions of social capital and firm competitiveness improvement: The mediating role of information sharing. Journal of Management Studies, n.45, p. 122-146, 2008.

ZAHRA, S. A conceptual model of entrepreneurship as firm behavior: A critique and extension. Entrepreneurship Theory and Practice, vol.16, p.5-21, 1993.

ZHOU, K.Z; YIM, C.K; TSE, D. K. The Effects of Strategic Orientations on Technology- and Market-based Breakthrough Innovations. Journal of Marketing, vol 69(2), p.42-60, 2005

ZHOU, K. Z; LI, C. B. How does strategic orientation matter in Chinese firms? Asia Pacific Journal of Management, vol 24(4), p. 447-466, 2007. 


\section{APÊNDICE A: DESCRIÇÃO DA BUSCA SISTEMÁTICA}

Para a busca sistemática, realizada com o objetivo de revisar o estado da arte sobre o tema de orientação estratégica, foram estabelecidas, com base nas leituras previamente realizadas sobre o tema, algumas palavras-chave de interesse. Essas palavras foram posteriormente refinadas em encontros com o orientador e o grupo de pesquisa, de forma que ao final foi instituído um grupo de palavras-chave contendo palavras relacionadas ao tema "orientação estratégica", com as seguintes palavras- chave: strategic orientation*, generic strateg* e strategic type*. As palavras desse grupo foram buscadas com o asterisco de forma a contemplar tanto resultados no singular como no plural, ampliando dessa maneira a base de dados encontrada.

As bases de dados escolhidas para a busca sistemática foram: ISI Web of knowledge, Scopus, Scielo Brasil e Portugal. Os artigos encontrados foram selecionados obedecendo algumas regras instituídas, tais quais número mínimo de citação e ano de publicação, de forma a manter apenas artigos tidos como referência dentro da área. Nessa fase os seguintes critérios foram adotados: para artigos publicados em 2005 no mínimo 25 citações, para artigos publicados em 2006 no mínimo 20 citações, para artigos publicados em 2007 no mínimo 15 citações, para artigos publicados em 2008 no mínimo 10 citações, para artigos publicados em 2009 no mínimo 8 citações, para artigos publicados em 2010 no mínimo 6 citações, para artigos publicados em 2011 no mínimo 4 citações e para artigos publicados em 2012 no mínimo 2 citações. Essa postura é coerente com a relação número de citações/ano de publicação, uma vez que artigos mais recentes, por apresentarem um tempo menor de exposição, estão sujeitos a uma quantidade menor de citações, que irá evoluindo com o passar dos anos.

A partir dessa lista, foi realizada a leitura dos textos o que permitiu o 
agrupamento dos artigos por afinidade em conjuntos. Como os artigos são recentes, esses conjuntos foram considerados tendências de abordagem do tema. 


\section{APÊNDICE B: PROTOCOLO DE PESQUISA}

Objetivo geral: Identificar quais os fatores contingenciais da pequena empresa que influenciam na relação entre orientação estratégica e desempenho organizacional.

\begin{tabular}{|c|c|}
\hline $\begin{array}{l}\text { VARIÁVEIS DE } \\
\text { PESQUISA }\end{array}$ & CONSTRUTOS \\
\hline $\begin{array}{l}\text { Orientação } \\
\text { Estratégica: } \\
\text { Prospectores, } \\
\text { tecnólogos e } \\
\text { empreendedore } \\
\text { s }\end{array}$ & 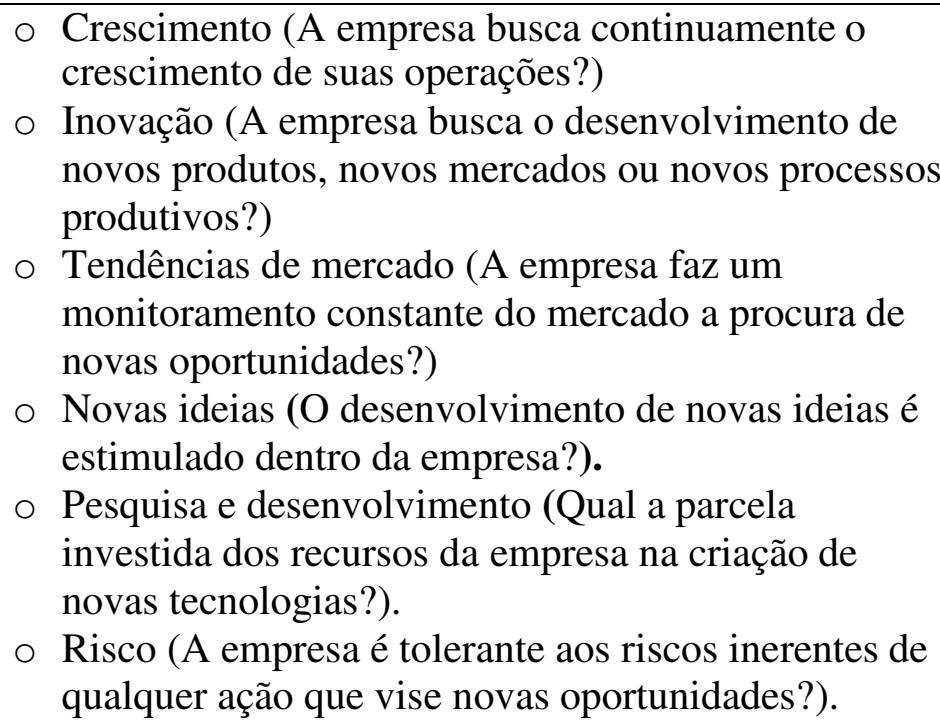 \\
\hline $\begin{array}{l}\text { Orientação } \\
\text { estratégica: Analistas } \\
\text { e orientados ao } \\
\text { mercado }\end{array}$ & $\begin{array}{l}\text { Eficiência (A empresa busca continuamente a } \\
\text { melhor forma possível de utilizar seus recursos, mas } \\
\text { sem perder de vista oportunidades de novos } \\
\text { negócios?). } \\
\text { Consumidores (Os consumidores são considerados o } \\
\text { bem mais valioso da empresa?). } \\
\text { Monitoramento dos clientes (A empresa busca } \\
\text { compreender quais as principais necessidades dos } \\
\text { clientes?) } \\
\text { Monitoramento dos concorrentes (Há por parte da } \\
\text { empresa um monitoramento das ações dos } \\
\text { concorrentes e posteriormente uma resposta a elas?). }\end{array}$ \\
\hline
\end{tabular}




\begin{tabular}{|l|c|}
\hline $\begin{array}{l}\text { Orientação } \\
\text { estratégica: } \\
\text { Defensores, } \\
\text { orientados para } \\
\text { produção e orientados } \\
\text { para vendas }\end{array}$ & $\begin{array}{l}\text { ○ Defesa da posição de mercado (A empresa busca } \\
\text { aperfeiçoar o uso dos seus recursos com o objetivo } \\
\text { de garantir permanência no mercado em que atua?) }\end{array}$ \\
$\begin{array}{l}\text { O Custos (Há por parte da empresa a tentativa } \\
\text { permanente de redução dos seus custos?) }\end{array}$ \\
$\begin{array}{l}\text { O Rede de distribuição (A empresa tem uma boa rede } \\
\text { de distribuição de seus produtos?) }\end{array}$ \\
$\begin{array}{l}\text { Retorno imediato (A empresa prefere um retorno } \\
\text { financeiro imediato?) }\end{array}$ \\
\hline $\begin{array}{l}\text { Desempenho } \\
\text { organizacional: } \\
\text { Aumento da Receita }\end{array}$ & $\begin{array}{c}\text { o O aumento da receita em um determinado período } \\
\text { de tempo é o melhor indicador de desempenho? }\end{array}$ \\
\hline
\end{tabular}

\begin{tabular}{|c|c|}
\hline $\begin{array}{l}\text { Desempenho } \\
\text { organizacional: } \\
\text { Retorno sobre o } \\
\text { investimento }\end{array}$ & $\begin{array}{l}\text { o Verificar quanto a mais ganhou com base no } \\
\text { dinheiro investido é o melhor indicador de } \\
\text { desempenho? }\end{array}$ \\
\hline $\begin{array}{l}\text { Especificidades da } \\
\text { pequena empresa: } \\
\text { dimensão organização }\end{array}$ & $\begin{array}{l}\text { Estratégia (A estratégia é elaborada de forma } \\
\text { intuitiva, sem uma estruturação pré-definida?) } \\
\circ \text { Estratégia (A estratégia é elaborada pelo dirigente da } \\
\text { empresa?) } \\
\circ \text { Visão global da empresa (Os funcionários } \\
\text { compreendem todas as etapas do processo } \\
\text { produtivo?) } \\
\text { Ausência de divisões (Há departamentos na } \\
\text { empresa?) } \\
\circ \text { Comunicação informal (A comunicação com os } \\
\text { funcionários se dá de maneira formal?) } \\
\circ \text { Avaliação de desempenho informal (Há avaliação } \\
\text { formal do desempenho dos funcionários?) } \\
\circ \text { Pouca burocracia (Existem processos formais na } \\
\text { empresa?) } \\
\circ \text { Baixa tecnologia (O processo produtivo requer alta } \\
\text { tecnologia?) } \\
\circ \text { Baixa qualificação (É exigido dos funcionários alta } \\
\text { qualificação profissional?) } \\
\circ \text { Flexibilidade das tarefas (Todos os funcionários são } \\
\text { capazes de realizar qualquer atividade operacional?) } \\
\circ \text { Recursos (Há escassez de recursos disponíveis para } \\
\text { a empresa?) }\end{array}$ \\
\hline
\end{tabular}




\begin{tabular}{|c|c|}
\hline $\begin{array}{l}\text { Especificidades da } \\
\text { pequena empresa: } \\
\text { dimensão dirigente }\end{array}$ & $\begin{array}{l}\text { Dirigente como figura principal (O dirigente é o } \\
\text { principal responsável pelas decisões } \\
\text { administrativas?) } \\
\text { O Forte influencia (O dirigente exerce alta influencia } \\
\text { sobre a empresa?) } \\
\text { Forte autoridade (O dirigente possui forte autoridade } \\
\text { nas atividade da empresa?) } \\
\text { Junção dos patrimônios (O patrimônio do dirigente } \\
\text { muitas vezes é utilizado nas atividades da empresa?) } \\
\text { Objetivos pessoal e da empresa similares (Os } \\
\text { objetivos pessoais do dirigente são refletidos nos } \\
\text { objetivos da empresa? }\end{array}$ \\
\hline $\begin{array}{l}\text { Especificidades da } \\
\text { pequena empresa: } \\
\text { dimensão ambiente }\end{array}$ & $\begin{array}{l}\text { Comunicação direta com os fornecedores e clientes } \\
\text { (Há uma comunicação direta do dirigente com seus } \\
\text { fornecedores e consumidores?) } \\
\text { O Comunicação informal com fornecedores e clientes } \\
\text { (O contato com os clientes e fornecedores é } \\
\text { realizado de maneira informal?) } \\
\text { O Proximidade com fornecedores e clientes (Os } \\
\text { consumidores e fornecedores se encontram na } \\
\text { mesma cidade ou região da empresa?) }\end{array}$ \\
\hline
\end{tabular}

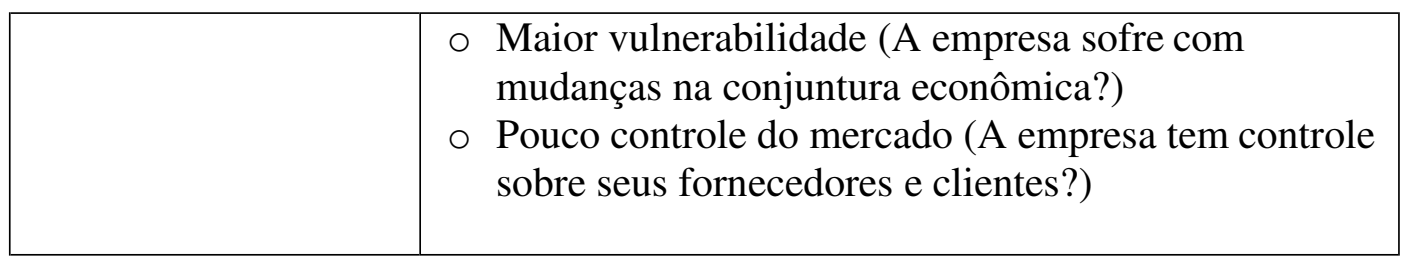




\section{APENDICE C - QUESTIONÁRIO SOBRE ESPECIFICIDADES}

\section{Dados sobre as especificidades da pequena empresa}

Pequenas empresas são caracterizadas por apresentarem particularidades que as diferem das grandes organizações. Assinale em que medida você concorda com as afirmações.

Legenda: 1) Discordo totalmente 2) Discordo parcialmente 3) Indiferente 4) Concordo parcialmente

5) Concordo totalmente

\begin{tabular}{|c|c|c|c|c|c|c|}
\hline 01 & $\begin{array}{l}\text { A visão sobre onde minha empresa deve estar no longo prazo é realizada } \\
\text { com base na minha experiência e de maneira informal (não segue uma } \\
\text { metodologia pré-definida) }\end{array}$ & 1 & 2 & 3 & & 5 \\
\hline 02 & $\begin{array}{l}\text { Os funcionários da minha empresa estão aptos para compreender todas as } \\
\text { etapas do processo produtivo. }\end{array}$ & 1 & 2 & 3 & & 5 \\
\hline 03 & $\begin{array}{l}\text { Há pouca, ou nenhuma, divisão em departamentos (marketing, finanças, } \\
\text { recursos humanos, etc..) na minha empresa. }\end{array}$ & 1 & 2 & 3 & & 5 \\
\hline 04 & $\begin{array}{l}\text { A comunicação com os funcionários é realizada pessoalmente e com pouco, } \\
\text { ou nenhum, uso de instrumentos formais, tais quais: memorando, } \\
\text { comunicação interna, mensagens escritas ou outro instrumento. }\end{array}$ & 1 & 2 & 3 & & 5 \\
\hline 05 & $\begin{array}{l}\text { A maioria dos funcionários da empresa possui uma formação sólida em } \\
\text { cursos técnicos, de graduação, especialização em sua área de atuação da } \\
\text { empresa. }\end{array}$ & 1 & 2 & 3 & & 5 \\
\hline 06 & $\begin{array}{l}\text { Eu, como dirigente da empresa, sou responsável por todas as tarefas } \\
\text { administrativas (gestão financeira, de marketing, de pessoas entre outras). }\end{array}$ & 1 & 2 & 3 & & 5 \\
\hline 07 & $\begin{array}{l}\text { Eu, como dirigente da empresa exerço uma grande influencia nas atividades } \\
\text { da empresa (supervisiono pessoalmente todas as atividades da empresa). }\end{array}$ & 1 & 2 & 3 & & 5 \\
\hline 08 & $\begin{array}{l}\text { Utilizo meu patrimônio pessoal nas atividades da empresa e/ou o } \\
\text { patrimônio da minha empresa para arcar com despesas pessoais. }\end{array}$ & 1 & 2 & 3 & & 5 \\
\hline 09 & $\begin{array}{l}\text { Minhas motivações, valores e objetivos pessoais estão refletidos nas } \\
\text { atividades da empresa. }\end{array}$ & 1 & 2 & 3 & & 5 \\
\hline 10 & Eu sou responsável por negociar diretamente com clientes e fornecedores. & 1 & 2 & 3 & & 5 \\
\hline 11 & Não temos grande influência sobre os fornecedores da empresa. & 1 & 2 & 3 & & 5 \\
\hline 12 & $\begin{array}{l}\text { Os meus fornecedores e clientes se encontram, em sua maioria, na mesma } \\
\text { região geográfica da empresa. }\end{array}$ & 1 & 2 & 3 & & 5 \\
\hline 13 & $\begin{array}{l}\text { Enfrento dificuldades em obter financiamento por parte das instituições } \\
\text { financeiras devido às exigências feitas para obtenção de crédito. }\end{array}$ & 1 & 2 & 3 & & 5 \\
\hline 14 & $\begin{array}{l}\text { O crescimento financeiro da empresa não é a motivação principal para ter } \\
\text { meu próprio negócio. }\end{array}$ & 1 & 2 & 3 & & 5 \\
\hline
\end{tabular}




\section{APÊNDICE D - TERMO DE COMPROMISSO}
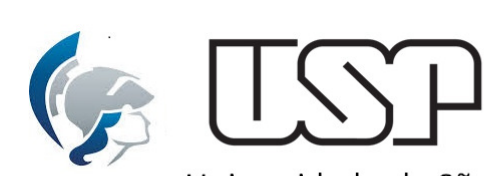

Universidade de São Paulo

Escola de Engenharia de São Carlos

Departamento de Engenharia de Produção

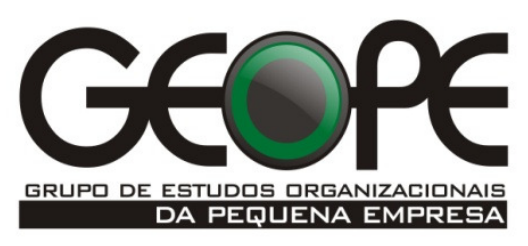

São Carlos, 23 de março de 2015.

Prezado Senhor,

Estamos realizando uma pesquisa acadêmica com o objetivo estudar o trabalho do administrador da pequena empresa, seu estilo de aprendizagem, a organização do trabalho e a orientação estratégica.

A pesquisa será realizada com empresas do setor metal-mecânico das cidades de Américo Brasiliense, Araraquara, Matão, São Carlos e Sertãozinho.

Para atingirmos nosso objetivo aplicaremos, no período de Março/2015 a Junho/2015, entrevistas com questões objetivas sobre os temas tratados na pesquisa.

Ressalta-se que a sua participação é fundamental para o sucesso da pesquisa. Informações sigilosas não serão solicitadas, e mesmo as informações fornecidas serão tratadas com o sigilo necessário e utilizadas de modo a não identificar a empresa.

Assumimos o compromisso que somente os pesquisadores envolvidos na pesquisa, sendo eles: Daniela Rosim, Lie Yamanaka, Rodrigo Messias Andrade e Edmundo Escrivão Filho, terão acesso e irão analisar os dados fornecidos pelas entrevistas.

Após a confecção do relatório final da pesquisa os dados serão destruídos e será enviada aos participantes uma cópia do relatório com os resultados finais.

Aproveitamos o ensejo para antecipar os agradecimentos por sua valiosa colaboração. 


\section{ANEXO A - QUESNTIONÁRIO DE ORIENTAÇÃO}

\section{ESTRATÉGICA}

\section{ORIENTAČ̃̃O ESTRATÉGICA - ASSINALAR APENAS UMA DAS 04 OPCÕES:}

1. Em comparação com nossos concorrentes, nossos produtos e serviços se caracterizam como:

( ) produtos e serviços que são mais inovadores, em contínuo estado de transformação.

( ) produtos e serviços que são relativamente estáveis em certas linhas e mercados, e inovadores em outras linhas e mercados.

( ) produtos e serviços que são bem estáveis em todas as linhas e mercados.

( ) produtos e serviços que estão em um estado de transição, e são baseados em oportunidades e ameaças percebidas no mercado.

2. Em comparação com nossos concorrentes, nossa imagem no mercado é a de uma empresa que:

( ) oferece poucos e selecionados produtos e serviços cuja qualidade é alta.

( ) adota novas idéias e inovações, mas só depois de uma análise cuidadosa.

( ) reage a oportunidades e ameaças do mercado de forma a manter ou melhorar nossa posição.

( ) tem uma reputação de ser inovadora e criativa.

3. Em comparação com nossos concorrentes, a quantidade de tempo que nossa empresa gasta monitorando mudanças e tendências no mercado é:

( ) intensiva: nós monitoramos o mercado de forma contínua.

( ) mínima: nós realmente não gastamos muito tempo monitorando o mercado.

( ) média: nós gastamos um tempo razoável monitorando o mercado.

( ) esporádica: nós, às vezes, gastamos um bom tempo monitorando o mercado e, outras vezes, gastamos pouco tempo monitorando o mercado.

4. A abordagem genérica da empresa em relação ao mercado é ser guiada por:

( ) uma prática de nos concentrarmos em desenvolver plenamente aqueles mercados que servimos atualmente.

( ) uma prática de responder às pressões do mercado tomando poucos riscos.

( ) uma prática de agressivamente entrar em novos mercados com novos tipos de produtos e serviços.

( ) uma prática de penetrar de forma mais profunda naqueles mercados nos quais atuamos no momento, mas ao mesmo tempo adotar novos produtos e serviços somente após uma análise cuidadosa de seu potencial.

5. Um de nossos mais importantes objetivos é a nossa dedicação e esforço em:

( ) manter custos sob controle.

( ) analisar nossos custos e receitas cuidadosamente, para manter os custos sobre controle e de forma seletiva criar novos produtos e serviços ou entrar em novos mercados.

( ) assegurar que as pessoas, recursos e equipamentos necessários para desenvolver 
novos produtos e serviços estejam disponíveis e acessíveis.

( ) garantir que estejamos prevenidos contra ameaças críticas tomando quaisquer medidas que sejam necessárias.

6. As habilidades que nossos administradores possuem são melhor caracterizadas como:

( ) analíticas: suas habilidades devem capacitá-los a identificar tendências e desenvolver novos produtos ou mercados.

( ) especializada: suas habilidades devem ser concentradas em uma ou poucas áreas específicas.

( ) diversas e empreendedoras: suas habilidades devem ser variadas, flexíveis e devem facilitar a ocorrência de mudanças

( ) fluídas: suas habilidades devem ser relacionadas com as demandas de curto prazo do mercado.

7. A única coisa que diferencia nossos produtos dos de nossos concorrentes é que nós:

( ) somos capazes de analisar de forma cuidadosa tendências emergentes e adotar somente aquelas que tenham um bom potencial.

( ) somos capazes de fazer um número limitado de coisas excepcionalmente bem.

( ) somos capazes de responder às tendências emergentes mesmo que elas possuam um potencial apenas moderado quando surgem.

( ) somos capazes de desenvolver consistentemente novos produtos, serviços e mercados.

8. Mais do que nossos concorrentes, a administração de nossa empresa concentra-se em:

( ) manter uma posição financeira segura através de medidas de controle de custo e qualidade.

( ) analisar oportunidades no mercado e selecionar somente aquelas com bom potencial, ao mesmo tempo em que protegemos nossa posição financeira segura.

( ) realizar atividades ou funções que mais requeiram atenção em vista dos problemas e oportunidades que enfrentamos no momento.

( ) desenvolver novos produtos e serviços e expandir em novos negócios ou mercados.

9. Em comparação com nossos concorrentes, nossa empresa prepara-se para o futuro:

( ) identificando as soluções melhores e possíveis para aqueles problemas e desafios que exijam atenção imediata.

( ) identificando tendências e oportunidades no mercado que resultem na criação de produtos ou serviços que são novos para a indústria ou que atinjam novos mercados.

( ) identificando aqueles problemas, que, se resolvidos, mantêm e melhoram nossos atuais produtos e serviços e nossa posição no mercado.

( ) identificando aquelas tendências na indústria que outras firmas tenham provado que possuem potencial de longo prazo e, ao mesmo tempo resolvendo problemas relacionados com nossos atuais produtos e serviços e necessidades de nossos atuais clientes.

10. A estrutura de nossa organização é:

( ) funcional: organizada por departamento - marketing, recursos humanos, produção, etc.

( ) organizada por produto ou serviço oferecido ou por mercados servidos. 
( ) primariamente funcional, mas uma organização por produto, serviço ou mercado é aplicada em áreas mais novas ou maiores.

( ) em mudança contínua de forma a nos permitir fazer face às oportunidades e resolver problemas conforme vão aparecendo.

11. Os procedimentos usados em nossa empresa para avaliar o desempenho são:

( ) descentralizados e participativos, encorajando muitos empregados a se envolverem.

( ) altamente orientados por aqueles requisitos que exijam atenção imediata.

( ) altamente centralizados e de responsabilidade primária da alta administração.

( ) centralizados nas áreas mais estabelecidas e mais participativos nas novas áreas. 